\title{
DÍPTEROS FRUGÍVOROS (TEPHRITIDAE E LONCHAEIDAE) NA REGIÃO DE MOSSORÓ/ASSU, ESTADO DO RIO GRANDE DO NORTE
}

\author{
ELTON LUCIO DE ARAUJO
}

Tese apresentada à Escola Superior de Agricultura "Luiz de Queiroz", Universidade de São Paulo, para a obtenção do título de Doutor em Ciências, Área de Concentração: Entomologia.

\author{
PIRACICABA \\ Estado de São Paulo \\ Janeiro - 2002
}




\title{
DÍPTEROS FRUGÍVOROS (TEPHRITIDAE E LONCHAEIDAE) NA REGIÃO DE MOSSORÓ/ASSU, ESTADO DO RIO GRANDE DO NORTE
}

\author{
ELTON LUCIO DE ARAUJO \\ Engenheiro Agrônomo
}

Orientador: Prof. Dr. ROBERTO ANTONIO ZUCCHI

\begin{abstract}
Tese apresentada à Escola Superior de Agricultura "Luiz de Queiroz", Universidade de São Paulo, para a obtenção do título de Doutor em Ciências, Área de Concentração: Entomologia.
\end{abstract}

\author{
PIRACICABA \\ Estado de São Paulo \\ Janeiro - 2002
}


Dados Internacionais de Catalogação na Publicação (CIP) DIVISÃO DE BIBLIOTECA E DOCUMENTAÇÃO - ESALQ/USP

\author{
Araujo, Elton Lucio de \\ Dípteros frugívoros (Tephritidae e Loncha eidae) na região de \\ Mossoró/Assu, Estado do Rio Grande do Norte / Elton Lucio de Ara ujo. - - \\ Piracicaba, 2002. \\ $112 \mathrm{p}$. \\ Tese (doutora do) - Escola Superior de Agricultura Luiz de Queiroz, 2002. \\ Bibliografia. \\ 1. Entomologia agríc ola 2. Frutic ultura 3. Insetos noc ivos 4. Mosca -das-frutas \\ I. Título \\ CDD 632.774
}

"Permitida a cópia total ou parcial deste documento, desde que citada a fonte - $\mathrm{O}$ autor" 
À Deus,

AGRADEÇO

Aos meus pais, Milton Araujo e Maria das Graças Silva Araujo

e aos meus irmãos Hermeson e Milton Jr.

pelo apoio e incentivo,

DEDICO. 


\section{AGRADECIMENTOS}

Ao prof. Dr. Roberto Antonio Zucchi, pela orientação, confiança e incentivo.

À FAPESP, pela bolsa concedida.

À COEX e a ESAM, pelo apoio nos trabalhos de campo e laboratório.

Aos agrônomos Valdemar E. da Silva e Lazaro Roberto e aos estagiários Leonardo A. da Slva, Mayara K. M. de Medeiros e Patricia A. R. Lopes, pela colaboração nas atividades de campo e laboratório.

Ao Biólogo Pedro Carlos Strikis, pela identificação dos lonqueídeos.

Aos professores do setor de Entomologia da ESALQ/USP, pelos ensinamentos.

Aos colegas do setor de Entomologia da ESALQ/USP, em especial aos do laboratório de Taxonomia (Américo, Clarice, Jorge, Martha, Miguel, Nelson, Ranyse, Renata e Uchôa), pela ótima convivência e amizade.

Aos funcionários da ESALQ/USP e a todos que colaboraram com este trabalho. 


\section{SUMÁRIO}

Página

RESUMO

ix

SUMMARY

$\mathrm{xi}$

1 INTRODUÇÃO

1

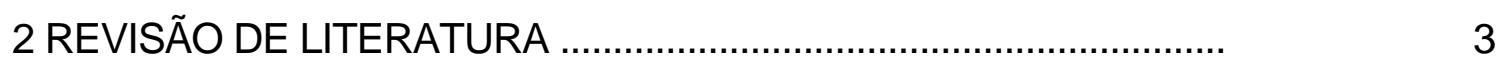

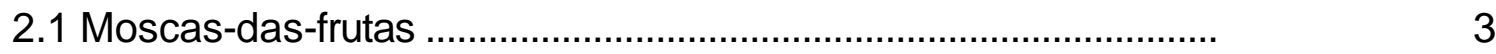

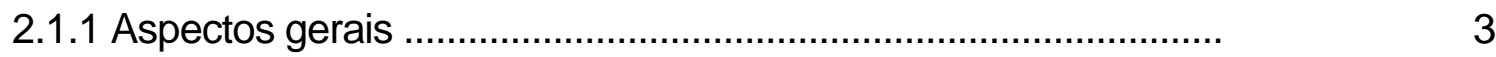

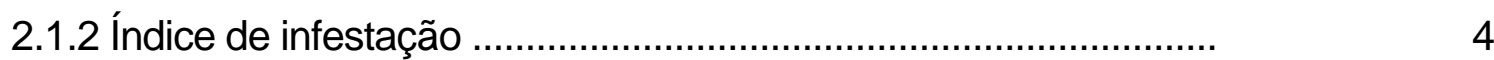

2.1.3 Fatores que influenciam as populações de moscas-das-frutas .... 5

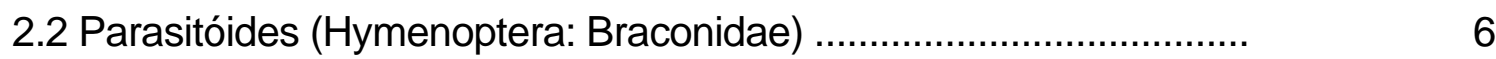

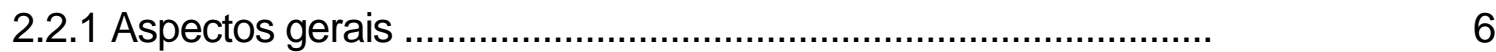

2.2.2 Percentagem de parasitismo ...............................................

2.2.3 Fatores que afetam o nível de parasitismo ............................... 8

2.3 Lonqueídeos frugívoros ...............................................................

3 ESPÉCIES DE MOSCAS-DAS-FRUTAS (DIPTERA: TEPHRITIDAE), SEUS HOSPEDEIROS E ÍNDICES DE INFESTAÇÃO, NA REGIÃO DE MOSSORÓ/ASSU (RN) .................................................... 10

Resumo ....................................................................................

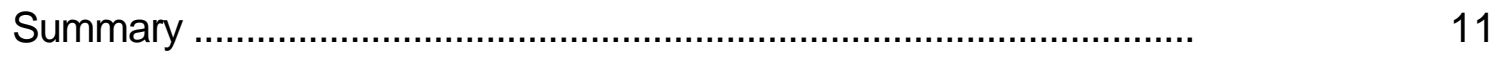

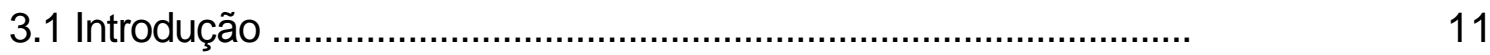

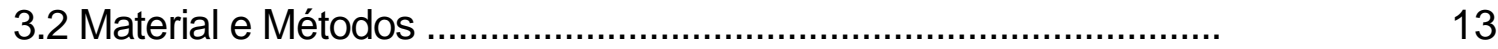

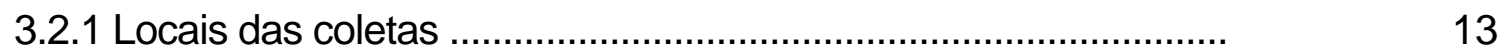

3.2.2 Coleta de moscas-das-frutas com armadilhas ............................. 13

3.2.3 Coleta de moscas-das-frutas em frutos ...................................... 


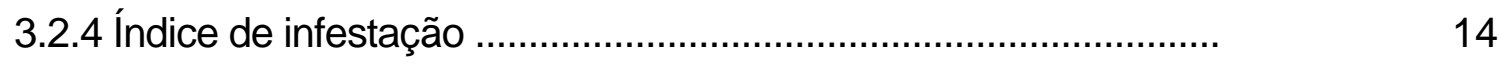

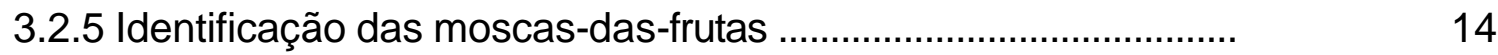

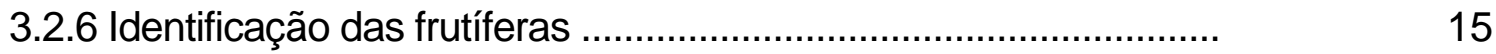

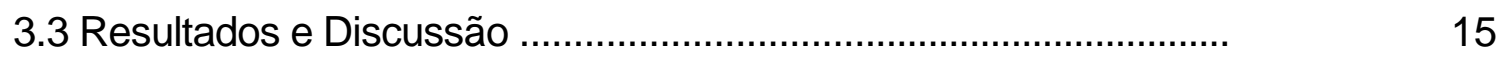

3.3.1 Espécies de moscas-das-frutas ............................................... 16

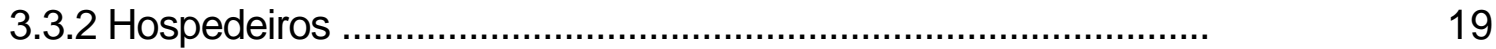

3.3.3 Índice de infestação de moscas-das-frutas ..................................

3.4 Conclusões ............................................................................

4 PARASITÓIDES (HYMENOPTERA: BRACONIDAE) DE MOSCASDAS-FRUTAS (DIPTERA: TEPHRITIDAE) NA REGIÃO DE MOSSORÓ/ASSU, ESTADO DO RIO GRANDE DO NORTE ........... 34

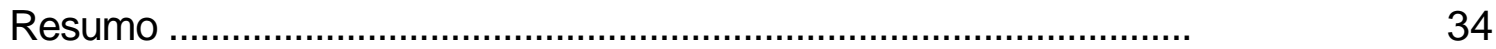

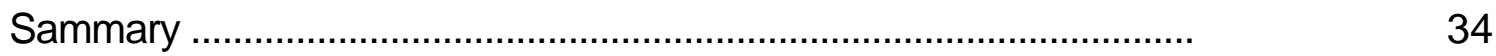

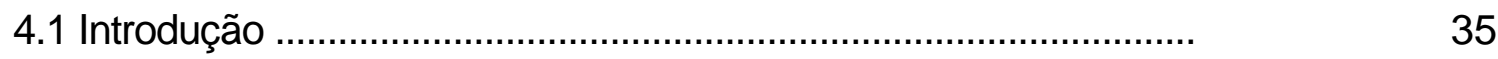

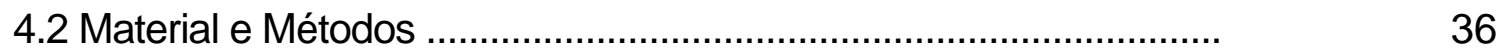

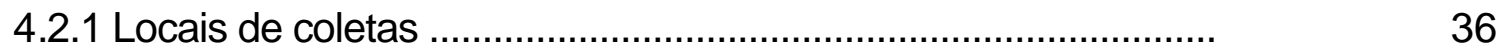

4.2.2 Obtenção dos parasitóides ....................................................... 36

4.2.3 Associação entre parasitóide/frutífera/moscas-das-frutas ............ 36

4.2.4 Cálculo da percentagem de parasitismo ..................................... 37

4.2.5 Identificação dos táxons ............................................................

4.3 Resultados e Discussão ……………………………………....

4.3.1 Espécies de braconídeos ........................................................ 38

4.3.2 Associação entre parasitóide/frutífera/moscas-das-frutas ............. $\quad 40$

4.3.3 Parasitismo ……………………..........................................

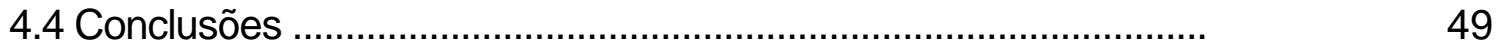

5 ÍNDICE DE INFESTAÇÃO E PERDAS EM GOIABA Psidium guajava L. OCASIONADAS POR Anastrepha spp. (DIPTERA:

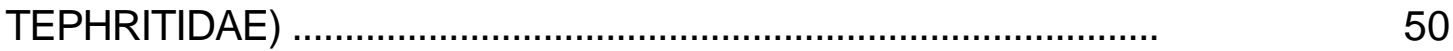

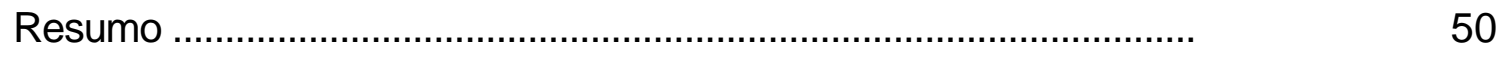

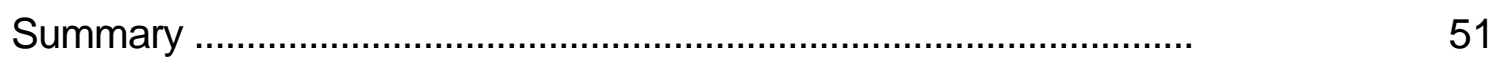

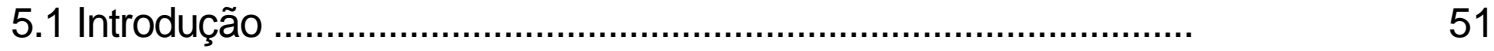


5.2 Material e Métodos

5.2.1 Local e caracterização do pomar estudado .................................. 53

5.2.2 Coleta de moscas-das-frutas com armadilhas ............................. 53

5.2.3 Coleta de moscas-das-frutas em frutos ........................................ 53

5.2.4 Percentagem de perda .........................................................

5.2 .5 Índice de infestação .............................................................

5.2.6 Flutuação populacional ........................................................

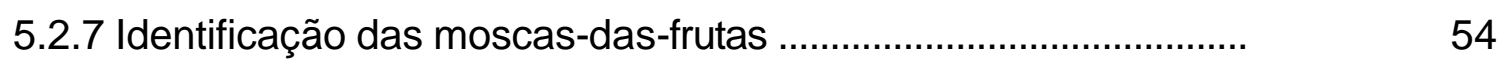

5.3 Resultados e Discussão ……………………………………....

5.3.1 Relação entre níveis de infestação e perdas ............................... 58

5.3.2 Relação entre índice de infestação e flutuação populacional ........... 60

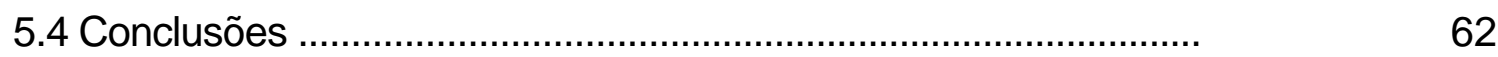

6 INFLUÊNCIA DE FATORES BIÓTICOS E ABIÓTICOS NO NÍVEL DE INFESTAÇÃO DE Anastrepha spp. (DIP., TEPHRITIDAE) EM GOIABA Psidium guajava L., NA REGIÃO SEMI-ÁRIDA DE

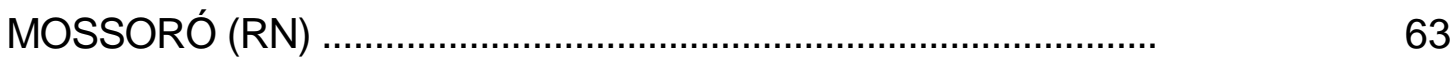

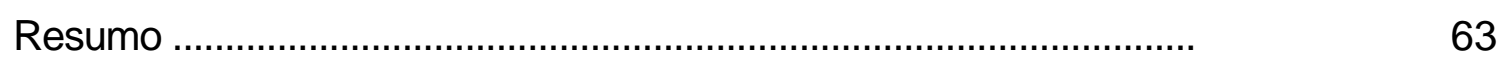

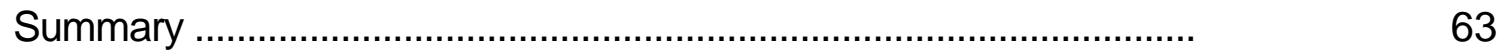

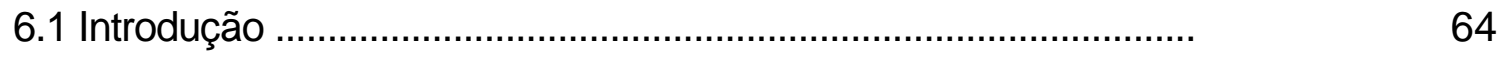

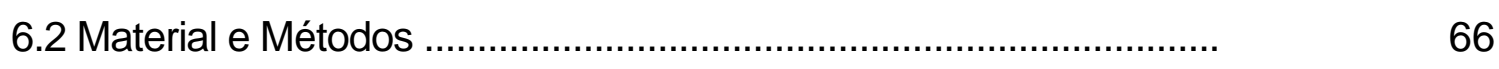

6.2.1 Local e caracterização do pomar estudado ................................... 66

6.2.2 Obtenção dos parasitóides e das moscas-das-frutas ...................... $\quad 66$

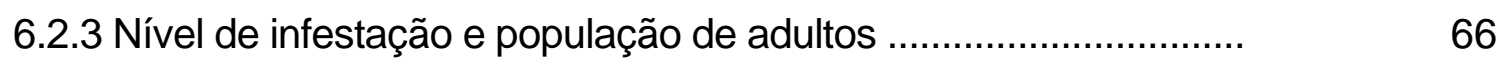

6.2.4 Fatores climáticos ................................................................. 66

6.2.5 Identificação das moscas-das-frutas e parasitóides ........................ 67

6.3 Resultados e Discussão ............................................................

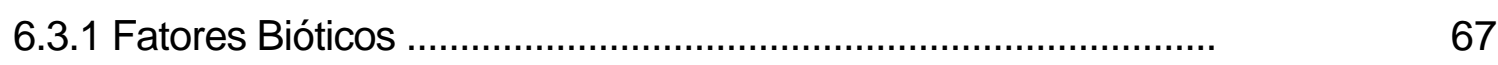

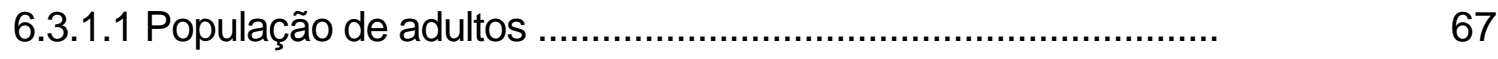

6.3.1.2 Disponibilidade de hospedeiro ............................................... 69

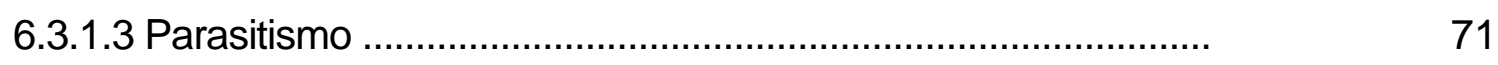

6.3.2 Fatores Abióticos ................................................................... 
6.3.2.1 Temperatura .................................................................

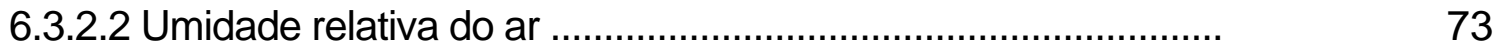

6.3.2.3 Precipitação pluvial ................................................................

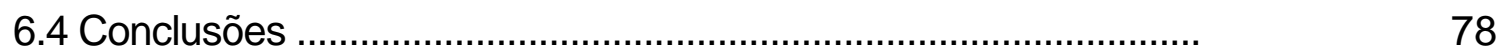

7 HOSPEDEIROS E NÍVEIS DE INFESTAÇÃO DE Neosilba pendula (Bezzi) (DIPTERA: LONCHAEIDAE) NA REGIÃO DE MOSSORÓ/ASSU (RN) …………………………....................

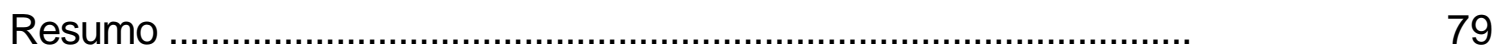

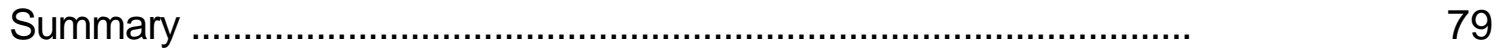

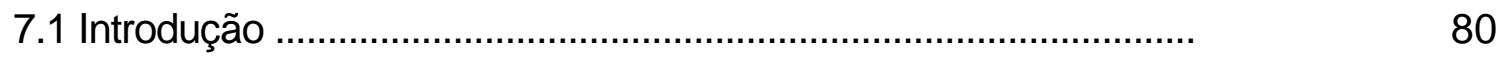

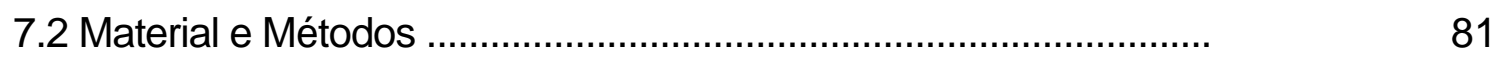

7.2.1 Locais das coletas ................................................................

7.2.2 Coleta dos lonqueídeos e índices de infestação ...........................

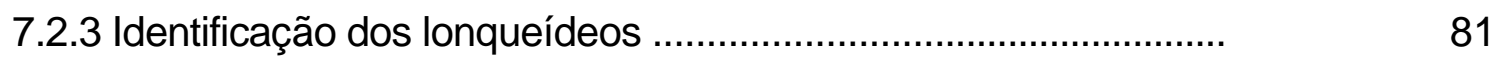

7.2.4 Identificação das frutíferas ......................................................

7.3 Resultados e Discussão ..........................................................

7.3.1 Índices de infestação ..............................................................

7.3.2 Neosilba pendula como invasor primário de acerola Malpighia emarginata..........................................................................

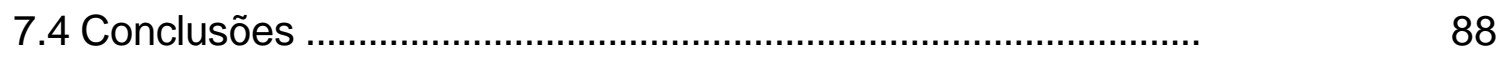

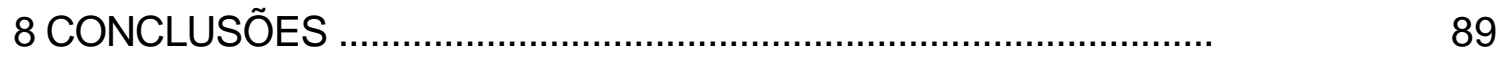

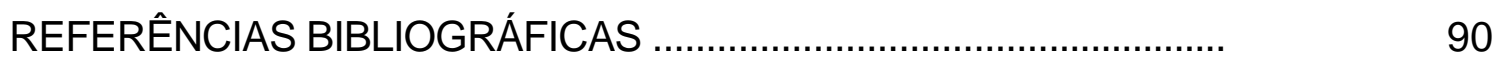

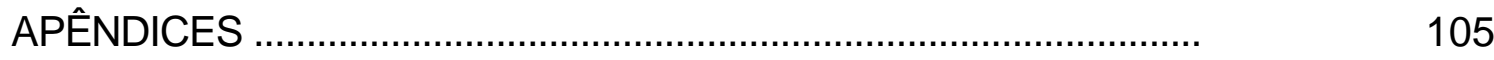




\title{
DÍPTEROS FRUGÍVOROS (TEPHRITIDAE E LONCHAEIDAE) NA REGIÃO DE MOSSORÓ/ASSU, ESTADO DO RIO GRANDE DO NORTE
}

\author{
Autor: Elton Lucio de Araujo \\ Orientador: Prof. Dr. Roberto Antonio Zucchi
}

\section{RESUMO}

A região de Mossoró/Assu ( $\mathrm{RN}$ ), localizada no semi-árido, destaca-se pela produção e exportação de frutas, principalmente o melão Cucumis melo e a manga Mangifera indica. Portanto, este trabalho teve como objetivo conhecerer vários aspectos relacionados as moscas-das-frutas (Dip.; Tephritidae) e aos lonqueídeos (Dip.; Lonchaeidae) nessa região. Após dois anos de coletas, em armadilhas McPhail e frutos, foram detectadas dez espécies de tefritídeos e uma única de lonqueídeo Neosilba pendula (Bezzi). As moscas-das-frutas mais comuns foram Anastrepha zenildae Zucchi, A. obliqua (Mcquart) e Ceratitis capitata (Wied.). As maiores infestações foram observadas em frutos de juá Ziziphus joazeiro (Rhamnaceae) e kunquat Fortunella sp. (Rutaceae). Em alguns meses do ano, A. zenildae foi considerada praga em pomares de goiaba Psidium guajava (Myrtaceae). A população de adultos, a disponibilidade do hospedeiro, a precipitação pluvial e a temperatura, foram os fatores que mais influenciaram os níveis de infestação das espécies de Anastrepha em frutos de goiaba. Neosilba pendula apresentou baixos níveis de infestação nas frutíferas da região, mas foi considerada um importante invasor primário de frutos de acerola Malpighia emarginata (Malpighiaceae). Três espécies de parasitóides (Braconidae) foram 
obtidos dos pupários das moscas-das-frutas, sendo Doryctobracon areolatus (Szépligeti) o mais comum. 


\title{
FRUGIVOROUS DIPTERANS (TEPHRITIDAE AND LONCHAEIDAE) IN THE MOSSORÓ/ASSU, STATE OF RIO GRANDE DO NORTE
}

\author{
Author: Elton Lucio de Araujo \\ Adviser: Prof. Dr. Roberto Antonio Zucchi
}

\section{SUMMARY}

The Mossoró/Assu region (RN), located in a semi-arid zone, is important as a center of fruit production and export, especially melons, Cucumis melo, and, mangoes, Mangifera indica. Thus, the objective of the present study was to investigate several aspects related to fruit flies (Dip.; Tephritidae) and lonchaeids (Dip.; Lonchaeidae) in this region. After two years of collection with McPhail traps and reared from fruits, ten tephritid species and a single lonchaeid species, Neosilba pendula (Bezzi), were detected. The most common fruit flies were Anastrepha zenildae Zucchi, A. obliqua (Mcquart), and Ceratitis capitata (Wied.). The highest infestation levels were observed on "juá" fruits, Ziziphus joazeiro (Rhamnaceae) and on kumquats, Fortunella sp. (Rutaceae). In some months of the year, A. zenildae was considered as a pest in guava, Psidium guajava (Myrtaceae), orchards. Adult population, host availability, rainfall and temperature were the factors that most influenced the levels of guava fruit infestation by Anastrepha species. Neosilba pendula showed low infestation levels on fruit trees of region, but was considered as an important primary invader of "acerola", Malpighia emarginata (Malpighiaceae). Three parasitoid species (Braconidae) 
were obtained from fruit fly puparia, the most common being Doryctobracon areolatus (Szépligeti). 


\section{INTRODUÇÃO}

A comercialização de frutas frescas e seus derivados é uma das principais atividades comerciais do mundo. O Brasil é um dos países mais propícios ao desenvolvimento da fruticultura, devido uma série de fatores, por exemplo, grande área possível de ser cultivada e as condições climáticas favoráveis. Apesar dos fatores favoráveis, uma grande quantidade de frutas é perdida no campo, devido ao ataque de pragas. Além disso, as exportações brasileiras representam apenas $0,32 \%$ da quantidade de frutas frescas comercializadas no mundo (Agrianual, 1999).

A região de Mossoró/Assu, localizada no semi-árido do Estado do Rio Grande do Norte, destaca-se pela produção e exportação de melão Cucumis melo. Além do melão, outras frutas são produzidas na região, contudo, sofrem sérias restrições fitossanitárias para serem exportadas.

Um dos maiores entraves para a produção e exportação de frutas no Brasil, são as moscas-das-frutas, Anastrepha spp. e Ceratitis capitata (Wied.). As larvas da maioria desses tefritídeos alimentam-se da polpa dos frutos, causando perdas e a ocorrência de espécies de moscas-das-frutas de importância quarentenária impedem a exportação de frutas frescas para outros países.

A geração de informações sobre as moscas-das-frutas, por exemplo, conhecimento da diversidade de espécies, hospedeiros, flutuação populacional, níveis de infestação, perdas, parasitismo, entre outros, é crucial para que seja possível diminuir as perdas nos pomares e proporcionar 0 aumento das exportações, pelo estabelecimento de áreas livres ou de baixa prevalência e do systems approach. 
Portanto, este trabalho teve como objetivo ampliar os conhecimentos a respeito dos dípteros frugívoros (Tephritidae e Lonchaeidae) na região de Mossoró/Assu, Estado do Rio Grande do Norte. 


\section{REVISÃO DE LITERATURA}

\subsection{Moscas-das-frutas}

\subsubsection{Aspectos gerais}

As moscas-das-frutas pertencem à família Tephritidae, que compreende 4.352 espécies, agrupadas em 481 gêneros (Norrbom, 2001). As larvas de aproximadamente $35 \%$ das espécies de tefritídeos desenvolvem-se em frutos (White \& Elson-Harris, 1994).

Os tefritídeos que se alimentam de frutos comerciais são tidos como uma das principais pragas da fruticultura mundial e brasileira. Os gêneros Anastrepha Schiner, Bactrocera Macquart, Ceratitis Macleay, Rhagoletis Loew e Toxotrypana Gerstaecker são os mais importantes do ponto de vista econômico e quarentenário, pois reúnem espécies que além de causarem danos diretos, constituem-se no principal entrave para a comercialização mundial de frutas frescas (Carey \& Dowell, 1989 e White \& Elson-Harris, 1994).

No Brasil, ocorrem dois gêneros de moscas-das-frutas de importância econômica e quarentenária, o gênero Anastrepha que compreende 197 espécies (Norrbom et al., 2000), das quais 94 estão presentes no Brasil (Zucchi, 2000a), e Ceratitis que é representado por apenas uma espécie, C. capitata (Wied.) (Zucchi, 2001). Em 1997, Bactrocera carambolae Drew \& Hancock foi detectada no Estado do Amapá, onde um programa de erradicação está sendo executado (Malavasi et al., 2000 e Zucchi, 2000a).

De acordo com Aluja (1999), o Brasil é um dos países que mais têm se dedicado ao conhecimento das espécies de moscas-das-frutas e seus hospedeiros. Na década de 30, Lima $(1934,1937$ a, 1937b e 1938) realizou 
trabalhos pioneiros, descrevendo espécies e relatando seus hospedeiros. Após alguns anos sem estudos dessa natureza, Zucchi (1978 e 1979) e Malavasi et al. (1980), entre outros, reiniciaram os trabalhos sobre a diversidade de espécies e seus hospedeiros. No entanto, foi só a partir da década de 90 , que se intensificaram os levantamentos regionais de moscas-das-frutas, como os realizados nos Estados do Amazonas (Silva, 1993), Minas Gerais (Canal D., 1997), Goiás (Veloso, 1997), Mato Grosso do Sul (Uchôa F., 1999) e São Paulo (Souza Filho, 1999). Das 94 espécies de Anastrepha que são conhecidas no País, 41 estão associadas a frutíferas de 31 famílias (Zucchi, 2000b). Apesar dos esforços, 56\% das espécies de Anastrepha que ocorrem no Brasil não têm hospedeiro conhecido (Zucchi, 2000b). Ceratitis capitata já foi assinalada em vários Estados, tendo sido associada a frutíferas de 21 famílias (Zucchi, 2001).

\subsection{2 Índice de infestação}

Os níveis de infestação das moscas-das-frutas são variáveis de região para região. Malavasi \& Morgante (1980) realizaram coletas de frutos em vários Estados brasileiros e relataram que pitanga Eugenia uniflora (Myrtaceae) e nêspera Eriobotrya japonica (Rosaceae) foram os hospedeiros mais infestados pelas moscas-das-frutas, com índices de infestação de 249 e 214 pupários $/ \mathrm{kg}$, respectivamente. Nos municípios de Ribeirão Preto (SP) e Sertãozinho (SP), os frutos mais infestados pelas moscas-das-frutas foram pitanga e serigüela Spondia purpurea (Anacardiaceae), 867 e 518 pupários/kg, respectivamente (Bressan \& Teles, 1991). Também no Estado de São Paulo, Souza Filho (1999) constatou as maiores infestações em frutos de cereja-da-terra Eugenia involucrata (Myrtaceae) e pitanga, 794 e 532 pupários/kg, respectivamente. No Estado do Amazonas, frutos de taperebá Spondias mombim (Anacardiaceae) (572 pupários/kg) e goiaba Psidium guajava (Myrtaceae) (299 pupários $/ \mathrm{kg}$ ) foram os mais infestados por Anastrepha spp., em algumas localidades (Silva, 1993). No Norte de Minas

Gerais, a goiaba também foi um dos hospedeiros preferidos por Anastrepha spp., com infestações de até 116 larvas/kg (Canal D. et al., 1998). Como observado por 
Bressan \& Teles (1991), no Estado de São Paulo, pitanga e serigüela também foram as frutíferas mais infestadas pelas moscas-das-frutas nos cerrados do Estado de Goiás, com infestações de 601 e 270 pupários $/ \mathrm{kg}$, respectivamente (Veloso, 1999). Já em áreas de cerrado do Estado do Mato Grosso do Sul, o fruto mais infestado pelas moscas-das-frutas foi o cajá-mirim Spondias lutea (Uchôa F., 1999).

\subsubsection{Fatores que influenciam as populações de moscas-das-frutas}

Vários fatores bióticos e abióticos interferem no nível populacional das moscas-das-frutas e, conseqüentemente, sobre seus índices de infestação.

Segundo Malavasi \& Morgante (1980), a densidade populacional é um importante fator biótico que influencia o nível de infestação das moscas-das-frutas, ou seja, quanto maior a densidade populacional das moscas-das-frutas num pomar, maiores serão os níveis de infestação.

A disponibilidade de hospedeiros é outro fator biótico que interfere nos níveis de infestação, pois é justamente nos períodos de maior disponibilidade de hospedeiros que ocorrem as maiores infestações (Puzzi \& Orlando, 1965 e Malavasi \& Morgante, 1980).

A ação dos predadores e parasitóides também afetam as populações de moscas-das-frutas, pois causa mortalidade durante todas as fases do desenvolvimento dos tefritídeos (Bateman, 1972; Carvalho et al., 2000; Eskafi \& Kolbe, 1990 e Sugayama, 2000).

Com relação aos fatores abióticos, os parâmetros climáticos estão entre os que mais interferem nas populações de moscas-das-frutas. Em temperaturas extremas, abaixo de $10^{\circ} \mathrm{C}$ e acima de $35^{\circ} \mathrm{C}$, não se constatou o desenvolvimento de nenhuma das fases de Anastrepha fraterculus (Wied.). Por outro lado, temperaturas entre 20 e $25^{\circ} \mathrm{C}$ favoreceram o desenvolvimento desta espécie (Salles, 2000). Pupários recém-formados de Anastrepha ludens (Loew.) são bastante afetados pela exposição à altas temperaturas (Baker, 1944). A precipitação pluvial é outro importante parâmetro climático que influencia as 
populações das moscas-das-frutas (Aluja, 1994). Segundo Baker (1944), a falta de umidade no solo pode provocar a mortalidade de um grande número de pupas e de adultos recém-emergidos, que têm dificuldade de atravessar solos secos. Bressan-Nascimento (2001) observou que a dessecação é um dos principais fatores de inviabilidade pupal de Anastrepha obliqua (Macquart), em condições de laboratório. Contudo, Salles relatou que à $25^{\circ} \mathrm{C}$, umidades do solo variando entre 2,6 e 28,3\% não interferem na duração e viabilidade pupal de $A$. fraterculus. Azevedo \& Parra (1989) constataram pouca influência das umidades do solo entre 5,5 e 32,8\%, na viabilidade pupal de C. capitata. Em alguns trabalhos desenvolvidos no Brasil (Puzzi \& Orlando, 1965; Suplicy Filho et al., 1978; Parra et al., 1982 e Nascimento et al., 1982), não se constatou correlação entre a flutuação populacional das moscas-das-frutas e a precipitação pluvial.

\subsection{Parasitóides (Hymenoptera: Braconidae)}

\subsubsection{Aspectos gerais}

A maioria dos programas de controle biológico de moscas-das-frutas tem utilizado parasitóides da família Braconidae (Clausen, 1956; Wharton, 1989 e Ovruski et al., 2000).

$\mathrm{Na}$ América Latina e sul dos EUA, 27 espécies de braconídeos já foram constatados como parasitóides de Anastrepha spp., sendo Doryctobracon areolatus (Szépligeti), com a mais ampla distribuição geográfica, da Argentina até o sul dos EUA (Ovruski et al., 2000). No Brasil, onde 13 espécies de braconídeos foram registrados, $D$. areolatus também foi a espécie mais comum (Leonel Jr. et al., 1995 e Canal D. \& Zucchi, 2000).

\subsubsection{Percentagem de parasitismo}

A percentagem de parasitismo tem sido o método mais utilizado para se estimar o impacto dos parasitóides como fator de mortalidade das moscas-das- 
frutas (Aguiar-Menezes, 2000). Nos trabalhos realizados até o momento, tem-se observado que as percentagens de parasitismo são variáveis nas diferentes regiões brasileiras.

$\mathrm{Na}$ região de Vacaria (RS), percentagem de parasitismo de até $29 \%$ foi detectada em larvas de $A$. fraterculus em guabiroba Campomonesia xanthocarpa (Myrtaceae) (Kovaleski, 1997).

Nos municípios de Limeira e Piracicaba (SP), a maior média de parasitismo foi de $11 \%$ em larvas de Anastrepha spp. que estavam infestando araçá Psidium cattelianum (Myrtaceae) (Leonel Jr. et al., 1996). Também no Estado de São Paulo, Souza Filho (1999) verificou índices de parasitismo de 63\% em larvas de tefritídeos em jambo Syzygium aqueum (Myrtaceae).

$\mathrm{Na}$ região de Itaguaí (RJ), a maior taxa de parasitismo (59\%) ocorreu em Anastrepha sororcula Zucchi que infestava pitanga Eugenia uniflora (Myrtaceae) (Aguiar-Menezes \& Menezes, 1997). Em Seropédica (RJ), foram observados níveis de parasitismo de até $80 \%$ em Anastrepha spp. em grumixama Eugenia brasiliensis (Myrtaceae) (Aguiar-Menezes, 2000).

Em Conceição do Almeida (BA), a maior percentagem de parasitismo em larvas de moscas-das-frutas, aproximadamente $43 \%$, foi constatada em pitanga (Matrangolo et al, 1998).

Na região Amazônica, o maior índice de parasitismo (58\%) foi detectado em larvas de Anastrepha spp. que infestavam goiaba-de-anta Bellucia grossularioides (Melastomaceae), no Estado de Roraima (Ronchi-Teles, 2000).

\subsubsection{Fatores que afetam o nível de parasitismo}

Além do local de coleta, vários fatores podem afetar o nível de parasitismo dos braconídeos.

A espécie de fruto infestada pelas moscas-das-frutas é um dos fatores que mais afetam o nível de parasitismo, pois os parasitóides são guiados para os sítios de parasitismo por meio das substâncias voláteis liberadas pelos frutos (Leyva et al., 1991 e Messing \& Jang, 1992) 
O tamanho e o peso dos frutos também interferem nos níveis de parasitismo, pois frutos maiores e mais pesados apresentam um menor índice de parasitismo (Malavasi \& Morgante, 1980; Leyva et al., 1991; Hernández-Ortiz, et al., 1994; Sivinski et al., 1997 e López et al., 1999).

De acordo com Purcell et al. (1994), quanto maior o tempo de permanência dos frutos no campo, após a absição, maior o nível de parasitismo, pois os parasitóides têm um tempo maior para encontrarem as larvas das moscas-dasfrutas. Contudo, Aguiar-Menezes (2000) observou que o tempo de permanência dos frutos no solo não resultou em aumento de parasitismo por braconídeos.

Além desses fatores relacionados apenas com os frutos, a densidade larval e o comprimento do ovipositor do parasitóide também interferem no nível de parasitismo, ou seja, quanto maior a densidade de larvas no fruto e o comprimento do ovipositor, maiores são os níveis de parasitismo dos braconídeos (Sivinski et al., 1997 e Sivinski et al, 1998).

\subsection{Lonqueídeos frugívoros}

As larvas da maioria dos lonqueídeos estão associadas a flores, frutos danificados e outros tipos de material orgânico em decomposição. No entanto, em algumas espécies, as larvas são invasoras primárias de frutos (McAlpine, 1961 e Fehn, 1981).

Apesar de haver relatos de lonqueídeos infestando frutos de importância econômica no Brasil desde a década de 30, os conhecimentos sobre esse grupo de dípteros são escassos em todas as regiões do País (Uchôa F., 1999).

Por um longo período de tempo, os lonqueídeos foram desconsiderados nos levantamentos de moscas frugívoras, devido principalmente à falta de conhecimentos taxonômicos. Num dos primeiros levantamentos em que se levou em conta a presença dos lonqueídeos, foram alistados 12 espécies de frutos como hospedeiros, em vários Estados brasileiros, sendo Citrus spp. os mais infestados (Malavasi et al., 1980 e Malavasi \& Morgante, 1980). Na região metropolitana de 
Curitiba e Irati (PR), várias espécies de lonqueídeos infestaram frutos de pêssego Prunus persica (Rosaceae) (Fehn, 1981).

Posteriormente, nos anos 90, em razão da quantidade de pupários de lonqueídeos obtidos nos levantamentos de moscas-das-frutas, ressurgiu o interesse em estudar esses dípteros. Dessa forma, Silva (1993) constatou a presença de espécies de Neosilba associadas a 19 espécies de frutos, em quatro locais do Estado do Amazonas. Raga et al. (1996 e 1997), observaram que 17 e 4,9\% dos dípteros frugívoros obtidos de café Coffea spp. e laranja Citrus sinensis, no Estado de São Paulo, respectivamente, eram lonqueídeos. Também no Estado de São Paulo, Souza Filho (1999) realizou um amplo levantamento de moscasdas-frutas em 94 municípios e constatou que 40 espécies de frutos foram infestadas por lonqueídeos. Durante os estudos de conhecimento da biodiversidade de moscas frugívoras em áreas de cerrado do Estado do Mato Grosso do Sul, os lonqueídeos foram associados a 22 espécies de frutos, sendo a uvaia Eugenia sp. (Myrtaceae), um dos frutos mais infestados (65 larvas $/ \mathrm{kg}$ ) (Uchôa F., 1999). 


\section{ESPÉCIES DE MOSCAS-DAS-FRUTAS (DIPTERA: TEPHRITIDAE), SEUS HOSPEDEIROS E ÍNDICE DE INFESTAÇÃO, NA REGIÃO DE MOSSORÓ/ASSU (RN)}

\section{Resumo}

A região de Mossoró/Assu, localizada no semi-árido do Estado do Rio Grande do Norte, destaca-se pela produção de frutas. O objetivo deste trabalho foi ampliar os conhecimentos sobre as espécies de moscas-das-frutas que ocorrem na região, conhecer os hospedeiros e índices de infestação. De janeiro de 1999 a dezembro de 2000, foram realizadas coletas de moscas-das-frutas em armadilhas e frutos. Dez espécies de moscas-das-frutas foram detectadas - Anastrepha alveata Stone, A. dissimilis Stone, A. distincta Greene, A. montei Lima, A. obliqua (Macquart), A. pickeli Lima, A. sororcula Zucchi, A. zenildae Zucchi, Anastrepha sp. aff. pickeli e Ceratitis capitata (Wied.). Das 42 espécies de frutíferas amostradas $(6.032 \mathrm{~kg}), 18$ estavam infestadas por pelo menos uma espécie de mosca-das-frutas. As frutíferas mais infestadas foram juá Ziziphus joazeiro e kunquat Fortunella sp. 


\section{FRUIT FLY SPECIES (DIPTERA: TEPHRITIDAE), THEIR HOSTS AND INFESTATION LEVELS IN THE MOSSORÓ/ASSU REGION (RN)}

\section{Summary}

The region of Mossoró/Assu, located in the semi-arid zone of state of Rio Grande do Norte, is important for fruit producing. Thus, the objective of the present study was to expand our knowledge about the fruit fly species that occur in the region and to determine their hosts and infestation levels. Fruit flies were collected in traps and reared from fruits from January/1999 to December/2000. Ten fruit fly species were detected - Anastrepha alveata Stone, A. dissimilis Stone, A. distincta Greene, A. montei Lima, A. obliqua (Mcquart), A. pickeli Lima, A. sororcula Zucchi, A. zenildae Zucchi, Anastrepha sp. aff. pickeli, and Ceratitis capitata (Wied.). Of the 42 fruit tree species sampled $(6,032 \mathrm{~kg}), 18$ were infested with at least one fruit fly specie. The most infested host species were "juá", Ziziphus joazeiro (Rhamnaceae), and kumquat Fortunella sp. (Rutaceae).

\subsection{Introdução}

O conhecimento da diversidade de espécies de moscas-das-frutas que ocorrem em uma região, suas plantas hospedeiras e índices de infestação é de fundamental importância, pois é a partir desses conhecimentos que, por exemplo, pode-se otimizar os métodos de controle e minimizar os problemas quarentenários.

O Brasil é um dos países que mais têm se dedicado ao conhecimento das espécies de moscas-das-frutas e seus hospedeiros (Aluja, 1999). A partir da década de 90 , se intensificaram os trabalhos dessa natureza, como os levantamentos realizados nos Estados do Amazonas (Silva, 1996), Minas Gerais 
(Canal D., 1997), Goiás (Veloso, 1997), Mato Grosso do Sul (Uchôa F., 1999) e São Paulo (Souza Filho, 1999).

As moscas-das-frutas dos gêneros Anastrepha e Ceratitis são as mais importantes, do ponto de vista econômico e quarentenário, no Brasil. Das 197 espécies de Anastrepha conhecidas, 94 já foram detectadas no País e 41 espécies estão associadas a plantas de 31 famílias (Zucchi, 2000b). O gênero Ceratitis é representado pela espécie Ceratitis capitata (Wied.), já tendo sido assinalada em vários Estados, associada a 58 espécies de frutíferas, pertencentes a 21 famílias (Zucchi, 2001).

Apesar dos esforços, em muitos Estados brasileiros ainda não se têm estudos básicos sobre moscas-das-frutas. Além disso, $56 \%$ das espécies de Anastrepha assinaladas no Brasil não têm hospedeiro conhecido (Zucchi, 2000b).

O conhecimento da diversidade de espécies de moscas-das-frutas que ocorrem na região de Mossoró/Assu, Estado do Rio Grande do Norte, é considerável, devido aos levantamentos realizados no final dos anos 80, para o estabelecimento da área livre da mosca-das-cucurbitáceas Anastrepha grandis (Macquart). Entretanto, as informações a respeito dos hospedeiros das moscasdas-frutas e seus índices de infestação são praticamente inexistentes na região, ficando essas informações restritas a coletas ocasionais de frutos (Araujo et al., 2000).

Portanto, o objetivo deste trabalho foi ampliar os conhecimentos sobre as espécies de moscas-das-frutas que ocorrem na região de Mossoró/Assu e conhecer suas plantas hospedeiras e índices de infestação.

\subsection{Material e Métodos}

\subsubsection{Locais das coletas}

As coletas das moscas-das-frutas, tanto em armadilhas como em frutos,

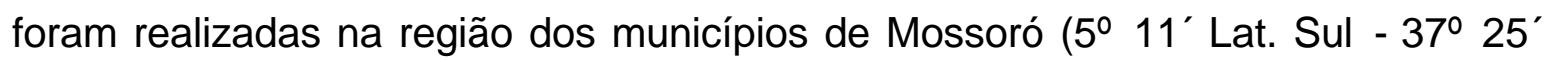

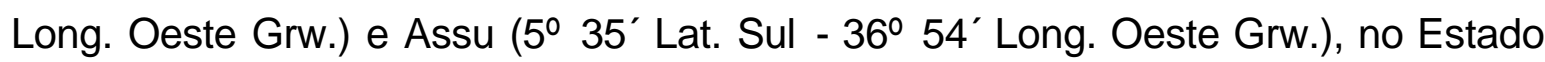


do Rio Grande do Norte, de janeiro de 1999 a dezembro de 2000. Foram realizadas coletas em vários pontos das áreas urbana e rural.

\subsubsection{Coleta de moscas-das-frutas com armadilhas}

Foram utilizadas armadilhas do tipo McPhail (plástica), tendo como atrativo a proteína hidrolisada de milho à $5 \%$. Eram colocados $250 \mathrm{ml}$ do atrativo em cada armadilha. Semanalmente trocava-se o atrativo, ocasião em que os insetos capturados eram transferidos para recipientes plásticos contendo álcool 70\%, com o código da armadilha (nome da área, número da armadilha e frutífera em que estava instalada).

Após a coleta, os frascos contendo os insetos eram conduzidos ao laboratório da COEX (Comissão Executiva da Área Livre das Moscas-das-frutas), no Departamento de Fitossanidade da ESAM (Escola Superior de Agricultura de Mossoró), onde era realizada a triagem do material. Em seguida, as moscas-dasfrutas eram contadas, sexadas e transferidas para recipientes plásticos contendo álcool $70 \%$, devidamente etiquetados e relacionados, onde permaneciam até a identificação específica.

O número de armadilhas instaladas no campo foi variável (máximo 400 armadilhas por mês), de acordo com a disponibilidade de hospedeiros e tamanho das áreas plantadas com as frutíferas perenes.

\subsubsection{Coleta de moscas-das-frutas em frutos}

Os frutos, potencialmente hospedeiros de moscas-das-frutas, foram coletados das árvores e do solo, de forma aleatória. O número e o tamanho das amostras foram variáveis, de acordo com a disponibilidade dos frutos no campo.

Os futos coletados em campo eram acondicionados em caixas plásticas (separados por espécie e local de coleta) e conduzidos ao laboratório da COEX na ESAM. No laboratório, os frutos eram pesados, contados e acondicionados em bandejas plásticas, contendo uma camada de vermiculita. Após uma semana, a 
vermiculita era peneirada e os pupários obtidos eram separados por gênero (Anastrepha e Ceratitis), contados e transferidos para recipientes plásticos contendo uma camada de vermiculita úmida, onde permaneciam até a emergência dos adultos. Após a emergência, as moscas-das-frutas eram colocadas em frascos contendo álcool $70 \%$, devidamente etiquetados, onde permaneciam até uma posterior sexagem e identificação específica.

\subsection{4 Índice de infestação}

Os índices de infestação foram calculados por meio de dois parâmetros: (1) número médio de pupários por fruto e (2) número médio de pupários por quilo de fruta fresca.

\subsubsection{Identificação das moscas-das-frutas}

As moscas-das-frutas foram identificadas observando-se o padrão alar, coloração do corpo e forma do acúleo, baseando-se nas chaves de identificação de Lima (1934), Stone (1942), Steyskal (1977) e Zucchi (1978 e 2000a); utilizando-

se a metodologia adotada por Zucchi (1978). Os espécimes voucher estão depositados na coleção do setor de Entomologia da ESALQ/USP e na coleção de insetos do Departamento de Fitossanidade da ESAM.

\subsubsection{Identificação das frutíferas}

As identificações das frutíferas foram baseadas na literatura e no material contido no herbário do laboratório de Botânica da ESAM.

\subsection{Resultados e Discussão}

Após dois anos de coleta, foram obtidas das armadilhas e dos frutos 155.129 moscas-das-frutas, sendo 27.381 exemplares de Anastrepha e 127.748 
de C. capitata (Tabela 1). O número de moscas-das-frutas capturadas é significativo, uma vez que a região de Mossoró/Assu é semi-árida e, portanto, possui condições climáticas que teoricamente desfavorecem altas populações de moscas-das-frutas. Contudo, vale salientar, que em determinados meses do ano foram instaladas cerca de 400 armadilhas em campo e foram amostrados $6.032 \mathrm{~kg}$ de frutos (3.529 kg de melão e $2.503 \mathrm{~kg}$ de vários outros hospedeiros), o que colaborou para o grande número de moscas coletadas.

Tabela 1. Número de moscas-das-frutas coletadas na região de Mossoró/Assu (RN), de janeiro/1999 a dezembro/2000.

\begin{tabular}{lccccc}
\hline \multirow{2}{*}{ Táxons } & \multicolumn{2}{c}{ Armadilhas } & \multicolumn{2}{c}{ Frutos } & \\
\cline { 2 - 5 } & Machos & Fêmeas & Machos & Fêmeas & \multirow{2}{*}{ Total } \\
\hline Anastrepha spp. & 3.983 & 6.829 & 8.338 & 8.231 & 27.381 \\
Ceratitis capitata & 38.396 & 74.740 & 7.348 & 7.264 & 127.748 \\
Total & 42.379 & 81.569 & 15.686 & 15.495 & 155.129 \\
\hline
\end{tabular}

Ceratitis capitata foi a espécie com o maior número de exemplares capturados. Até 1992, nenhum exemplar havia sido detectado na região (Araujo et al., 2000) e, menos de dez anos após sua chegada, ocorre em altas populações, demostrando seu elevado poder de colonização. No entanto, as altas populações estão restritas a focos isolados, ou seja, em alguns pomares de frutíferas exóticas (acerola e kunquat).

\subsubsection{Espécies de moscas-das-frutas}

Foram detectadas 10 espécies de moscas-das-frutas (Tabela 2), sendo que a maioria já havia sido assinalada na região (Nascimento, 1990; Araujo et al., 1996b e Araujo et al., 2000). Apenas, Anastrepha distincta Greene, 1934 está sendo registrada pela primeira vez em Mossoró/Assu. 
Na região semi-árida de Petrolina/Juazeiro, onde há monitoramento desde 1989, a diversidade das espécies de moscas-das-frutas é semelhante à constatada na região de Mossoró/Assu. Das 11 espécies assinaladas em Petrolina/Juazeiro (Haji \& Miranda, 2000), apenas Anastrepha fraterculus (Wied.), Anastrepha manihoti Lima e Anastrepha serpentina (Wied.) não foram detectadas em Mossoró/Assu.

No norte de Minas Gerais, que também é uma região semi-árida, já foram detectadas 21 espécies de moscas-das-frutas (Canal D., 1997), sendo esta diversidade bem maior do que a encontrada nas regiões de Mossoró/Assu e Petrolina/Juazeiro. Provavelmente, esta maior diversidade de espécies está relacionada à existência de um variado número de frutíferas nos pomares domésticos no norte de Minas Gerais.

Tabela 2. Espécies de moscas-das-frutas coletadas na região de Mossoró/Assu (RN), de janeiro/1999 a dezembro/2000.

\begin{tabular}{lccr}
\hline & \multicolumn{3}{c}{ Exemplares (n) } \\
\cline { 2 - 4 } Espécies & Armadilhas & Frutos & Total \\
\hline Anastrepha alveata Stone, 1942 & 12 & - & 12 \\
Anastrepha dissimilis Stone, 1942 & 46 & - & 46 \\
Anastrepha distincta Greene, 1934 & 1 & - & 1 \\
Anastrepha montei Lima, 1934 & 14 & - & 14 \\
Anastrepha obliqua (Macquart, 1835) & 181 & 1.517 & 1.698 \\
Anastrepha pickeli Lima, 1934 & 11 & - & 11 \\
Anastrepha sororcula Zucchi, 1979 & 1.435 & 899 & 2.334 \\
Anastrepha zenildae Zucchi, 1979 & 4.981 & 5.755 & 10.736 \\
Anastrepha sp. aff. pickeli & 148 & 60 & 208 \\
Ceratitis capitata (Wied., 1824) & 113.136 & 14.612 & 127.748 \\
\hline
\end{tabular}


Assim como em outras regiões, C. capitata é a espécie de moscas-dasfrutas mais importante do ponto de vista quarentenário, que ocorre em Mossoró/Assu. Dentre as espécies de Anastrepha coletadas, A. zenildae, A. sororcula e $A$. obliqua são as mais comuns. Anastrepha sororcula e $A$. obliqua são de importância quarentenária. Anastrepha zenildae não tem importância quarentenária, mas possui status de praga, como no norte de Minas Gerais (Canal D. et al., 1998), onde foi constatada como praga de goiaba Psidium guajava.

As demais espécies capturadas em Mossoró/Assu, Anastrepha sp. aff. pickeli, A. alveata, A. dissimilis, A. distincta, A. montei e A. pickeli não possuem importância quarentenária e econômica, apesar de algumas delas terem ampla distribuição no território brasileiro (Kovaleski et al., 1999).

Nas regiões de Petrolina/Juazeiro e norte de Minas Gerais, que também são semi-áridas, foram assinaladas a ocorrência de cinco espécies de importância quarentenária - A. fraterculus, $A$. obliqua, $A$. sororcula, $A$. serpentina e $C$. capitata (Canal D., 1997 e Haji \& Miranda, 2000).

Anastrepha fraterculus é uma das moscas-das-frutas mais comum no Brasil, contudo, nenhum exemplar foi detectado neste trabalho. Vale salientar, que em levantamentos anteriores, realizados na região de Mossoró/Assu, $A$. fraterculus havia sido erroneamente identificada como A. zenildae (Araujo et al., 1996a).

Chave para a identificação das espécies de Anastrepha coletadas na região de Mossoró/Assu (RN)

1 Mediotergito e subescutelo totalmente amarelados...................................

1' Mediotergito e subescutelo escurecidos lateralmente..................................6

2 Acúleo com menos de $0,07 \mathrm{~mm}$ de largura e amplamente alargado na base, ápice muito curto; asa com todas as faixas separadas. A. montei

2' Acúleo com mais de 0,07 mm de largura...................................................

3 Ápice do acúleo no mínimo duas vezes mais longo do que a largura no fim 
da abertura cloacal; asa com todas as faixas separadas.

A. dissimilis

3' Ápice do acúleo em torno de 1,5 vezes mais longo do que a largura no fim da abertura cloacal.

4 Ápice do acúleo com as laterais voltadas para baixo. A. alveata

4' Ápice do acúleo com as laterais normais e dentes ultrapassando o nível do fim da abertura cloacal... .5

5 Acúleo com menos de 1,7 mm; escamas dorsobasais da membrana eversível em forma de espinhos finos, curvos e anteriormente dispostos em forma triangular.

A. pickeli

5' Acúleo com mais de 2,0 mm; escamas dorsobasais da membrana eversível em forma de espinhos finos, curvos e anteriormente dispostos em forma circular. Anastrepha sp. aff. pickeli

6 Acúleo com dentes sobre menos da metade apical, sem constrição antes da serra. A. distincta

6' Acúleo com dentes estendendo-se no mínimo até a metade apical. .7

7 Ápice do acúleo com 0,15 a 0,22 mm e com nítida constrição antes da serra.

A. sororcula

7' Ápice do acúleo com uma leve constrição antes da serra. .8

8 Ápice do acúleo com 0,28 a $0,36 \mathrm{~mm}$ e dentes arredondados A. zenildae

8' Ápice do acúleo com 0,15 a $0,25 \mathrm{~mm}$ e dentes agudos ..A. obliqua

\subsubsection{Hospedeiros}

Dezoito espécies de frutíferas, das 42 amostradas (Apêndice 1), estavam infestadas por pelo menos uma espécie de moscas-das-frutas (Tabela 3). Das dez espécies de moscas-das-frutas coletadas, para cinco (Anastrepha sp. aff. pickeli, 
A. obliqua, A. sororcula, A. zenildae e C. capitata) foi associado pelo menos um hospedeiro.

Anastrepha obliqua foi detectada infestando serigüela, umbu, cajarana, cajá, atemoia, acerola e carambola (Tabela 3). A maioria destas frutíferas pertence à família Anacardiaceae e já havia sido referida como hospedeiras de $A$. obliqua em outras regiões do País (Malavasi et al., 1980; Canal D., 1997 e Zucchi, 2000b). Várias espécies de anonáceas do gênero Annona são referidas como hospedeiras de A. obliqua (Norrbom \& Kim, 1988). No Brasil, espécies desta família não haviam sido assinaladas como hospedeira de A. obliqua (Zucchi, 2000b). Contudo, neste trabalho verificou-se atemoia sendo infestada por $A$. obliqua, mas apenas um exemplar foi obtido. Assim como em outras regiões (Malavasi et al., 1980; Ohashi et al., 1997 e Souza Filho et al., 2000), acerola e carambola também foram referidos como hospedeiros de A. obliqua. Das quatro frutíferas que foram infestadas por $A$. sororcula (Tabela 3 ), apenas a cajarana não havia sido referida como hospedeira de $A$. sororcula.

Entre as espécies de Anastrepha, A. zenildae foi a que infestou a maior diversidade de famílias de frutíferas (Tabela 3). A goiaba e o juá são frutíferas freqüentemente associadas à $A$. zenildae (Araujo et al., 1996a e Canal D., 1997). A acerola, a cajarana e o kunquat estão sendo referidos pela primeiras vez como hospedeiros de $A$. zenildae.

Canal D. (1997) constatou a presença de Anastrepha sp. aff. pickeli no norte de Minas Gerais, infestando frutos de mandioca. Neste estudo, esta espécie infestou frutos de maniçoba, sendo este o primeiro relato neste hospedeiro, que é uma planta comum na região de Mossoró/Assu.

De todas as espécies de moscas-das-frutas capturadas, C. capitata foi a mais polífaga, infestando 13 espécies de frutíferas (Tabela 3). Apesar de ser extremamente polífaga, mais de 374 relatos de hospedeiros no mundo (Liquido et al., 1998) e 58 no Brasil (Zucchi, 2001), C. capitata está sendo referida pela primeira vez infestando frutos de juá, trapia e umbu. Estas frutíferas são nativas da caatinga e possuem uma distribuição regional considerável. Vale salientar, que um pequeno número de exemplares de $C$. capitata foi obtido destas frutíferas, e que 
estas estavam situadas próximos a hospedeiros primários, tendo sido, provavelmente, infestados ocasionalmente.

Um dos hospedeiros de C. capitata que mais chama a atenção é o caju, pois sabe-se que não é um bom hospedeiro de moscas-das-frutas, por causa dos altos teores de tanino do fruto. Contudo, apenas uma amostra estava infestada por C. capitata, apesar de haver grandes áreas plantadas com esta frutífera na região de Mossoró/Assu. O caju já havia sido referido como hospedeiro de C. capitata e Anastrepha sp., no norte de Minas Gerais (Canal D., 1997) e nos cerrados do Mato Grosso do Sul (Uchôa F., 1999), respectivamente.

As espécies, para as quais nenhum hospedeiro foi associado, foram Anastrepha alveata (hospedeiro desconhecido no Brasil); Anastrepha dissimilis que ataca maracujá (Passifloraceae); Anastrepha distincta cria-se principalmente em frutos de ingá (Mimosaceae); Anastrepha montei e Anastrepha pickeli que infestam principalmente frutos de mandioca (Euphorbiaceae) (Norrbom \& Kim, 1988 e Zucchi, 2000b).

Tabela 3. Hospedeiros de moscas-das-frutas na região de Mossoró/Assu (RN), de janeiro/1999 a dezembro/2000.

\begin{tabular}{lll}
\hline \multirow{2}{*}{ Espécies } & \multicolumn{2}{c}{ Hospedeiros } \\
\cline { 2 - 3 } & Famílias & Espécies \\
\hline Anastrepha obliqua & Anacardiaceae & $\begin{array}{l}\text { Spondias purpurea serigüela (E) } \\
\text { Spondias tuberosa umbu (N) } \\
\end{array}$ \\
& & $\begin{array}{l}\text { Spondias sp. cajarana (N) } \\
\text { Spondias sp. cajá (N) }\end{array}$ \\
& Annonaceae & Annona sp. atemoia (N) \\
& Malpighiaceae & Malpighia emarginata acerola (E) \\
& Oxalidaceae & Averrhoa carambola carambola (E) \\
Anastrepha sororcula & Anacardiaceae & S. purpurea serigüela (E) \\
& & Spondias sp. cajarana (N) * \\
\hline
\end{tabular}




\begin{tabular}{|c|c|c|}
\hline & Myrtaceae & Psidium guajava goiaba $(\mathrm{N})$ \\
\hline & & Syzygium jambos jambo (E) \\
\hline \multirow[t]{7}{*}{ Anastrepha zenildae } & Anacardiaceae & S. purpurea serigüela $(\mathrm{E})$ \\
\hline & & Spondias sp. cajarana $(\mathrm{N})$ * \\
\hline & Combretaceae & Terminalia catappa castanhola (E) \\
\hline & Malpighiaceae & M. emarginata acerola $(\mathrm{E})$ * \\
\hline & Myrtaceae & P. guajava goiaba $(\mathrm{N})$ \\
\hline & Rhamnaceae & Ziziphus joazeiro juá (N) \\
\hline & Rutaceae & Fortunella sp. kunquat $(\mathrm{E})$ * \\
\hline
\end{tabular}

Tabela 3. Hospedeiros de moscas-das-frutas na região de Mossoró/Assu (RN), de janeiro/1999 a dezembro/2000.

\begin{tabular}{|c|c|c|}
\hline \multirow[b]{2}{*}{ Espécies } & \multicolumn{2}{|r|}{ Hospedeiros } \\
\hline & Famílias & Espécies \\
\hline Anastrepha sp. aff. pickeli & Euphorbiaceae & Manihot glaziovii maniçoba $(\mathrm{N}){ }^{*}$ \\
\hline \multirow[t]{13}{*}{ Ceratitis capitata } & Anacardiaceae & Anacardium occidentale caju $(\mathrm{N})$ \\
\hline & & Mangifera indica manga $(\mathrm{E})$ \\
\hline & & Spondias cytherea caja-manga (E) \\
\hline & & S. purpurea serigüela $(E)$ \\
\hline & & S. tuberosa umbu $(\mathrm{N}){ }^{*}$ \\
\hline & Capparidaceae & Crateva tapia trapia $(\mathrm{N})$ * \\
\hline & Combretaceae & T. catappa castanhola $(\mathrm{E})$ \\
\hline & Malpighiaceae & M. emarginata acerola (E) \\
\hline & Myrtaceae & P. guajava goiaba $(\mathrm{N})$ \\
\hline & Oxalidaceae & A. carambola carambola $(\mathrm{E})$ \\
\hline & Rhamnaceae & Z. joazeiro juá $(\mathrm{N})$ * \\
\hline & Rutaceae & Citrus reticulata tangerina $(\mathrm{E})$ \\
\hline & & Fortunella sp. kunquat $(\mathrm{E})$ \\
\hline
\end{tabular}

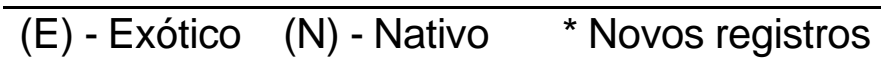


Os frutos de nove famílias foram atacadas por larvas de moscas-das-frutas, entretanto, Anacardiaceae foi a que apresentou o maior número de espécies infestadas (Figura 1), com destaque para as frutíferas do gênero Spondias. Malavasi et al. (1980) já haviam observado a preferência dos tefritídeos por frutos de Spondias. Também no norte de Minas Gerais, que é semi-árido, a família Anacardiaceae foi a que teve o maior número de frutíferas infestadas por moscasdas-frutas (Canal D., 1997). Em outros levantamentos realizados no País, como no Estado do Amazonas (Silva et al., 1996), cerrado de Goiás (Veloso, 1997), cerrado do Mato Grosso do Sul (Uchôa F., 1999) e Estado de São Paulo (Sousa Filho, 1999), a família Myrtaceae foi a que teve o maior número de espécies infestadas.

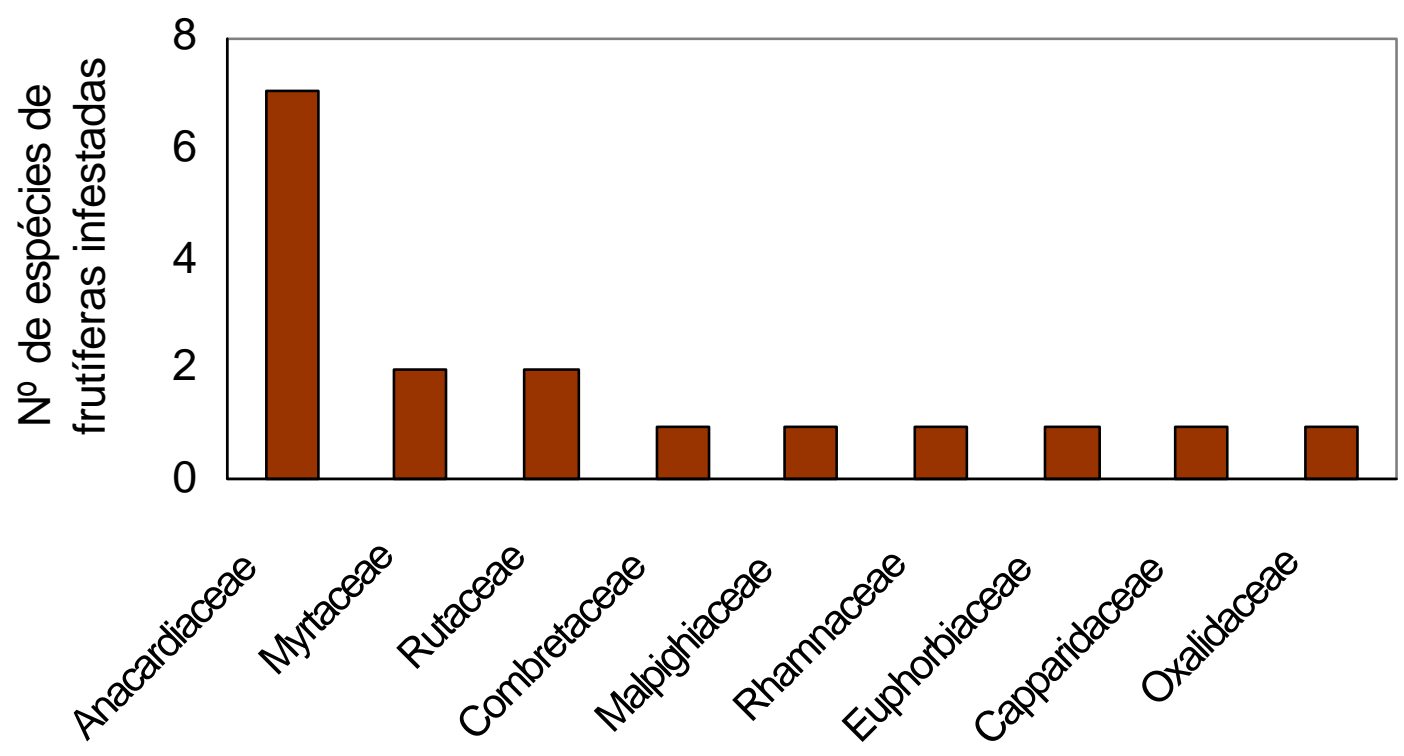

Figura 1 - Número de espécies de frutíferas infestadas por moscas-das-frutas na região de Mossoró/Assu (RN), de janeiro/1999 a dezembro/2000.

Das frutíferas hospedeiras de moscas-das-frutas, caja-manga, atemoia, jambo, carambola, tangerina e kunquat estão restritas a poucos pomares 
domésticos. Mas cajá, cajarana, umbu, trapia, maniçoba e juá fazem parte da vegetação nativa do semi-árido (caatinga).

Das 42 espécies de frutíferas amostradas, 24 não estavam infestadas por moscas-das-frutas - graviola Annona muricata, carnaúba Copernica prunifera, mandacaru Cereus jamacaru, palma Opuntia ficus-indica, feijão-bravo Capparis flexuosa, mamão Carica papaya, oiticica Licania rigida, maxixe Cucumis anguria, melão Cucumis melo, melancia Citrullus lanatus, melão-de-são-caetano Momordica charantia, pinhão-roxo Jatropha sp., pinhão-bravo Jatropha mollissima, mandioca Manihot esculenta, groselha Phyllanthus acidus, mari Geoffroca spinosa, sabiá Mimosa caesalpiniifolia, lírio Melia azedarach, ameixa-do-mato Ximenia americana, limão Citrus limon, laranja Citrus sinensis, sapoti Achras sapota, melancia-da-praia Solanum agrarium e canapum Physalis angulata.

O levantamento dos hospedeiros nativos de moscas-das-frutas nas regiões semi-áridas é bastante trabalhoso. A dificuldade para se encontrar estes hospedeiros, deve-se ao fato de que a vegetação nativa (caatinga) é do tipo

xerófila (permanece em estado de latência durante os meses secos), com frutificação restrita a uma curta época do ano. Além disso, constata-se que a caatinga possui um número reduzido de hospedeiros de moscas-das-frutas, ou seja, plantas com frutos carnosos, potencialmente hospedeiros de moscas-dasfrutas, como o juá e a cajarana.

\subsection{3 Índice de infestação de moscas-das-frutas}

$\mathrm{Na}$ região de Mossoró/Assu, as espécies de Anastrepha infestaram com maior intensidade juá, cajarana e goiaba, com índices médios de infestação de 67, 32,3 e 32,1 pupários/kg, respectivamente (Tabela 4). As informações sobre os níveis de infestação em juá e cajarana são escassos, pois apenas recentemente estes frutos foram relatados como hospedeiros de moscas-das-frutas (Araujo et al., 1996a e Canal D., 1997). Contudo, Canal D. (1997) relatou que no norte de Minas Gerais, juá e cajarana apresentaram infestações de 94 e 55,5 pupários/kg, respectivamente. Por outro lado, vários são os relatos sobre as infestações de 
Anastrepha em goiaba, pois este é um dos hospedeiros preferidos das moscasdas-frutas (Zucchi, 2000b), apresentando níveis de infestação variáveis ao longo do País. Em Ribeirão Preto (SP), Bressan \& Teles (1991) constataram uma infestação de Anastrepha spp. em goiaba de 55,3 pupários/kg e no norte do Estado de Minas Gerais, onde A. zenildae foi constatada como praga de goiaba, Canal D. et al. (1998) verificaram infestações de até 116 larvas de Anastrepha spp. por $\mathrm{kg}$ de fruto. Dessa forma, juá, cajarana e goiaba apresentaram infestações consideráveis por Anastrepha spp. na região de Mossoró/Assu (RN), contudo, os índices detectados foram menores do que em algumas regiões do País.

Os frutos de acerola e carambola foram os menos infestados com índices de 0,02 e 0,1 pupários $/ \mathrm{kg}$, respectivamente (Tabela 4). No entanto, Ohashi et al. (1997) relataram a ocorrência de altas infestações de $A$. obliqua em frutos de acerola no Estado do Pará. Além disso, Souza Filho et al. (2000) constataram, em Presidente Prudente (SP), um índice de infestação de $A$. obliqua em carambola de 262,7 pupários/kg.

Nenhum pupário de Anastrepha foi obtido das $2.781(1.266 \mathrm{~kg})$ mangas amostradas. Entretanto, o cultivo da manga em escala comercial é recente em Mossoró/Assu e, nitidamente, observou-se que as populações locais de $A$. obliqua, principal espécie relacionada com a manga no Brasil, estão associadas à anacardiáceas do gênero Spondias, que são nativas da região. É provável que no futuro alguma espécie de Anastrepha infeste mangas na região. No entanto, vários mecanismos estão envolvidos na exploração do hospedeiro por uma espécie de mosca-das-frutas (Selivon, 2000).

Ao contrário do que foi observado para as espécies de Anastrepha, as maiores infestações de $C$. capitata ocorreram em kunquat, carambola e serigüela 159, 118 e 34 pupários $/ \mathrm{kg}$, respectivamente (Tabela 4). Os níveis de infestação de C. capitata verificados por Souza Filho (1999), no Estado de São Paulo, para esses três hospedeiros (kunquat 6,8; carambola 0,1 e serigüela 1,2 pupários $/ \mathrm{kg}$ ) foram inferiores aos constatados neste trabalho. No norte de Minas Gerais, carambola também foi pouco infestada por C. capitata, com um índice de 4,7 
pupários/kg (Canal D., 1997). Vale salientar, que kunquat e carambola não são comuns na região de Mossoró/Assu, até mesmo em pomares domésticos. Além disso, todas as amostras dessas duas frutíferas foram coletadas em um único pomar, onde kunquat, carambola e tangerina ocorriam simultaneamente. Por outro lado, serigüela é comum nos pomares domésticos da região, podendo em algumas ocasiões, ser responsável por infestações consideráveis de moscas-dasfrutas. A acerola foi outro hospedeiro de $C$. capitata que se destacou, pelo índice de infestação na região. Em algumas amostras foram observadas infestações superiores a 200 pupários $/ \mathrm{kg}$. No entanto, estas altas infestações estavam restritas a poucos pomares e, em alguns casos, pomares distantes menos de $5 \mathrm{~km}$ um do outro apresentaram níveis de infestação bem distintos. Além disso, o índice médio de infestação na região foi baixo (16,9 pupários/kg), quando comparado com os de outros hospedeiros.

As menores infestações de C. capitata ocorreram em umbu e juá $(0,04 \mathrm{e}$ 0,09 pupários/kg, respectivamente) (Tabela 4). O umbu e o juá estão sendo referidas pela primeira vez como hospedeiros de $C$. capitata neste trabalho. 
Tabela 4. Índices de infestação de moscas-das-frutas na região de Mossoró/Assu (RN), de janeiro/1999 a dezembro/2000.

\begin{tabular}{|c|c|c|c|c|c|c|c|c|}
\hline \multirow{3}{*}{$\begin{array}{l}\text { Famílias } \\
\text { Hospedeiros }\end{array}$} & \multirow{2}{*}{\multicolumn{2}{|c|}{$\begin{array}{c}\text { Amostras } \\
\text { Infestadas (n) }\end{array}$}} & \multirow{2}{*}{\multicolumn{2}{|c|}{$\begin{array}{c}\text { Pupários } \\
\text { Obtidos (n) }\end{array}$}} & \multicolumn{4}{|c|}{ Índices de Infestação } \\
\hline & & & & & \multicolumn{2}{|c|}{ Pupários/fruto } & \multicolumn{2}{|c|}{ Pupários/kg } \\
\hline & Anastrepha & Ceratitis & Anastrepha & Ceratitis & Anastrepha & Ceratitis & Anastrepha & Ceratitis \\
\hline \multicolumn{9}{|l|}{ Anacardiaceae } \\
\hline Anacardium occidentale & - & 1 & - & 20 & - & 0,08 & - & 1,3 \\
\hline Mangifera indica & - & 14 & - & 752 & - & 0,27 & - & 0,6 \\
\hline Spondias sp. (Cajarana) & 24 & - & 4.574 & - & 0,48 & - & 32,3 & - \\
\hline Spondias sp. (Cajá) & 7 & - & 164 & - & 0,17 & - & 21,9 & - \\
\hline Spondias cytherea & - & 2 & - & 23 & - & 1,28 & - & 12,6 \\
\hline Spondias purpurea & 5 & 7 & 188 & 733 & 0,15 & 0,57 & 8,8 & 34,25 \\
\hline Spondias tuberosa & 6 & 1 & 412 & 1 & 0,30 & * & 15,7 & 0,04 \\
\hline \multicolumn{9}{|l|}{ Annonaceae } \\
\hline Annona sp. (Atemoia) & 1 & - & 1 & - & 0,25 & - & 1,0 & - \\
\hline \multicolumn{9}{|l|}{ Capparidaceae } \\
\hline Crateva tapia & - & 1 & - & 9 & - & 0,01 & - & 0,6 \\
\hline \multicolumn{9}{|l|}{ Combretaceae } \\
\hline Terminalia catappa & 1 & 6 & 18 & 200 & 0,01 & 0,13 & 0,5 & 5,1 \\
\hline \multicolumn{9}{|l|}{ Euphorbiaceae } \\
\hline Manihot glaziovii & 5 & - & 140 & - & 0,09 & - & 15,3 & - \\
\hline
\end{tabular}


Tabela 4. Índices de infestação de moscas-das-frutas na região de Mossoró/Assu (RN), de janeiro/1999 a dezembro/2000.

\begin{tabular}{|c|c|c|c|c|c|c|c|c|}
\hline \multirow{3}{*}{$\begin{array}{l}\text { Famílias } \\
\text { Hospedeiros }\end{array}$} & \multirow{2}{*}{\multicolumn{2}{|c|}{$\begin{array}{c}\text { Amostras } \\
\text { Infestadas (n) }\end{array}$}} & \multirow{2}{*}{\multicolumn{2}{|c|}{$\begin{array}{c}\text { Pupários } \\
\text { Obtidos (n) }\end{array}$}} & \multicolumn{4}{|c|}{ Índices de Infestação } \\
\hline & & & & & \multicolumn{2}{|c|}{ Pupários/fruto } & \multicolumn{2}{|c|}{ Pupários/kg } \\
\hline & Anastrepha & Ceratitis & Anastrepha & Ceratitis & Anastrepha & Ceratitis & Anastrepha & Ceratitis \\
\hline \multicolumn{9}{|l|}{ Malpighiaceae } \\
\hline Malpighia emarginata & 3 & 42 & 5 & 3.967 & * & 0,09 & 0,02 & 16,9 \\
\hline \multicolumn{9}{|l|}{ Myrtaceae } \\
\hline Psidium guajava & 68 & 32 & 15.109 & 2.880 & 2,67 & 0,51 & 32,1 & 6,1 \\
\hline Syzygium jambos & 1 & - & 9 & - & 0,08 & - & 1,9 & - \\
\hline \multicolumn{9}{|l|}{ Oxalidaceae } \\
\hline Averrhoa carambola & 5 & 18 & 10 & 6.421 & 0,01 & 5,48 & 0,2 & 118,8 \\
\hline \multicolumn{9}{|l|}{ Rhamnaceae } \\
\hline Ziziphus joazeiro & 19 & 1 & 4.426 & 6 & 0,23 & * & 67,7 & 0,1 \\
\hline \multicolumn{9}{|l|}{ Rutaceae } \\
\hline Citrus reticulata & - & 7 & - & 403 & - & 1,05 & - & 21,1 \\
\hline Fortunella sp. (Kunquat) & 1 & 16 & 1 & 7.171 & * & 2,16 & 0,02 & 159,1 \\
\hline
\end{tabular}

\footnotetext{
* Valor menor que duas casas decimais
} 
Dentre as frutíferas infestadas por $C$. capitata, a manga é a mais importante na região, do ponto de vista comercial. Entretanto, constatou-se que em Mossoró/Assu foi uma das frutíferas menos infestada (0,6 pupários $/ \mathrm{kg}$ ), como observado nos cerrados de Goiás (Veloso, 1997), Mato Grosso do Sul (Uchôa F., 1999) e Estado de São Paulo (Souza Filho, 1999). Além dos baixos níveis de infestação de $C$. capitata em manga no Brasil, observou-se que em vários outros levantamentos regionais, esta associação muitas vezes nem foi verificada, como relatado por Bressan \& Teles (1991), Silva (1993), Canal D. (1997) e Matrangolo et al. (1998).

De acordo com o que foi discutido, constatou-se que os índices de infestação são variáveis de região para região. Vários fatores podem influenciar as infestações dos tefritídeos em cada hospedeiro e região. De forma geral, pode-se dizer que a densidade populacional das moscas-das-frutas e as características dos frutos (tamanho, cor, formato etc.) são uns dos fatores que mais influenciam os níveis de infestação dos frutos (Malavasi \& Morgante, 1980).

$\mathrm{Na}$ região de Mossoró/Assu, constatou-se que a origem do hospedeiro (nativo ou exótico) é um dos fatores relacionado com os níveis de infestação. As frutíferas nativas foram mais infestadas por espécies de Anastrepha (Figura 2), ao passo, que as exóticas foram preferidas por C. capitata (Figura 3), como já havia sido observado por Malavasi \& Morgante (1980).

Além dos elevados níveis de infestação, constatados nas cinco frutíferas preferidas pelas espécies de Anastrepha e C. capitata, também foi observado nestes hospedeiros uma considerável viabilidade pupal, no mínimo 60\% (Figuras 4 e 5). Portanto, essas frutíferas contribuem significativamente para 0 aumento populacional das moscas-das-frutas na região. 


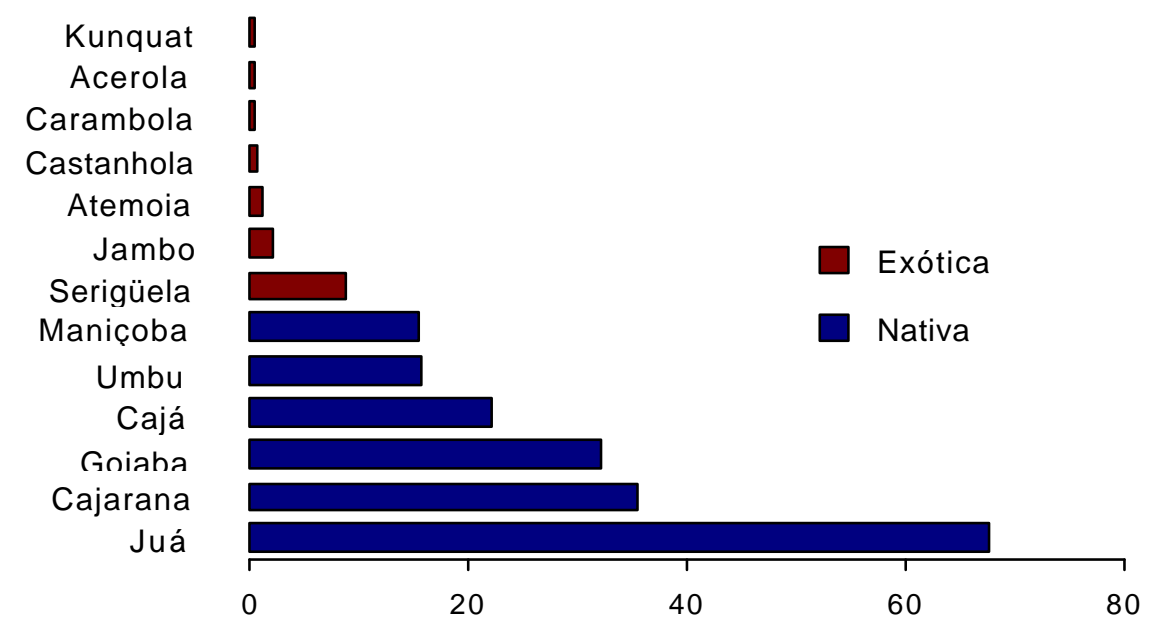

Figura 2 - Índice de infestação (pupários/kg) de Anastrepha spp. na região de Mossoró/Assu (RN), de janeiro/1999 a dezembro/2000.

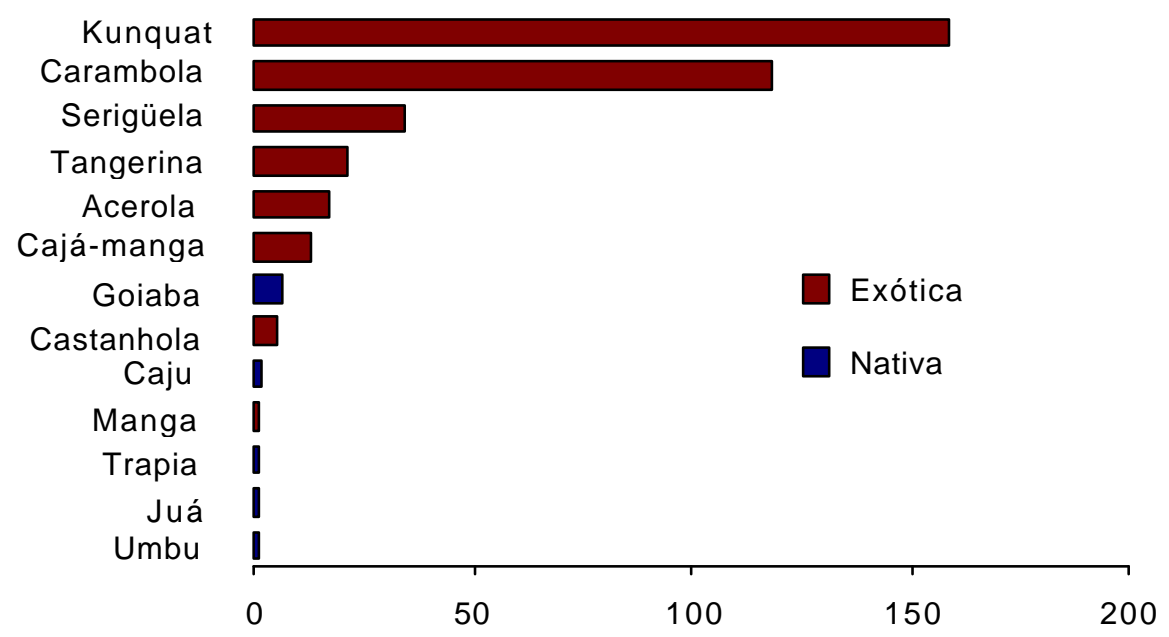

Figura 3 - Índice de infestação (pupários/kg) de Ceratitis capitata na região de Mossoró/Assu (RN), de janeiro/1999 a dezembro/2000. 


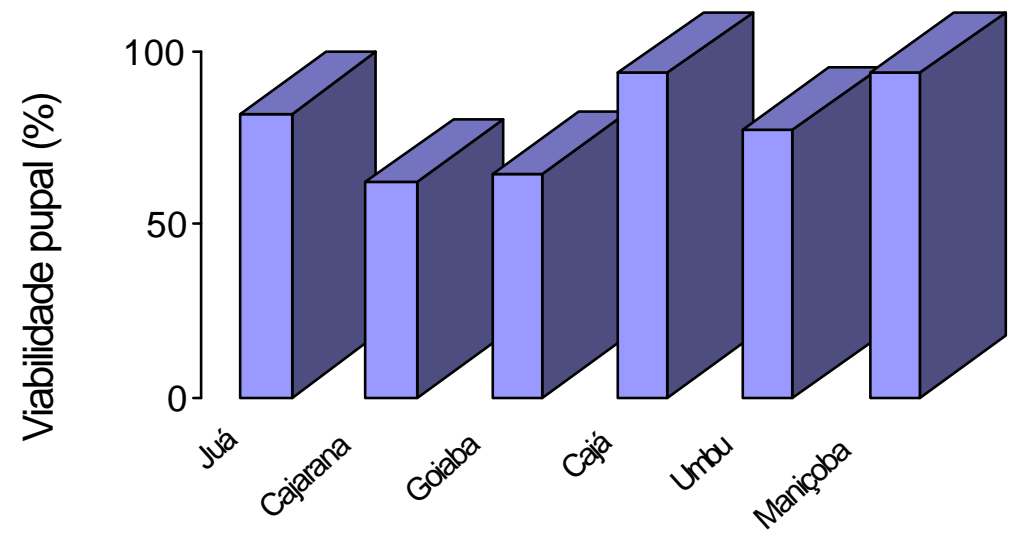

Figura 4 - Viabilidade pupal (\%) de Anastrepha spp. nas cinco frutíferas mais infestadas na região de Mossoró/Assu (RN), de janeiro/1999 a dezembro/2000.

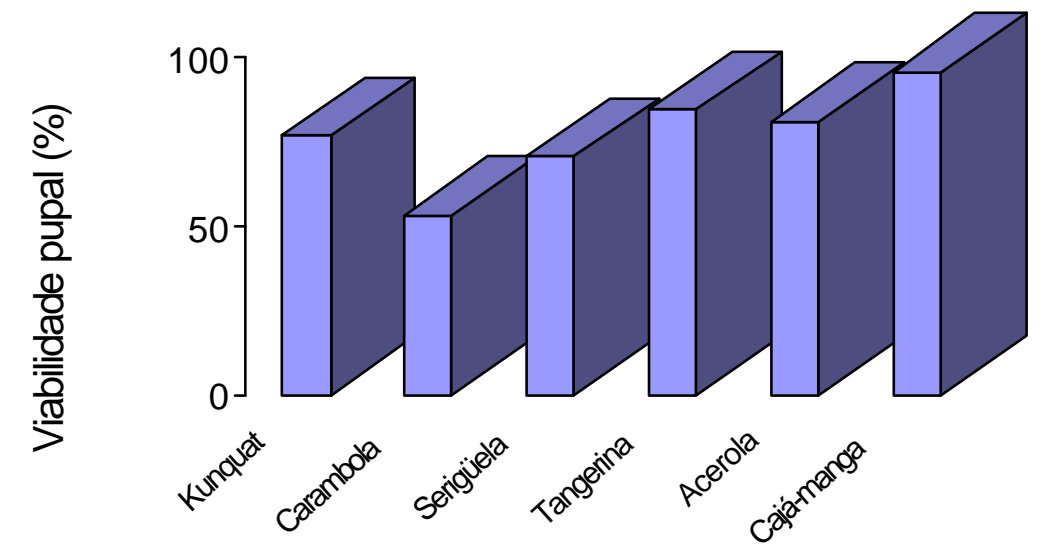

Figura 5 - Viabilidade pupal (\%) de Ceratitis capitata nas cinco frutíferas mais infestadas na região de Mossoró/Assu (RN), de janeiro/1999 a dezembro/2000. 
O conhecimento dos hospedeiros primários e secundários das moscas-dasfrutas em uma região é muito importante para o manejo desses tefritídeos. Segundo Malavasi \& Morgante (1980), o nível de infestação e a freqüência com que são encontrados frutos atacados no campo, podem ser utilizados como critério para se considerar um fruto como hospedeiro primário ou secundário. Constatou-se que na região de Mossoró/Assu, juá, cajarana e goiaba são hospedeiros primários de Anastrepha spp., ao passo que, apenas serigüela foi constatado como hospedeiro primário de $C$. capitata. Apesar dos altos índices de infestação em kunquat e carambola, estas frutíferas não foram consideradas hospedeiros primários de $C$. capitata, pois além do nível de infestação e a freqüência com que são encontrados frutos infestados no campo, considerou-se a distribuição do hospedeiro na região e, kunquat e carambola possuem uma distribuição limitada na região de Mossoró/Assu.

O status de juá, cajarana, goiaba e serigüela como hospedeiros primários de moscas-das-frutas é incerto para outras regiões, pois os níveis de infestação, freqüência com que são encontrados frutos infestados no campo e distribuição dos hospedeiros nas áreas são variáveis de região para região. Além disso, os valores de alguns critérios podem variar. Neste trabalho, considerou-se como hospedeiros primários aquelas frutíferas que apresentaram um índice de infestação acima de 30 pupários/kg. Entretanto, Silva (1993) e Souza Filho (1999) consideraram como hospedeiros primários apenas frutos com infestações superiores a 100 pupários $/ \mathrm{kg}$. Dessa forma, percebe-se que a utilização de um único valor de índice de infestação para todas as regiões seria incoerente, pois a densidade populacional dos tefritídeos é variável de uma região para outra. Portanto, o estabelecimento dos hospedeiros primários e secundários de uma região deve ser baseado nas características locais. 


\subsection{Conclusões}

As moscas-das-frutas detectadas na região de Mossoró/Assu (RN) são Anastrepha sp. aff. pickeli, A. alveata Stone, A. dissimilis Stone, A. distincta Greene, A. montei Lima, A. obliqua (Macquart), A. pickeli Lima, A. sororcula Zucchi, A. zenildae Zucchi e Ceratitis capitata.

Dezoito frutíferas são assinaladas como hospedeiras das moscas-dasfrutas, com destaque para as anacardiáceas.

A vegetação nativa da região de Mossoró/Assu (caatinga) possui poucos hospedeiros de moscas-das-frutas.

O juá Ziziphus joazeiro, a cajarana Spondias sp., a goiaba Psidium guajava e a serigüela Spondias purpurea são hospedeiros primários de moscas-das-frutas na região de Mossoró/Assu. 


\section{PARASITÓIDES (HYMENOPTERA: BRACONIDAE) DE MOSCAS-DAS- FRUTAS (DIPTERA: TEPHRITIDAE) NA REGIÃO DE MOSSORÓ/ASSU, ESTADO DO RIO GRANDE DO NORTE}

\section{Resumo}

As informações sobre @s parasitóides (Braconidae) de moscas-das-frutas são escassas em várias regiões do Brasil. Portanto, o objetivo deste trabalho foi conhecer a diversidade de espécies de braconídeos e seus níveis de parasitismo natural, na região semi-árida de Mossoró/Assu. Três espécies de braconídeos foram registradas - Doryctobracon areolatus (Szépligeti) (96,6\%), Utetes anastrephae (Viereck) (1,5\%) e Asobara anastrephae (Muesebeck) (1,9\%). O maior nível de parasitismo foi de $11,3 \%$, observado em larvas de moscas-dasfrutas em cajarana Spondias sp.

PARASITOIDS (HYMENOPTERA: BRACONIDAE) OF FRUIT FLIES (DIPTERA: TEPHRITIDAE), IN THE MOSSORÓ/ASSU REGION, STATE OF RIO GRANDE DO NORTE

\section{Summary}

Information about fruit fly parasitoids (Braconidae) is scarce in various regions of Brazil. Therefore, the objective of the present study was to determine the diversity of broconid species and their natural parasitism levels in the semi-arid 
region of Mossoró/Assu. Three braconid species were recorded - Doryctobracon areolatus (Szépligeti) (96.6\%), Utetes anastrephae (Viereck) (1.5), and Asobara anastrephae (Muesebeck) (1.9\%). The righest level of parasitism was $11.3 \%$, observed on fruit fly larvae on "cajarana", Spondias sp. (Anacardiaceae).

\subsection{Introdução}

Em vários países tem sido utilizado o controle biológico, principalmente através do uso de parasitóides da família Braconidae, como um método de controle de moscas-das-frutas (Clausen, 1956; Wharton \& Gilstrap, 1983; Ovruski et al., 2000 e Carvalho et al., 2000). No entanto, para o sucesso de um programa de controle biológico utilizando parasitóides, numa região ou país, é necessário o conhecimento da diversidade de espécies dos parasitóides nativos e sua dinâmica populacional.

Nos estudos realizados no Brasil, até o momento, foram constatadas 13 espécies de braconídeos, sendo Doryctobracon areolatus (Szépligeti), o mais comum (Leonel Jr. et al., 1995 e Canal D. \& Zucchi, 2000). A importância dos braconídeos como agentes de mortalidade de moscas-das-frutas foi observada em várias regiões do País, como em Limeira e Piracicaba (SP) (Leonel Jr. et al., 1996), Pelotas (RS) (Salles, 1996), Itaguaí e Seropédica (RJ) (Aguiar-Menezes \& Menezes, 1997 e Aguiar-Menezes, 2000) e em Conceição do Almeida (BA) (Matrangolo et al., 1998). Entretanto, em muitas regiões onde a fruticultura ocupa lugar de destaque, por exemplo, no norte de Minas Gerais, Petrolina/Juazeiro e Mossoró/Assu, as informações sobre os braconídeos são escassas (Alvarenga et al., 2000; Haji \& Miranda, 2000 e Araujo et al., 2000).

Portanto, o objetivo deste trabalho foi conhecer as espécies de braconídeos parasitóides de moscas-das-frutas que ocorrem na região de Mossoró/Assu, seus hospedeiros e índices de parasitismo natural. 


\subsection{Material e Métodos}

\subsubsection{Locais das coletas}

As coletas foram realizadas na região de Mossoró/Assu (RN), conforme metodologia descrita no capítulo 3, item 3.2.1.

\subsubsection{Obtenção dos parasitóides}

Para obtenção dos parasitóides foram coletados frutos, potencialmente hospedeiros de larvas de moscas-das-frutas e, conseqüentemente, dos parasitóides, utilizando-se a mesma metodologia descrita no capítulo 3, item 3.2.3.

\subsubsection{Associação entre parasitóide/frutífera/moscas-das-frutas}

Essa associação foi estabelecida quando em um mesmo recipiente houve emergência de uma única espécie de parasitóide e no máximo de duas espécies de moscas-das-frutas.

\subsubsection{Cálculo da percentagem de parasitismo}

A percentagem de parasitismo dos braconídeos sobre larvas/pupas de moscas-das-frutas foi calculada de acordo com Hernandes-Ortiz et al. (1994):

$\%$ Parasitismo $=\frac{\text { Número de parasitóides emergidos }}{\text { Número de pupários obtidos }} \times 100$ 


\subsubsection{Identificação dos táxons}

A identificação dos parasitóides foi baseada na disposição das mandíbulas, esculturação do propódeo e nervação alar, utilizando-se chaves de identificação específica (Leonel Jr., 1991 e Canal D. \& Zucchi, 2000).

As moscas-das-frutas foram identificadas baseando-se no padrão alar e no exame ventral do ápice do acúleo (Steyskal, 1977 e Zucchi, 2000a).

Os espécimes voucher foram depositados na coleção da ESALQ/USP (Entomologia), em Piracicaba (SP).

\subsection{Resultados e Discussão}

Das 42 espécies de frutíferas amostradas, 18 estavam infestadas por moscas-das-frutas e em apenas 6 foram obtidos braconídeos (Tabela 1). Dessas seis espécies de frutíferas, foram obtidos 34.760 pupários de moscas-das-frutas (24.719 de Anastrepha e 10.041 de Ceratitis capitata), de onde emergiram 1.405 braconídeos. Além destes, vários microimenópteros (Diapriidae e Eulophidae) foram também obtidos.

Tabela 1. Frutíferas com larvas de moscas-das-frutas parasitadas por braconídeos na região de Mossoró/Assu (RN), de janeiro/1999 a dezembro/2000.

\begin{tabular}{lccc}
\hline Famílias & & \multicolumn{2}{c}{ Frutos } \\
\cline { 4 - 4 } Frutíferas & Amostras (n) & $\mathrm{n}$ & $\mathrm{kg}$ \\
\hline Anacardiaceae & & & \\
$\quad$ Cajarana Spondias sp. (N) & $37[8]$ & 9.544 & 129,6 \\
Serigüela Spondias purpurea (E) & $18[1]$ & 1.289 & 21,4 \\
$\quad$ Umbu Spondias tuberosa (N) & $8[2]$ & 1.387 & 26,2 \\
Myrtaceae & & & \\
$\quad$ Goiaba Psidium guajava (N) & $80[27]$ & 5.660 & 470,4 \\
Oxalidaeceae & & &
\end{tabular}



Carambola Averrhoa carambola
$20[3]$
1.171
54,1

(E)

Rhamnaceae

$\begin{array}{lccc}\text { Juá Ziziphus joazeiro (N) } & 25[9] & 19.246 & 65,3 \\ \text { Total } & 188[50] & 38.297 & 767\end{array}$

\begin{tabular}{lll}
\hline [Número de amostras com braconídeos] & $(\mathrm{N})$ - Nativo & (E) - Exótico
\end{tabular}

As frutíferas, das quais foram obtidas larvas de moscas-das-frutas parasitadas, são abundantes na região de Mossoró/Assu, com exceção da carambola e da serigüela, que são espécies introduzidas no Brasil.

\subsubsection{Espécies de braconídeos}

No Brasil, já foram registradas 13 espécies de braconídeos (Alysiinae e Opiinae) parasitóides de moscas-das-frutas, a maioria pertencente à subfamília Opiinae (Leonel Jr. et al., 1995 e Canal D. \& Zucchi, 2000).

Três espécies de braconídeos foram coletadas neste trabalho, duas espécies de Opiinae - Doryctobracon areolatus (Szépligeti) e Utetes anastrephae (Viereck) e uma de Alysiinae - Asobara anastrephae (Muesebeck) (Figura 1). Esses parasitóides têm sido normalmente coletados em outras regiões brasileiras, como nos Estados de São Paulo (Leonel Jr. et al., 1996), Mato Grosso do Sul (Uchôa F., 1999), Goiás (Veloso, 1997) e Amazonas (Canal D. et al., 1994).

Os primeiros relatos de braconídeos parasitando moscas-das-frutas, no Estado do Rio Grande do Norte, foram feitos por Araujo et al. (1996a), que relataram a ocorrência de $D$. areolatus e $A$. anastrephae. Portanto, este é o primeiro registro de Utetes anastrephae parasitando larvas/pupas de moscas-dasfrutas no Estado do Rio Grande do Norte.

Após dois anos de coletas, constatou-se que a espécie de Braconidae mais comum na região de Mossoró/Assu foi $D$. areolatus (96,6\%). 


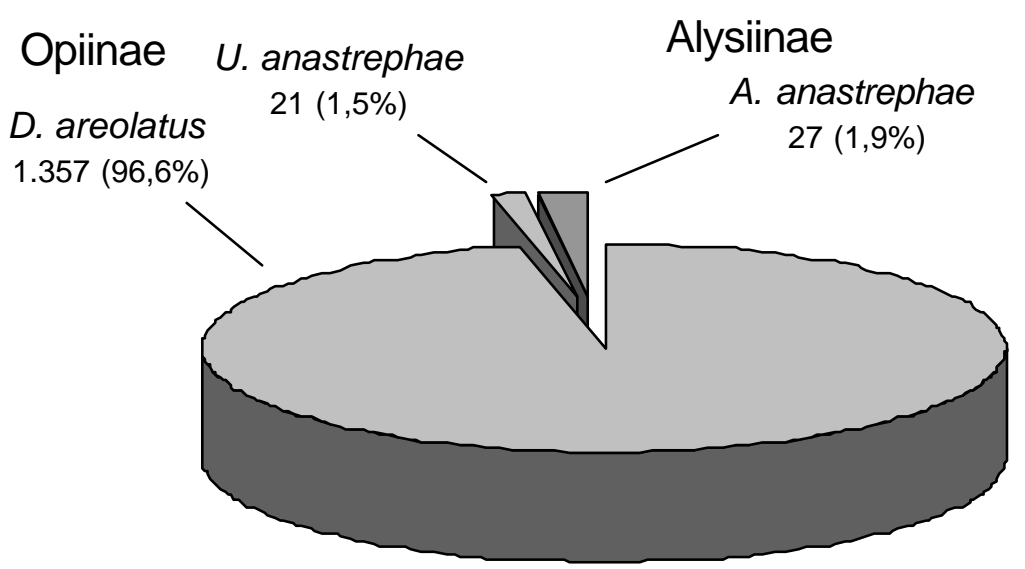

Figura 1 - Espécies de parasitóides (Braconidae) da região de Mossoró/Assu (RN), de janeiro/1999 a dezembro/2000.

Dos braconídeos obtidos, $D$. areolatus é o que possui a mais ampla distribuição geográfica na América Latina, tendo sido registrado do México à Argentina (Wharton \& Gilstrap, 1983 e Ovruski et al., 2000). No Brasil, esse parasitóide ocorre de norte à sul (Canal D. \& Zucchi, 2000). Assim como em Mossoró/Assu, D. areolatus predomina em várias regiões do País, como nos cerrados de Goiás (Veloso, 1997) e Mato Grosso do Sul (Uchôa F., 1999), em Conceição do Almeida (BA) (Matrangolo et al., 1998), em Itaguaí e Seropédica (RJ) (Aguiar-Menezes \& Menezes, 1997 e Aguiar-Menezes, 2000) e em Limeira e Piracicaba (SP) (Leonel Jr. et al., 1996).

Utetes anastrephae também é uma espécie comum no Brasil (Canal D. \& Zucchi, 2000). No entanto, apesar da ampla distribuição geográfica, tem sido menos predominante que $D$. areolatus, em várias localidades (Canal $D$. et al., 1994; Leonel Jr. et al., 1996 e Aguiar-Menezes \& Menezes, 1997).

Asobara anastrephae é o menos comum dos três braconídeos em Mossoró/Assu. Segundo Canal \& Zucchi (2000), essa espécie ocorre nos Estados de São Paulo, Mato Grosso do Sul, Goiás, Amazonas e Rio Grande do Norte. 


\subsubsection{Associação entre parasitóide/frutífera/moscas-das-frutas}

Em Mossoró/Assu, D. areolatus foi obtido de larvas/pupas de A. obliqua, $A$. zenildae e C. capitata em cajarana, serigüela, umbu, goiaba, carambola e juá. Portanto, esse braconídeo foi registrado nas três espécies de moscas-das-frutas e nas seis frutíferas de onde foram obtidas larvas/pupas parasitadas (Tabela 2). Situação semelhante foi constatada em outras regiões, como em Limeira e Piracicaba (SP) (Leonel Jr. et al., 1996) e Itaguaí (RJ) (Aguiar-Menezes \& Menezes, 1997).

Doryctobracon areolatus foi o único parasitóide obtido de larvas/pupas de C. capitata. No entanto, o maior número desse braconídeo foi obtido de larvas/pupas de A. obliqua e A. zenildae em goiaba, cajarana e juá (Tabelas 2 e 3). No norte de Minas Gerais, que é uma região semi-árida, também foi constatado $D$. areolatus parasitando larvas/pupas de $A$. obliqua e $A$. zenildae associadas à cajarana e ao juá, respectivamente (Canal D., 1997). Vale salientar, que cajarana (também chamada de umbu-cajá) e juá são nativos das regiões semi-áridas do Brasil.

$\mathrm{Na}$ região de Mossoró/Assu, ocorrem grandes infestações de $A$. zenildae em frutos de goiaba e juá e de $A$. obliqua em cajarana. Portanto, pode-se afirmar que existe uma forte relação trófica entre $D$. areolatus/goiaba - juá/A. zenildae e entre $D$. areolatus/cajarana/A. obliqua.

Tabela 2. Associação entre parasitóides, frutíferas e moscas-das-frutas na região de Mossoró/Assu (RN), de janeiro/1999 a dezembro/2000.

\begin{tabular}{lll}
\hline Parasitóides & Frutíferas & Moscas-das-frutas \\
\hline D. areolatus & Cajarana Spondias sp. & Anastrepha obliqua \\
& Serigüela Spondias purpurea & A. obliqua e A. zenildae \\
& Umbu Spondias tuberosa & A. obliqua \\
& Goiaba Psidium guajava & A. zenildae; Ceratitis capitata
\end{tabular}


Carambola Averrhoa carambola A. obliqua; C. capitata Juá Ziziphus joazeiro

A. zenildae

U. anastrephae Cajarana Spondias sp. A. obliqua e A. zenildae

A. anastrephae Cajarana Spondias sp. A. obliqua Serigüela Spondias purpurea

A. obliqua e A. zenildae

Juá Ziziphus joazeiro

A. zenildae

Utetes anastrephae foi obtido apenas de larvas/pupas em cajarana (Tabela 2) e, como em Mossoró/Assu os frutos de cajarana são infestados basicamente por $A$. obliqua, houve uma maior associação entre $U$. anastrephae/cajarana/A. obliqua.

Em Itaguaí (RJ), U. anastrephae foi obtido de larvas/pupas de $A$. obliqua, $A$. fraterculus, $A$. sororcula e $A$. distincta. As larvas de $A$. obliqua parasitadas infestavam manga Mangifera indica, serigüela, goiaba e citros (Aguiar-Menezes \& Menezes, 1997). Segundo Canal \& Zucchi (2000), U. anastrephae está associado a várias espécies de Anastrepha e de frutíferas, no Brasil.

Asobara anastrephae parasitou larvas/pupas de A. obliqua e A. zenildae, em cajarana, serigüela e juá (Tabela 2). Contudo, o maior número de $A$. anastrephae foi proveniente de larvas/pupas em frutos de cajarana (Tabela 3). Dessa forma, constatou-se uma maior associação entre $A$. anastrephae/cajarana/A. obliqua, provavelmente em decorrência da atração desse parasitóide pela cajarana.

Tabela 3. Número de braconídeos obtidos de larvas/pupas de moscas-das-frutas, na região de Mossoró/Assu (RN), de janeiro/1999 a dezembro/2000.

Espécies de Braconídeos

Frutíferas $\quad$ D. areolatus U. anastrephae $A$. anastrephae


Cajarana Spondias sp.

$472(8)$

$21(3)$

$25(5)$

Serigüela $S$. purpurea

Umbu S. tuberosa

Goiaba P. guajava

$706(27)$

Carambola

A.

carambola

Juá Z. joazeiro

$138(9)$

Total

$1.357(50)$

$21(3)$

$27(7)$

(Número de amostras com braconídeos)

As informações sobre as relações tróficas de $A$. anastrephae são escassas na literatura. Entretanto, Canal D. et al. (1994) verificou, no Estado do Amazonas, A. anastrephae parasitando A. obliqua, cujas larvas atacavam taperebá Spondias mombin. No Estado de São Paulo, Souza Filho (1999) relatou a ocorrência de $A$. anastrephae associado a larvas/pupas de $A$. obliqua em carambola, constatou também esse braconídeo em larvas/pupas de C. capitata em frutos de castanhola Terminalia catappa.

As interações parasitóide/frutífera/mosca-das-frutas são bastante complexas, pois evoluíram ao longo de milhares de anos. De forma geral, os braconídeos são inicialmente atraídos por substâncias voláteis liberadas pelos frutos (infestados ou não). Quando o parasitóide (fêmea) encontra um fruto infestado, localiza a larva através da vibrotaxia (som produzido pelo movimento da larva no interior do fruto) e em seguida, insere o ovipositor na larva para verificar se é adequada àoviposição (Leyva et al., 1991).

Em princípio, em vários trabalhos de levantamento de parasitóides de larva/pupa de moscas-das-frutas, tentou-se estabelecer a associação entre parasitóide/frutífera/mosca-das-frutas. Entretanto, constatou-se que os braconídeos são generalistas, ou seja, parasitam larvas/pupas de várias espécies de Anastrepha e também $C$. capitata, que estão associadas a diferentes espécies de frutíferas (Hernández-Ortiz, 1994; Leonel Jr. et al., 1996; López et al., 1999 e Souza Filho, 1999). 
Apesar dos braconídeos serem generalistas, Aluja et al. (1990) chamaram a atenção para o fato de que os parasitóides poderiam ter algum grau de adaptação aos frutos hospedeiros das moscas-das-frutas. Em estudos subseqüentes, Leyva et al. (1991) relataram que o braconídeo Diachasmimorpha longicaudata (Ashmead) é mais atraído por voláteis liberados por frutos de Citrus paradisi e laranja Citrus sinensis do que de manga. Além disso, em vários levantamentos realizados no Brasil, constatou-se que os braconídeos parasitam principalmente larvas/pupas de espécies de Anastrepha (Leonel Jr. et al., 1995 e Canal D. \& Zucchi, 2000).

Neste estudo, a maioria dos braconídeos (Tabela 3) foram obtidos de larvas/pupas de Anastrepha que estavam em cajarana, goiaba e juá. Apenas oito parasitóides foram obtidos de larvas/pupas de C. capitata em carambola (6 braconídeos) e em goiaba (2 braconídeos). Portanto, verificou-se que apesar de generalistas, os parasitóides nativos tiveram preferência pelos frutos nativos e, conseqüentemente, apresentaram maior associação com larvas/pupas de espécies de Anastrepha, que foram predominantes nestes frutos.

\subsubsection{Parasitismo}

A maior percentagem de parasitismo foi observada em larvas/pupas de moscas-das-frutas em cajarana e o menor índice foi œnstatado nas larvas/pupas em carambola (Figura 2).

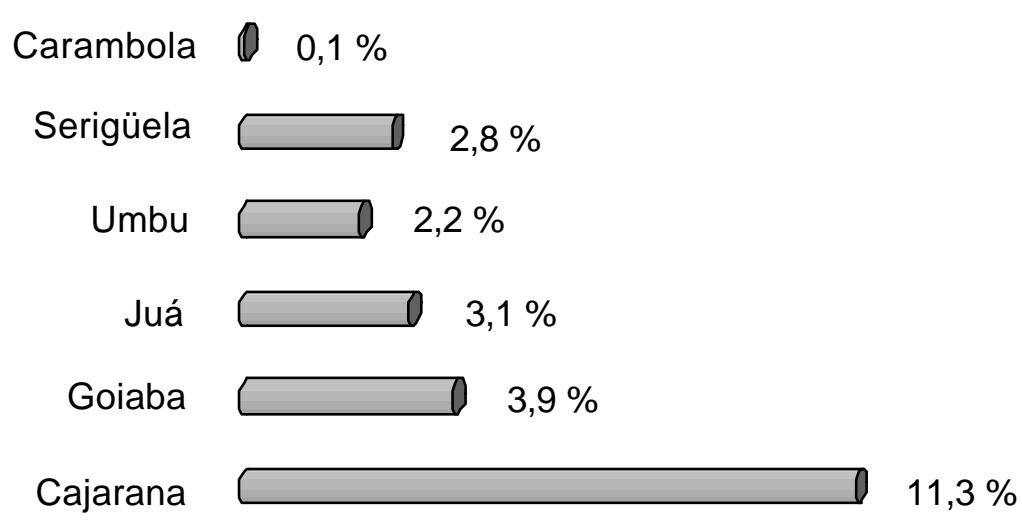


Figura 2 - Percentagem de parasitismo de larvas/pupas de moscas-das-frutas por braconídeos, em frutíferas nativas e exóticas, na região de Mossoró/Assu (RN), de janeiro/1999 a dezembro/2000.

Diversos fatores podem ter influenciado os níveis de parasitismo. O peso e o tamanho dos frutos apresentam uma correlação negativa com os níveis de parasitismo, ou seja, quanto mais pesado e maior o fruto, menor o nível de parasitismo dos braconídeos (Hernández-Ortiz et al., 1994; Sivinski et al., 1997 e Lopéz et al., 1999). De acordo com Sivinski et al. (1997), larvas que infestam frutos maiores podem aprofundar-se na polpa, dificultando a ação do parasitóide. Outro fator que pode afetar o parasitismo é o nível de infestação das larvas nos frutos. Altos níveis de infestação podem facilitar a localização do hospedeiro pelo parasitóide, pois nessas condições, as larvas tendem a se localizar mais na periferia do fruto, aumentando os níveis de parasitismo. O fato da futífera e da espécie da mosca hospedeira ser exótica ou nativa também pode interferir no nível de parasitismo (Sivinski et al., 1997).

Vários destes fatores explicam porque a percentagem de parasitismo foi maior nas larvas/pupas que infestavam cajarana do que nas larvas/pupas em carambola. A cajarana, menor e mais leve, foi mais infestada por larvas de Anastrepha, além disso, é uma frutífera nativa, coexistindo há mais tempo com os parasitóides nativos da região.

Entretanto, vários outros fatores bióticos e abióticos certamente influenciaram os níveis de parasitismo nas diversas frutíferas. Portanto, não é possível, com base apenas no que foi comentado, explicar todas as variações de parasitismo que foram constatadas (Figura 2).

Nas seis frutíferas de onde foram obtidos larvas/pupas de moscas-dasfrutas parasitadas, não foi observada uma correlação significativa entre peso médio de fruto e percentagem de parasitismo (Figura 3) e entre índice de infestação e percentagem de parasitismo (Figura 4). 


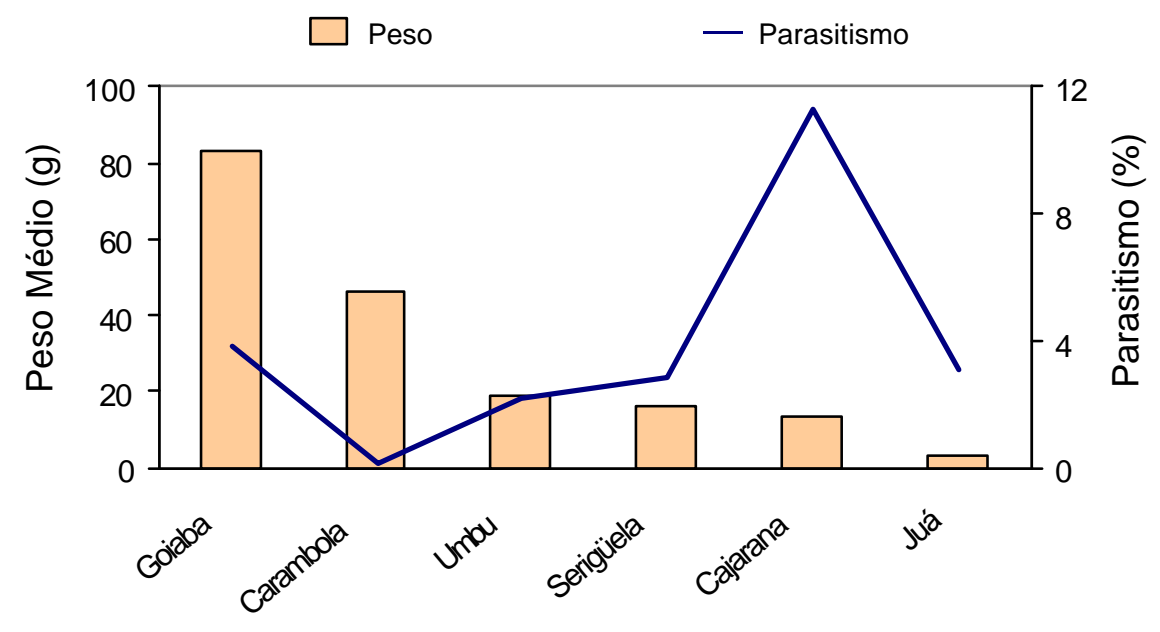

Figura 3 - Relação entre peso médio (g) de frutos e o parasitismo (\%) em larvas/pupas de moscas-das-frutas por braconídeos na região de Mossoró/Assu (RN), em 1999 e 2000.

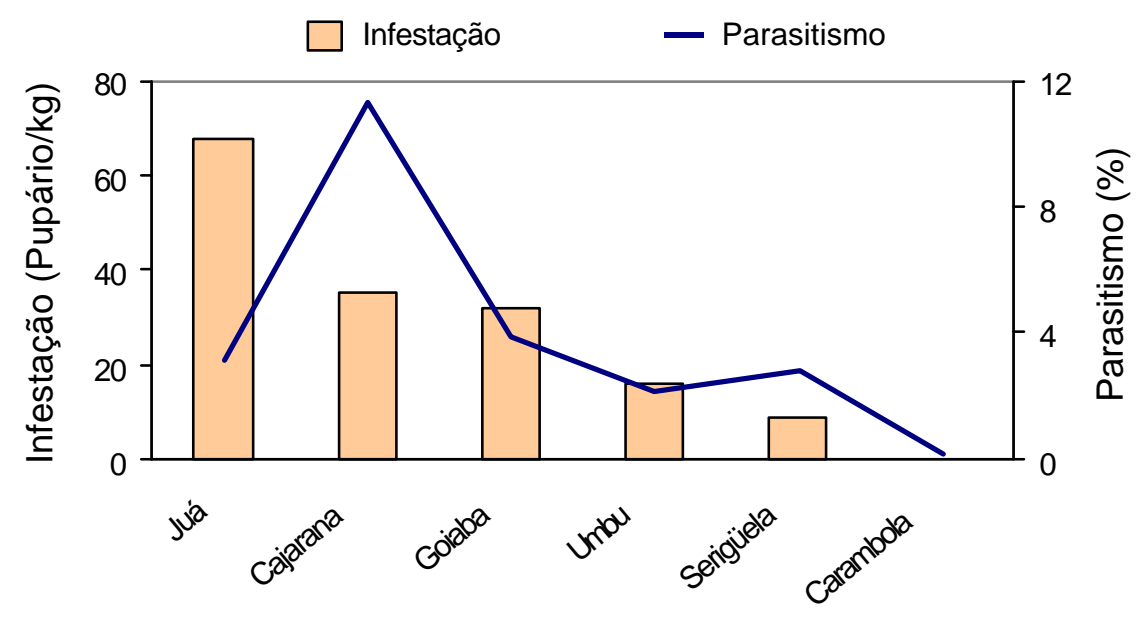


Figura 4 - Relação entre infestação (pupário/kg) e o parasitismo (\%) em larvas/pupas de moscas-das-frutas por braconídeos na região de Mossoró/Assu (RN), em 1999 e 2000.

Por outro lado, quando foi analisado apenas as amostras de cajarana, observou-se uma correlação significativa entre índice de infestação e percentagem de parasitismo (Figura 5). Essa análise foi realizada apenas com a cajarana, pelo fato de várias amostras terem sido parasitadas e apenas pupários de Anastrepha foram obtidos. Portanto, quando alguns fatores puderam ser isolados, observou-se uma correlação significativa entre índice de infestação e percentagem de parasitismo.

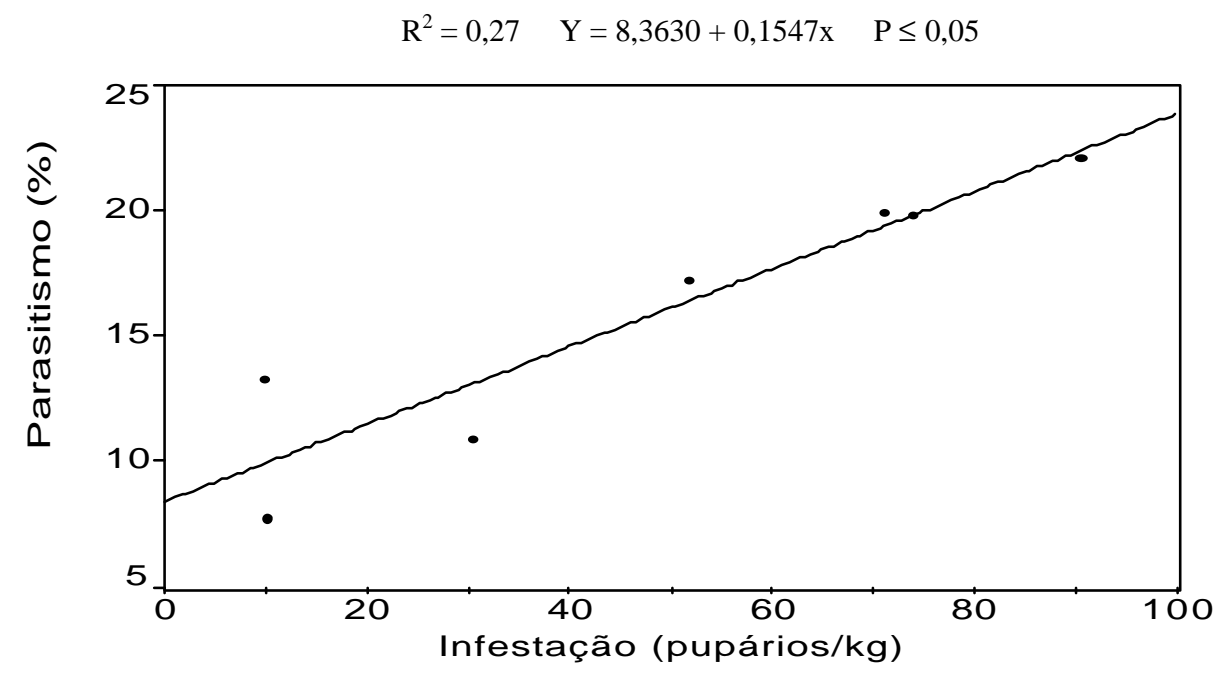

Figura 5 - Relação entre infestação (pupários/kg) e o parasitismo (\%) em larvas/pupas de Anastrepha spp. em cajarana, por braconídeos na região de Mossoró/Assu (RN), em 1999 e 2000.

A cajarana foi o único fruto do qual foram obtidas as três espécies de braconídeos, sendo $D$. areolatus a espécie que apresentou o maior índice de parasitismo (Tabela 4). Em várias outras regiões do País, verificou-se índices de 
parasitismo de $D$. areolatus superiores ao de $U$. anastrephae e de $A$. anastrephae. Segundo Matrangolo et al. (1998), em Conceição do Almeida (BA), o maior nível de parasitismo de $D$. areolatus em relação às outras espécies de parasitóides, deve-se ao fato de que $D$. areolatus é a primeira espécie a chegar nos frutos. Além disso, o ovipositor mais longo de $D$. areolatus (Sivinski et al., 1997), certamente favorece o parasitismo por esse braconídeo.

Tabela 4. Parasitismo em larvas/pupas de moscas-das-frutas por braconídeos, na região de Mossoró/Assu (RN), de janeiro/1999 a dezembro/2000.

\begin{tabular}{lrrrcc}
\hline & \multicolumn{2}{c}{ Pupários $(\mathrm{n})$} & \multicolumn{3}{c}{ Parasitismo (\%) } \\
\cline { 2 - 6 } Frutíferas & Anastrepha & Ceratitis & D. areolatus & U. anastrephae & A. anastrephae \\
\hline Cajarana & 4.574 & - & 10,3 & 0,5 & 0,6 \\
Serigüela & 188 & 733 & 2,7 & - & 0,1 \\
Umbu & 412 & 1 & 2,2 & - & - \\
Goiaba & 15.109 & 2.880 & 3,9 & - & - \\
Carambola & 10 & 6.421 & 0,1 & - & - \\
Juá & 4.426 & 6 & 3,1 & - & 0,02 \\
\hline
\end{tabular}

De forma geral, os índices de parasitismo observados na região de Mossoró/Assu foram próximos aos obtidos por Leonel Jr. et al. (1996), nos municípios de Limeira e Piracicaba (SP) e inferiores aos constatados em Itaguaí (RJ) (Aguiar-Menezes \& Menezes, 1997).

Portanto, verificou-se que vários fatores influenciam as relações tróficas dos parasitóides e os níveis de parasitismo. Daí a importância de se fazer os estudos regionais, pois estes permitem a compreensão de parte das relações tróficas e dos processos de parasitismo. Esse conhecimento é fundamental para o controle ou manejo das moscas-das-frutas utilizando-se braconídeos. 


\subsection{Conclusões}

Três espécies de parasitóides (Braconidae) ocorrem na região de Mossoró/Assu (RN) - Doryctobracon areolatus (Szépligeti), Utetes anastrephae (Viereck) e Asobara anastrephae (Muesebeck).

Doryctobracon areolatus é o braconídeo predominante em Mossoró/ Assu.

Os maiores índices de parasitismo são registrados nas larvas/pupas de espécies de Anastrepha parasitadas por Doryctobracon areolatus em frutos nativos.

A cajarana é o hospedeiro de moscas-das-frutas que mais atrai braconídeos em Mossoró/Assu. 


\section{5 ÍNDICES DE INFESTAÇÃO E PERDAS EM GOIABA Psidium guajava L. OCASIONADAS POR Anastrepha spp. (DIPTERA: TEPHRITIDAE)}

\section{Resumo}

A goiaba Psidium guajava L. é uma das frutíferas mais infestadas pelas moscas-das-frutas, no Brasil. Em algumas regiões, os níveis de infestação em goiaba são bem conhecidos. No entanto, pouco se conhece sobre as perdas nos pomares e as relações entre os níveis de infestação, as perdas e a flutuação populacional das moscas-das-frutas. Com o objetivo de conhecer os índices de infestação das espécies de Anastrepha em frutos de goiaba e relacionar as infestações com as percentagens de perdas e com a flutuação populacional, foram coletados frutos mensalmente em um pomar localizado em Mossoró (RN), durante 1999 e 2000. Os maiores níveis de infestação (67 e 97 pupários/kg) e picos populacionais (6,8 e 7,6 moscas/armadilha/dia) ocorreram no período de maio a julho. Nos meses de janeiro, fevereiro, novembro e dezembro não foram observados frutos infestados. No período de maior infestação ocorreram perdas de 78 a 100\% dos frutos. Em amostras com infestações acima de 35 pupários $/ \mathrm{kg}$ ocorreram perdas de mais de $70 \%$ dos frutos. Entretanto, as relações entre os níveis de infestação e a flutuação populacional não foram bem definidas. 


\section{INFESTATION LEVELS AND LOSSES OF GUAVA, Psidium guajava L., CAUSED BY Anastrepha spp. (DIPTERA: TEPHRITIDAE)}

\section{Summary}

Guava, Psidium guajava L., is one of the fruit trees most heavily infested by fruit flies in Brazil. In some regions, the levels of guava infestation are well known. However, little is known about orchard losses and the relations between infestation levels, losses and fluctuations of fruit fly populations. The objective of the present study was to determine the levels of guava fruit infestation by Anastrepha species and related hem to loss percentage and to population fluctuation in a survey in which fruits were collected monthly in 1999 and 2000 on an orchard located in Mossoró (RN). The highest levels of infestation (67 and 97 puparia/kg) and population peaks (6,8 and 7,6 flies/trap/day) occured from May to July. In January, February, November and December, no infested fruits were observed. In samples with infestation levels exceeding 35 puparia/ $/ \mathrm{kg}$, fruit losses were more than $70 \%$. However, the relations between infestation levels and populational fluctuation were not well defined.

\subsection{Introdução}

As moscas-das-frutas causam sérios prejuízos à fruticultura, uma vez que suas larvas alimentam-se da polpa dos frutos, tornando-os impróprios para o consumo in natura e para a industrialização. Em alguns frutos, como a maçã Pyrus malus, a simples tentativa de oviposição das moscas-das-frutas provoca deformação nos frutos, tornando-os sem valor comercial (Orth et al., 1996).

Dentre as várias frutíferas afetadas pelas moscas-das-frutas no Brasil, destaca-se a goiaba Psidium guajava. Segundo Pereira \& Martinez Jr. (1986) e 
Manica et al. (2000), as moscas-das-frutas do gênero Anastrepha e Ceratitis capitata (Wied.) são as principais pragas desse fruto.

Dez espécies de Anastrepha e C. capitata estão associadas à goiaba no Brasil (Zucchi, 2000b e 2001). Os índices de infestação destas espécies em goiaba são variáveis. Bressan \& Teles (1991) verificaram um índice médio de infestação de Anastrepha em goiaba de 58,7 pupários $/ \mathrm{kg}$, no município de Santo Antônio da Alegria (SP), sendo A. sororcula Zucchi a espécie mais comum seguida de A. bistrigata Bezzi. Souza Filho (1999), realizando estudos em vários municípios do Estado de São Paulo, constatou infestações médias de 36,9 pupários $/ \mathrm{kg}$, com predominância de $A$. fraterculus (Wied.). No cerrado de Goiás, Veloso (1997) verificou um índice médio de infestação de 37,9 pupários $/ \mathrm{kg}$, sendo $A$. sororcula e $A$. fraterculus as espécies predominantes. Na região semi-árida do norte de Minas Gerais, Canal D. et al. (1998) observaram, no município de Itacarambí, índices médios de infestação de até 116 pupários $/ \mathrm{kg}$, com predominância de $A$. zenildae Zucchi. Além disso, chamaram a atenção para o fato de que os pomares de goiaba em regiões áridas apresentam condições favoráveis para que $A$. zenildae atinja o nível de dano econômico.

Entretanto, apesar dos avanços nos conhecimentos dos índices de infestação das moscas-das-frutas em goiaba e outras frutíferas (Malavasi \& Morgante, 1980; Raga et al., 1997 e Souza Filho et al., 2000), em várias regiões do Brasil, pouca atenção tem sido dedicada para quantificar as perdas provocadas pelas moscas-das-frutas nos pomares. Segundo Carey \& Dowell (1989), as perdas provocadas pelas moscas-das-frutas em algumas partes do mundo podem alcançar $100 \%$ em muitas culturas.

Além da falta de informações sobre as perdas provocadas pelas moscasdas-frutas, são raros os estudos relacionando os índices de infestação com as percentagens de perdas e flutuação populacional. Um dos poucos estudos dessa natureza foi realizado por Malavasi \& Morgante (1981).

Portanto, o objetivo deste trabalho foi avaliar os índices de infestação das moscas-das-frutas do gênero Anastrepha em goiaba, no município de Mossoró $(\mathrm{RN})$, relacionando-os com as percentagens de perdas e a flutuação populacional. 


\subsection{Material e Métodos}

\subsubsection{Local e caracterização do pomar estudado}

O trabalho foi desenvolvido em um pomar de goiaba de 0,5 ha localizado na fazenda experimental da ESAM - Escola Superior de Agricultura de Mossoró, no município de Mossoró (RN), de janeiro de 1999 a dezembro de 2000.

O pomar era formado por mais de uma variedade de goiaba e não havia pomares de outras frutíferas, hospedeiras de moscas-das-frutas, nas proximidades. A irrigação era pelo sistema de gotejamento e o pomar havia sido podado apenas no início de 1999. Nenhuma pulverização foi realizada durante o período do trabalho.

\subsubsection{Coleta de moscas-das-frutas com armadilhas}

Para a coleta das moscas-das-frutas foram utilizadas quatro armadilhas do tipo McPhail (plástica), usando a mesma metodologia descrita no capítulo 3 (item 3.2.2).

\subsubsection{Coleta de moscas-das-frutas em frutos}

De acordo com a disponibilidade em campo, as goiabas eram coletadas, acondicionadas em bandejas plásticas e transportadas até o laboratório da COEX na ESAM, onde eram contadas e pesadas. A obtenção das moscas-das-frutas seguiu a mesma metodologia relatada no capítulo 3 (item 3.2.3).

\subsubsection{Percentagem de perda}

No período em que foi desenvolvido o trabalho de percentagem de perda, 27 de abril a 29 de junho de 2000, foram realizadas coletas semanais de goiabas. O tamanho das amostras dependia da disponibilidade de frutos em campo. No 
laboratório as goiabas eram contadas, pesadas e individualizadas em recipientes plásticos contendo uma camada de vermiculita. A obtenção das moscas-das-frutas seguiu a mesma metodologia relatada no capítulo 3 (item 3.2.3).

Para o cálculo da percentagem de perda, estabeleceu-se que quando um único pupário era obtido, o fruto era considerado perdido.

\subsection{5 Índice de infestação}

O índice de infestação foi calculado da mesma forma que no capítulo 3 (item 3.2.4).

\subsubsection{Flutuação populacional}

Foi avaliada por meio do índice MAD (número de moscas-das-frutas capturadas dividido pelo número de armadilhas instaladas dividido pelo número de dias de exposição das armadilhas em campo).

\subsubsection{Identificação das moscas-das-frutas}

Foi realizada seguindo a mesma metodologia descrita no capítulo 3 (item 3.3.5). Espécimes voucher estão depositados na coleção da ESALQ/USP (Entomologia), em Piracicaba (SP).

\subsection{Resultados e Discussão}

Durante os dois anos de trabalho foram coletados 10.847 exemplares de Anastrepha, provenientes de frutos e armadilhas. Dos 1.660 frutos $(263,9 \mathrm{~kg})$ coletados, foram obtidos 6.341 pupários dos quais emergiram 5.781 adultos (2.907 machos e 2.874 fêmeas). Nas armadilhas, foram coletados 5.066 exemplares (1.940 machos e 3.126 fêmeas). Apenas 301 exemplares de $C$. capitata foram 
obtidos dos frutos e das armadilhas, mostrando a baixa interferência desta espécie neste estudo.

Seis espécies de Anastrepha foram capturadas nas armadilhas (Tabela 1), com predominância de $A$. zenildae seguida de $A$. sororcula. Apenas $A$. zenildae $(86,9 \%)$ e $A$. sororcula $(13,1 \%)$ foram obtidas de frutos (Tabela 1). Informações semelhantes foram obtidas por Canal D. et al. (1998), durante seus estudos de determinação de níveis de infestação de goiaba por $A$. zenildae, no norte de Minas Gerais.

Tabela 1. Número de fêmeas de Anastrepha spp. obtidas em um pomar de goiaba P. guajava em Mossoró (RN), de janeiro/1999 a dezembro/2000.

\begin{tabular}{lcccccccc}
\hline Espécies de & \multicolumn{4}{c}{ Frutos } & \multicolumn{5}{c}{ Armadilhas } \\
\cline { 2 - 9 } Anastrepha & 1999 & 2000 & Total & $\%$ & 1999 & 2000 & Total & $\%$ \\
\hline A. zenildae & 647 & 1.851 & 2.498 & 86,9 & 1.053 & 1.603 & 2.656 & 84,9 \\
A. sororcula & 159 & 217 & 376 & 13,1 & 149 & 203 & 352 & 11,3 \\
A. obliqua & - & - & - & - & 7 & 5 & 12 & 0,4 \\
A. montei & - & - & - & - & - & 11 & 11 & 0,4 \\
A. dissimilis & - & - & - & - & - & 1 & 1 & 0,1 \\
Anastrepha sp. & - & - & - & - & 2 & 92 & 94 & 2,9 \\
Total & 806 & 2.068 & 2.874 & 100 & 1.211 & 1.915 & 3.126 & 100 \\
\hline
\end{tabular}

Apesar de ter havido coletas de frutos praticamente durante todos os meses de 1999 e 2000 (Apêndice 3), não foram verificados frutos infestados nos meses de janeiro, fevereiro, novembro e dezembro. Nos meses de maio, junho e julho, os frutos apresentaram altos níveis de infestação (Figura 1).

O período de maiores infestações de frutos foi também o período de maiores picos populacionais, com um índice máximo de 7 MAD em maio de 1999 e 8 MAD em julho de 2000 (Figura 1). Estes resultados são próximos aos observados por Canal D. et al. (1998) nos pomares de goiaba no norte de Minas Gerais, onde a maioria dos picos populacionais, concentraram-se entre os meses de janeiro e abril, com valores entre 6 e 10 MAD. 


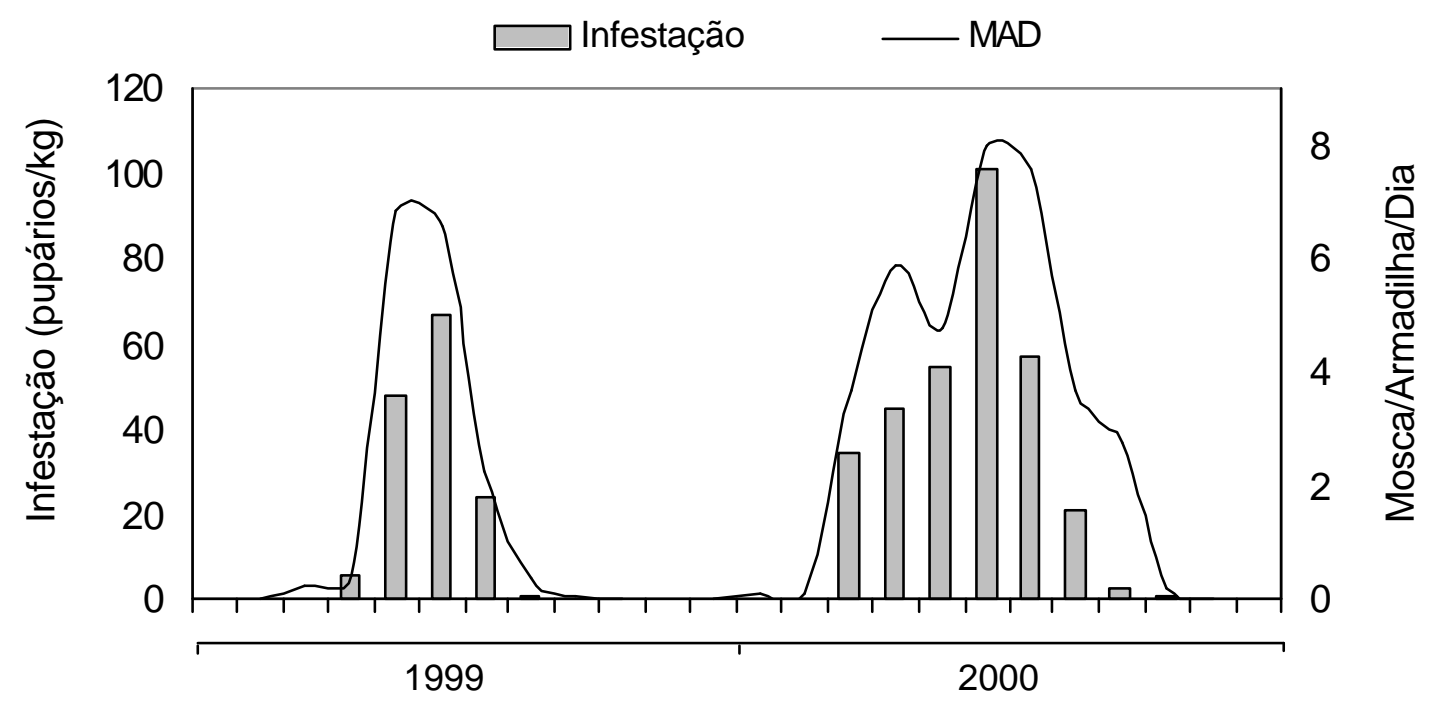

Figura 1 - Níveis de infestação e flutuação populacional de Anastrepha spp. em um pomar de goiaba $P$. guajava, em Mossoró (RN), de janeiro/1999 a dezembro/2000.

Das duas espécies de Anastrepha obtidas de goiaba, A. zenildae é a primeira a iniciar a infestação do pomar, posteriormente surge $A$. sororcula (Figura 2). A interação dessas duas espécies na exploração da goiaba, ficou bem evidente principalmente no ano de 1999 , pois primeiro ocorreu o pico populacional de $A$. zenildae, em maio, e em seguida o pico populacional da $A$. sororcula, em julho (Figura 2). 


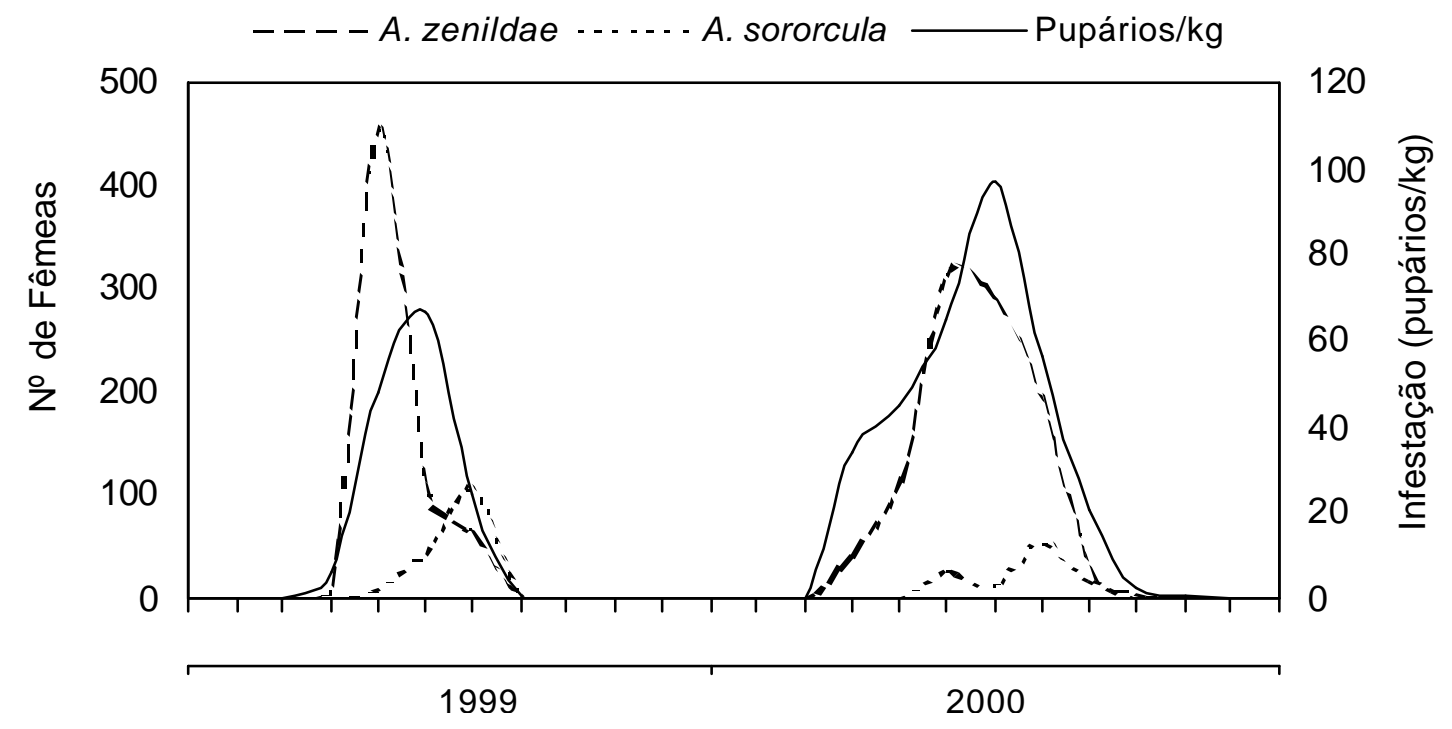

Figura 2 - Número de fêmeas de Anastrepha obtidas de goiaba $P$. guajava, em um pomar em Mossoró (RN), de janeiro/1999 a dezembro/2000.

Observando-se a distribuição sazonal das moscas-das-frutas no pomar, constatou-se que os maiores níveis de infestação e picos populacionais ocorreram num mesmo período do ano, ou seja, de abril a julho (Figura 1). Vários fatores podem influenciar o nível de infestação (Malavasi \& Morgante, 1980) e a flutuação populacional das moscas-das-frutas nos pomares (Puzzi \& Orlando, 1965; Nascimento et al., 1982 e Parra et al., 1982). Nas regiões semi-áridas, tudo indica que a precipitação pluvial aliada à disponibilidade de hospedeiros são os fatores preponderantes, pois os meses seguintes as maiores precipitações pluviais e o período de maior frutificação da goiaba em Mossoró, foram justamente os meses de maiores picos populacionais e níveis de infestação.

No entanto, vários outros fatores (cultivar, proximidade de outros pomares etc.) podem interferir na densidade populacional das moscas-das-frutas. Dessa forma, mesmo outros pomares situados na região de Mossoró, podem apresentar níveis de infestação e épocas de picos populacionais distintos dos que foram observados neste trabalho. 


\subsubsection{Relação entre níveis de infestação e perdas}

A relação entre o níveis de infestação e percentagens de perdas foi avaliado num período de alta infestação, 27 de abril a 29 de junho de 2000 (Figura 1). Neste período, os níveis de infestações variaram entre 35 e 118 pupários/kg de goiaba e as percentagens de perdas entre 78 e 100\% (Figura 3).

De acordo com os resultados obtidos, constatou-se que níveis de infestação acima de 30 pupários $/ \mathrm{kg}$ ocasionaram perdas de mais de $70 \%$ dos frutos. Vale salientar que neste trabalho, quando era obtido um único pupário do fruto, ele era considerado perdido. Contudo, geralmente mais de um pupário era obtido por fruto. $\mathrm{Na}$ data de coleta de menor infestação foi observado uma média de seis pupários por fruto (Figura 4).

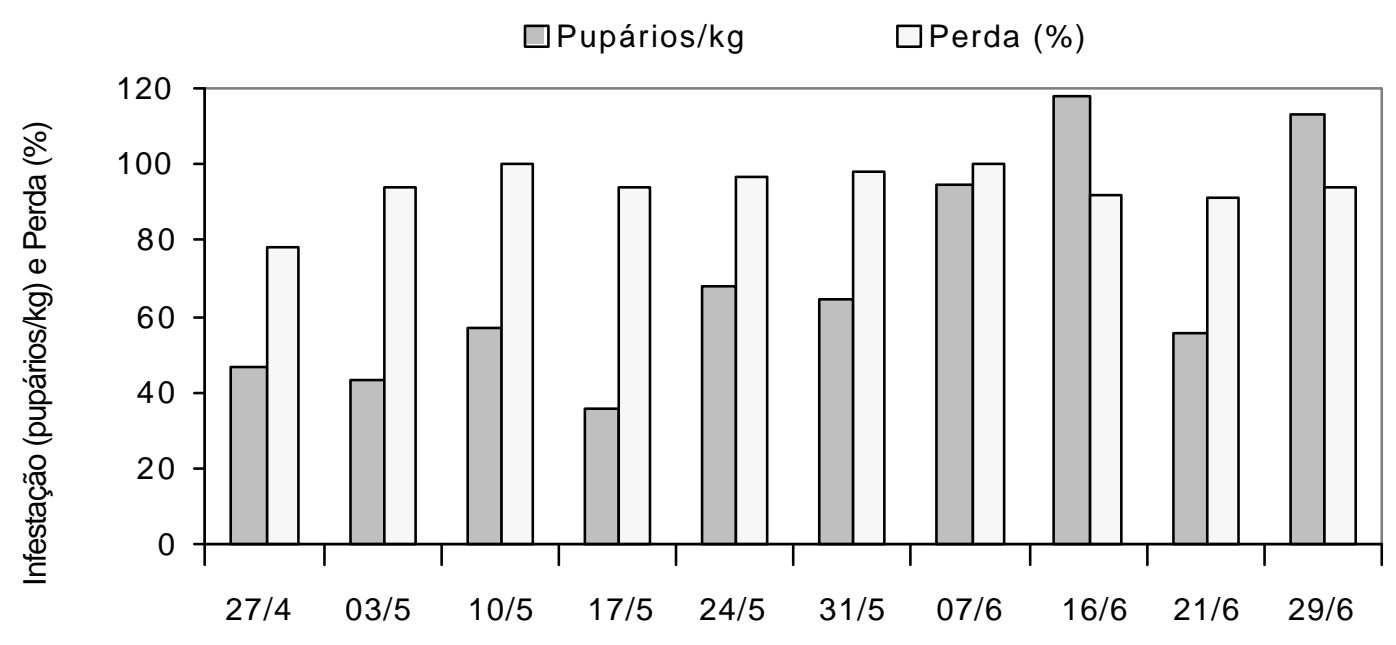

Figura 3 - Relação entre níveis de infestação e percentagem de perda em goiaba P. guajava ocasionado por Anastrepha spp., em Mossoró (RN), entre abril e junho de 2000. 


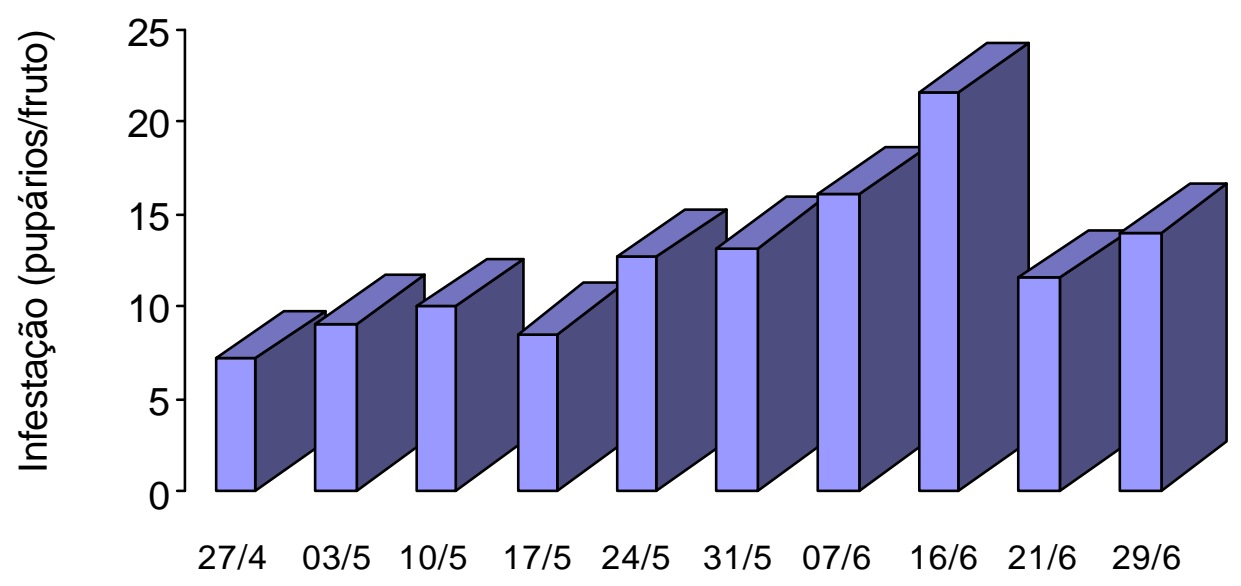

Figura 4 - Níveis de infestação (pupário/fruto) de Anastrepha spp. em goiaba $P$. guajava, em Mossoró (RN), entre abril e junho de 2000.

Constatou-se que as perdas ocasionadas pelas moscas-das-frutas em goiaba foram significativas, nesta época do ano em Mossoró (RN). No entanto, muitas vezes as perdas não são levadas em conta pelos produtores.

Apesar dos níveis de infestação verificados neste trabalho serem próximos aos detectados em outras localidades brasileiras (Bressan \& Teles, 1991; Veloso, 1997; Canal D. et al., 1998 e Souza Filho, 1999), não é prudente extrapolar a relação (infestação-perda) obtida para outras frutíferas e regiões. O ideal é que estudos dessa natureza sejam desenvolvidos em cada região, considerando-se os fatores locais.

\subsubsection{Relação entre índice de infestação e flutuação populacional}

Durante o período em que foi desenvolvido o estudo da relação entre índice de infestação e flutuação populacional, 27 de abril a 29 de maio de 2000, constatou-se que os picos populacionais das moscas-das-frutas variaram bastante de uma semana para outra (Figura 5). Os índices de infestação também foram variáveis, contudo, numa menor intensidade. Além disso constatou-se uma tendência sempre crescente nos níveis de infestação a cada semana. Portanto, 
tudo isso dificultou bastante o estabelecimento da relação entre infestação e a flutuação populacional.

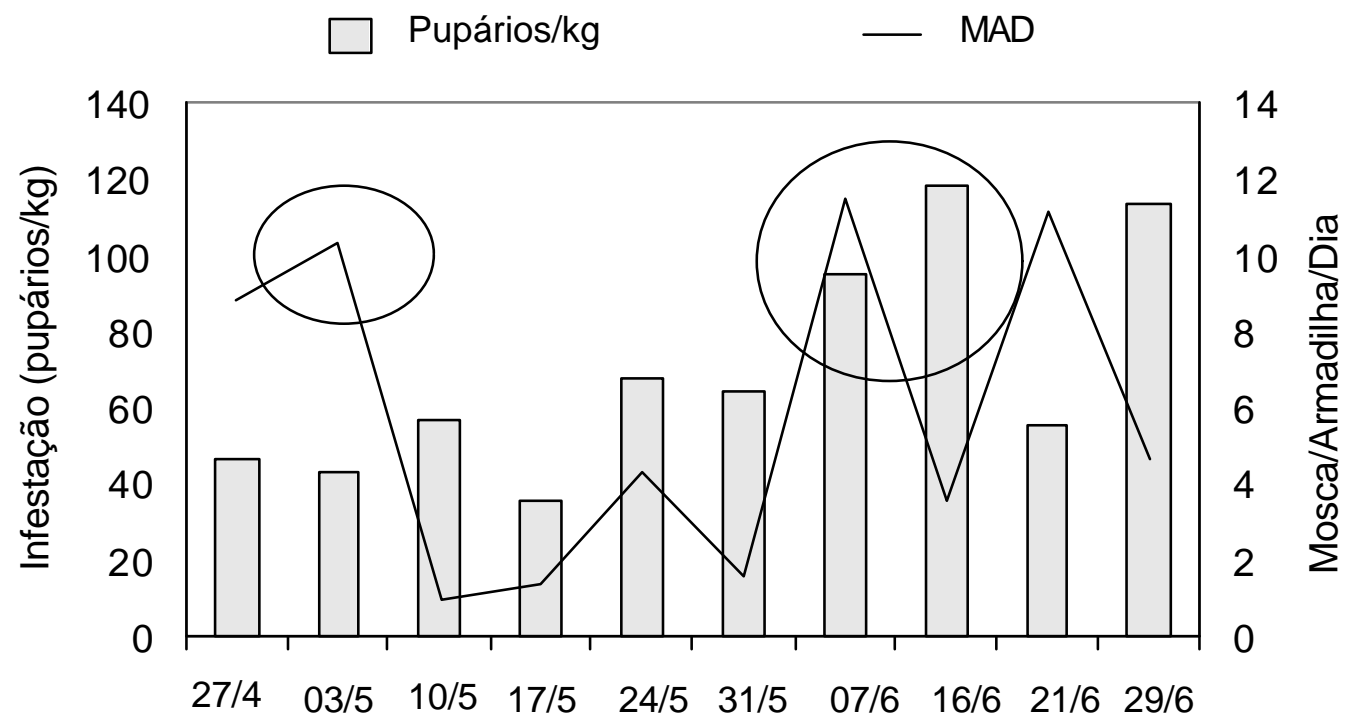

Figura 5 - Relação entre níveis de infestação e flutuação populacional de Anastrepha spp. em um pomar de goiaba $P$. guajava, em Mossoró (RN), entre abril e junho de 2000.

Assim, como observado por Malavasi \& Morgante (1981), constatou-se que cerca de cinco semanas após um pico populacional de moscas-das-frutas (10 
MAD), houve um pico considerável no nível de infestação, 118 pupários $/ \mathrm{kg}$ de goiaba (Figura 5). Segundo Malavasi \& Morgante (1981), cinco semanas são aproximadamente o tempo que as moscas-das-frutas levam para passar de ovo a adulto na natureza.

Portanto, devido aos vários fatores que interferem sobre as populações das moscas-das-frutas, não foi possível estabelecer uma precisa relação entre índice de infestação e a flutuação populacional.

No entanto, foi observado que durante o período do estudo, a semana de menor pico populacional das moscas-das-frutas no pomar foi de 1 MAD e a menor infestação foi de 35 pupários/kg (Figura 5), e esse nível de infestação foi suficiente para provocar uma perda de aproximadamente $70 \%$ dos frutos (Figura 3). Dessa forma, quando as moscas-das-frutas encontram condições favoráveis no pomar de goiaba, até mesmo uma infestação de 1 MAD foi suficiente para provocar perdas consideráveis.

\subsection{Conclusões}

Maio a julho é o período de maiores infestações e picos populacionais das moscas-das-frutas do gênero Anastrepha em goiaba, em Mossoró (RN).

Níveis de infestação de Anastrepha spp. superiores a 35 pupários $/ \mathrm{kg}$ ocasionam perdas de mais de $70 \%$ dos frutos, em pomar de goiaba, em Mossoró $(\mathrm{RN})$.

Anastrepha zenildae atinge o status de praga em pomares de goiaba, em Mossoró (RN). 


\section{INFLUÊNCIA DE FATORES BIÓTICOS E ABIÓTICOS NO NÍVEL DE INFESTAÇÃO DE Anastrepha spp. (DIP., TEPHRITIDAE) EM GOIABA Psidium guajava L., NA REGIÃO SEMI-ÁRIDA DE MOSSORÓ (RN)}

\section{Resumo}

Vários fatores bióticos e abióticos agem sobre as populações de moscasdas-frutas e conseqüentemente sobre seus níveis de infestação. Após dois anos de estudos, em um pomar de goiaba localizado em Mossoró, região semiárida do Estado do Rio Grande do Norte, constatou-se que a disponibilidade de frutos, a temperatura e a precipitação fluvial foram os fatores que mais influenciaram as populações de espécies de Anastrepha e, portanto, seus níveis de infestação em goiaba.

INFLUENCE OF BIOTICS AND ABIOTICS FACTORS ON THE INFESTATION LEVEL OF Anastrepha spp. (DIP., TEPHRITIDAE) IN GUAVA, Psidium guajava L., IN THE SEMI-ARID REGION OF MOSSORÓ (RN)

\section{Summary}

Several biotic and abiotic factors act on fruit fly populations and consequently on their levels of infestation. After two year study in a guava orchard located in Mossoró, a semi-arid region of the State of Rio Grande do 
Norte, it was observed that fruit availability, temperature and rainfall were the factors that most influenced the populations of Anastrepha species and consequently their infestation levels of guava.

\subsection{Introdução}

Os fatores bióticos e abióticos exercem grande influência sobre as populações das moscas-das-frutas e conseqüentemente sobre seus níveis de infestação (Aluja, 1994).

Dentre os fatores bióticos que interferem nas populações das moscasdas-frutas, destacam-se os inimigos naturais e a disponibilidade do hospedeiro. Os inimigos naturais, principalmente os parasitóides e predadores, são importantes fatores de mortalidade das moscas-das-frutas, durante todo ciclo de vida (Bateman, 1972; Carvalho et al., 2000 e Sugayama, 2000). A disponibilidade de hospedeiros é outro fator biótico importante que influencia as populações dos tefritídeos frugívoros, pois estes utilizam os frutos como substrato de oviposição e alimentação (larvas). Dessa forma, os maiores picos populacionais das moscas-das-frutas ocorrem no período de maior frutificação de seus hospedeiros (Puzzi \& Orlando, 1965 e Aluja, 1994).

Além dos fatores bióticos, vários fatores abióticos interferem nas populações das moscas-das-frutas, em praticamente todos os estágios de vida. Segundo Aluja (1994) e Salles (1995), os parâmetros climáticos são os que mais agem sobre as populações dos tefritídeos. Em temperaturas inferiores à $10^{\circ} \mathrm{C}$ e superiores à $35^{\circ} \mathrm{C}$, não ocorre o desenvolvimento de nenhuma das fases do ciclo de vida de Anastrepha fraterculus (Wied.) (Salles, 2000). A precipitação pluvial é também um dos principais fatores climáticos que influenciam as populações das moscas-das-frutas (Aluja, 1994). A falta de umidade no solo inviabiliza muitos pupários e provoca a mortalidade de adultos recémemergidos, devido a dificuldade de ultrapassar o solo seco (Baker, 1944 e 
Bateman, 1972). Em condições de laboratório, a dessecação é a principal causa de mortalidade pupal de Anastrepha obliqua (Macquart) (BressanNascimento, 2001). Além disso, durante os períodos secos as populações das moscas-das-frutas são afetadas, pois há redução na fecundidade das fêmeas (Bateman, 1972). Por outro lado, Salles et al. (1995) relataram que em condições de laboratório à $25^{\circ} \mathrm{C}$, umidades do solo variando entre 2,6 e $28,5 \%$, não interferiram na viabilidade pupal de $A$. fraterculus. Azevedo \& Parra (1989), também constataram que umidades de solo variando entre 5,5 e $32,8 \%$ praticamente não alteraram a viabilidade pupal de Ceratitis capitata (Wied.). Em vários trabalhos desenvolvidos no Brasil, não foi constatado a influência da precipitação pluvial sobre a flutuação populacional de adultos de moscas-dasfrutas (Puzzi \& Orlando, 1965; Suplicy Filho et al., 1978 e Parra et al., 1982).

Dessa forma, verifica-se que os fatores ambientais podem agir de forma distinta sobre as populações de moscas-das-frutas de cada região. O município de Mossoró (RN) está localizado numa região semi-árida que se caracteriza pela vegetação xerófila (caatinga), altas temperaturas (média de $27^{\circ} \mathrm{C}$ ) e baixas precipitações pluviais (600 - $700 \mathrm{~mm}$ anuais). Contudo, as interações ecológicas das populações de moscas-das-frutas com os fatores ambientais das regiões semi-áridas são pouco conhecidas.

Portanto, este trabalho teve por objetivo analisar a influência dos fatores bióticos e abióticos no nível de infestação de espécies de Anastrepha em goiaba, na região semi-árida de Mossoró (RN). 


\subsection{Material e Métodos}

\subsubsection{Local e caracterização do pomar estudado}

O trabalho foi realizado no mesmo pomar de goiaba descrito no capítulo 5 (item 5.2.1).

\subsubsection{Obtenção dos parasitóides e das moscas-das-frutas}

A coleta dos parasitóides e das moscas-das-frutas (tanto em armadilhas como em frutos) foi realizada da mesma forma que nos capítulos 4 (item 4.2.2) e 5 (item 5.2 .2 e 5.2.3).

\subsubsection{Nível de infestação e população de adultos}

O índice de infestação foi calculado segundo a metodologia do capítulo 3 (item 3.2.4). A população de adultos foi estimada com base na flutuação populacional, por meio do índice MAD, seguindo-se a metodologia descrita no capítulo 5 (item 5.2.6).

\subsubsection{Fatores climáticos}

Os valores médios mensais da temperatura, umidade relativa do ar e precipitação pluvial mensal acumulada foram obtidos na estação climatológica da ESAM (Apêndice 3). 


\subsubsection{Identificação das moscas-das-frutas e parasitóides}

Foi realizada utilizando-se os mesmos critérios relatados no capítulo 4 (item 4.2.5). Espécimes voucher estão depositados na coleção da ESALQ/USP (Entomologia), em Piracicaba (SP).

\subsection{Resultados e Discussão}

Foram obtidos 5.781 exemplares de Anastrepha dos frutos e 5.066 nas armadilhas. Apenas A. zenildae Zucchi $(86,9 \%)$ e A. sororcula Zucchi $(13,1 \%)$ foram obtidas dos frutos. Nas armadilhas, seis espécies foram capturadas, com predominância de $A$. zenildae (84,9\%), seguida de $A$. sororcula $(11,3 \%)$.

As populações de moscas-das-frutas e, conseqüentemente, seus níveis de infestação, foram influenciados por fatores bióticos e abióticos, durante os dois anos de trabalho.

\subsubsection{Fatores Bióticos}

\subsubsection{População de adultos}

A população de adultos está diretamente relacionada com o índice de infestação das larvas nos frutos. No pomar estudado, constatou-se uma alta correlação $(r=0,94 ; P \leq 0,01)$ entre a flutuação populacional e os níveis de infestação (Figura 1). 


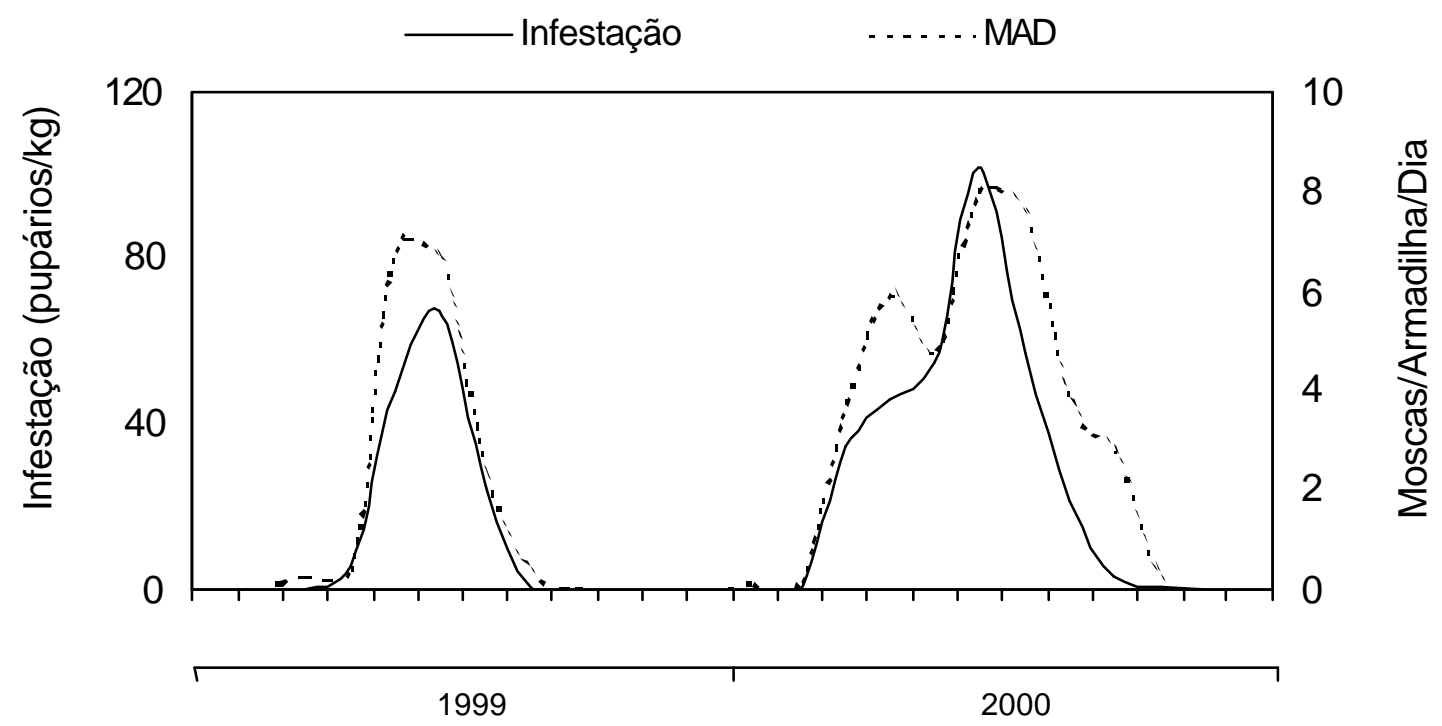

Figura 1 - Relação entre a flutuação populacional e o índice de infestação de Anastrepha spp. em um pomar de goiaba P. guajava, em Mossoró (RN), de janeiro/1999 a dezembro/2000.

Quando as informações foram avaliadas semanalmente, verificou-se uma assincronia entre os picos de infestação e os de captura nas armadilhas (Figura 2). No entanto, há de se considerar que entre a fase de pré-oviposição e o fim da fase pupal, de algumas espécies de Anastrepha, podem decorrer até 40 dias, dependendo das condições climáticas (Salles, 2000). Portanto, há uma diferença de aproximadamente cinco semanas entre o pico populacional das moscas-das-frutas detectadas em armadilhas e o pico de infestação das larvas em goiaba, em condições de campo (Malavasi \& Morgante, 1981). 


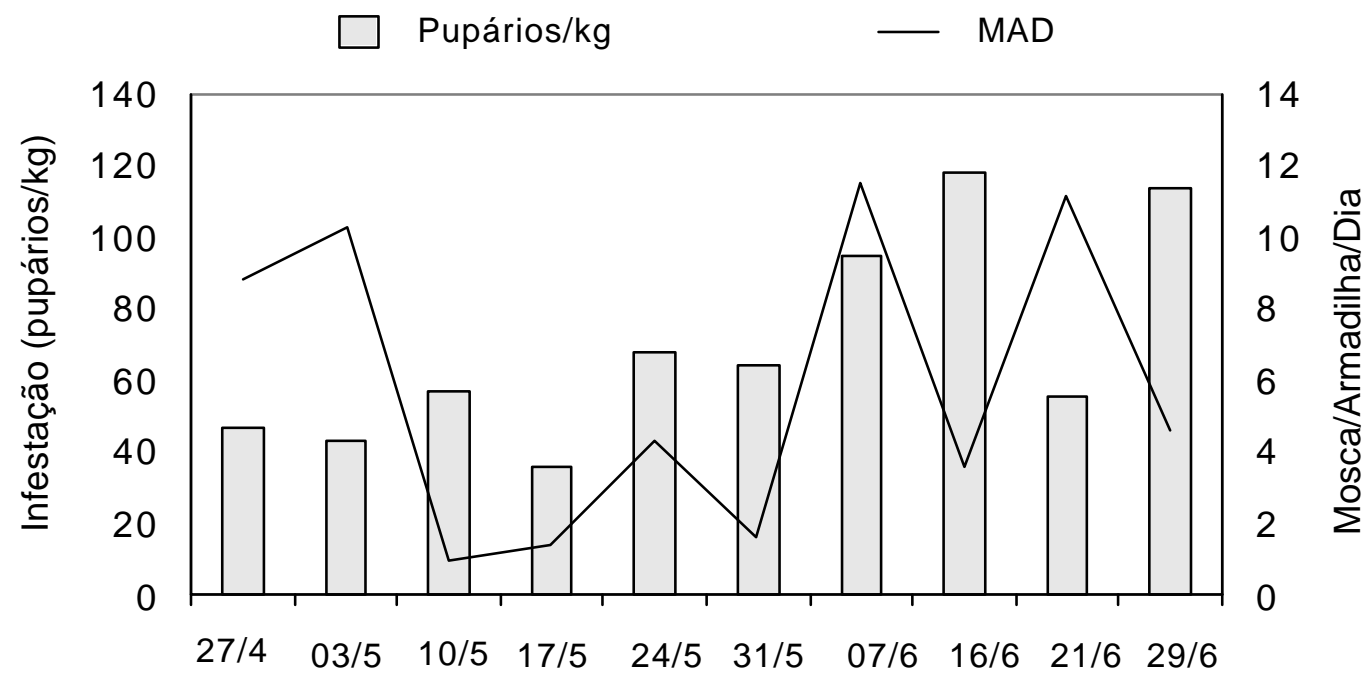

Figura 2 - Assincronia entre infestações e flutuação populacional de Anastrepha spp. em goiaba $P$. guajava, em Mossoró (RN), abril a junho de 2000.

\subsubsection{Disponibilidade do hospedeiro}

É um dos principais fatores responsáveis pela manutenção das populações das moscas-das-frutas nos pomares. Segundo Puzzi \& Orlando (1965), é no período de grande disponibilidade de hospedeiros que ocorrem os altos níveis de infestação nos pomares. No pomar de goiaba estudado, houve disponibilidade de frutos durante todo ano, mas foi no período de maior frutificação que ocorreram os maiores níveis de infestação das moscas-dasfrutas (Figura 3). Apenas nos meses de janeiro, fevereiro e março de 1999 não foram coletados frutos, pois o pomar havia sido podado. 


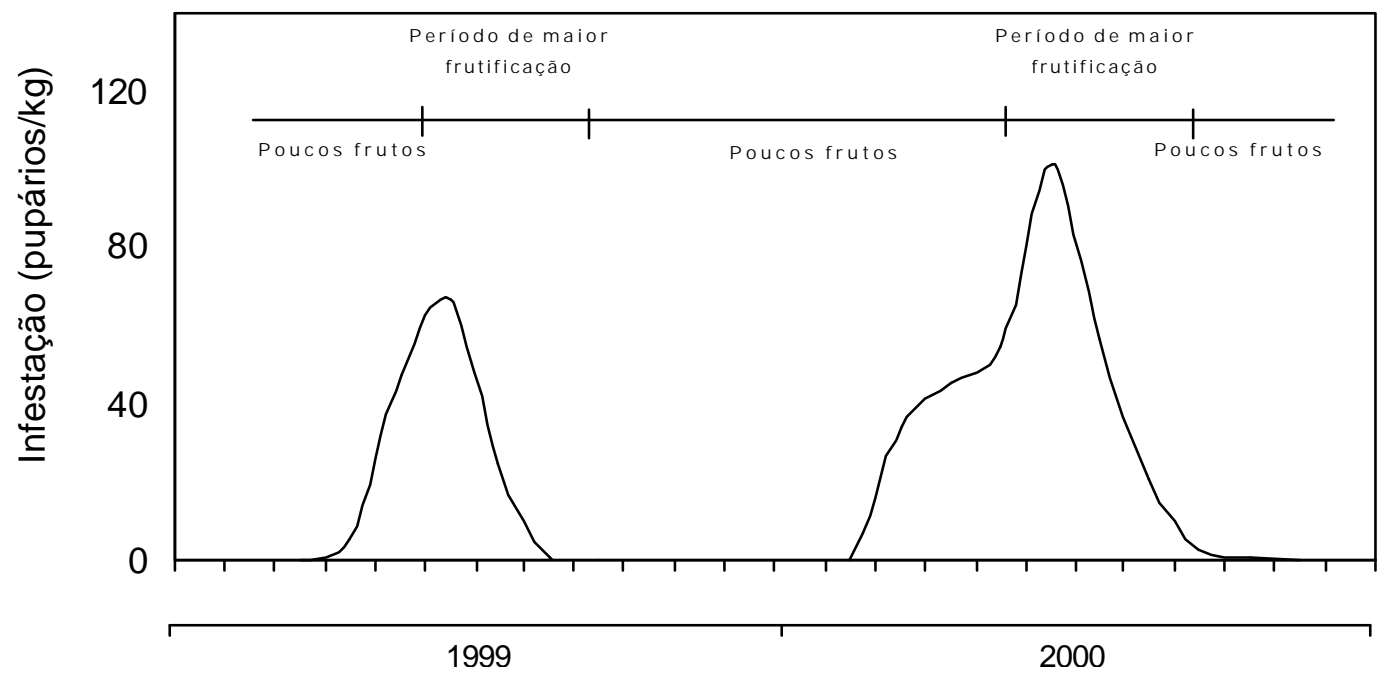

Figura 3 - Relação entre a disponibilidade de frutos e o índice de infestação de espécies de Anastrepha em pomar de goiaba $P$. guajava, em Mossoró (RN), de janeiro/1999 a dezembro/2000.

Curiosamente nos meses de janeiro, fevereiro, novembro e dezembro não foram observados frutos infestados e o número de moscas-das-frutas capturadas nas armadilhas foi insignificante. Talvez, nesse período as moscasdas-frutas tenham migrado para outros pomares mais afastados, pois a sucessão hospedeira é fundamental para a manutenção das populações de moscas-das-frutas (Puzzi \& Orlando, 1965 e Salles, 1995). No entanto, quando os tefritídeos encontram frutos hospedeiros disponíveis para oviposição, não costumam migrar para outras áreas (Bateman, 1972). Além disso, a goiaba é um dos hospedeiros preferidos de $A$. zenildae e $A$. sororcula, que foram as espécies obtidas dos frutos. Outro fato importante é que o pomar de goiaba era cercado por pomares de outras frutíferas (caju Anacardium occidentale e graviola Annona muricata), que não são infestadas por espécies de Anastrepha 
na região e a vegetação nativa estava em estado de latência durante os meses citados acima.

Portanto, a disponibilidade de frutos interferiu nos niveis de infestação, mas não foi o fator principal na manutenção das moscas-das-frutas no pomar, pois nos meses de janeiro, fevereiro, novembro e dezembro foram coletadas quantidades consideráveis de goiabas (Apêndice 2), mas não foram constatadas infestações.

\subsubsection{Parasitismo}

Uma série de inimigos naturais são responsáveis pela mortalidade das moscas-das-frutas no campo, entre eles destacam-se os parasitóides e predadores (Carvalho et al., 2000). Apesar de uma série de insetos predarem as larvas e pupas das moscas-das-frutas (Bateman, 1972; Eskafi \& Kolbe, 1990 e Sugayama, 2000), apenas os parasitóides (Braconidae) foram considerados neste trabalho.

As maiores percentagens de parasitismo ocorreram justamente no período em que foram constatados os maiores níveis de infestações, tanto em 1999 como em 2000. Apesar de algumas amostras coletadas em junho de 2000 , terem apresentado níveis de parasitismo de até $20 \%$, foi observado que o parasitismo natural não afetou consideravelmente a população das moscasdas-frutas, e conseqüentemente seus níveis de infestação, pois o maior parasitismo médio mensal foi de 10\% (Figura 4). A maioria dos parasitóides de moscas-das-frutas ocorre em baixas densidades em condições naturais, dessa forma, raramente interfere nos níveis de infestações das moscas-das-frutas em pomares comerciais (Bateman, 1972). 


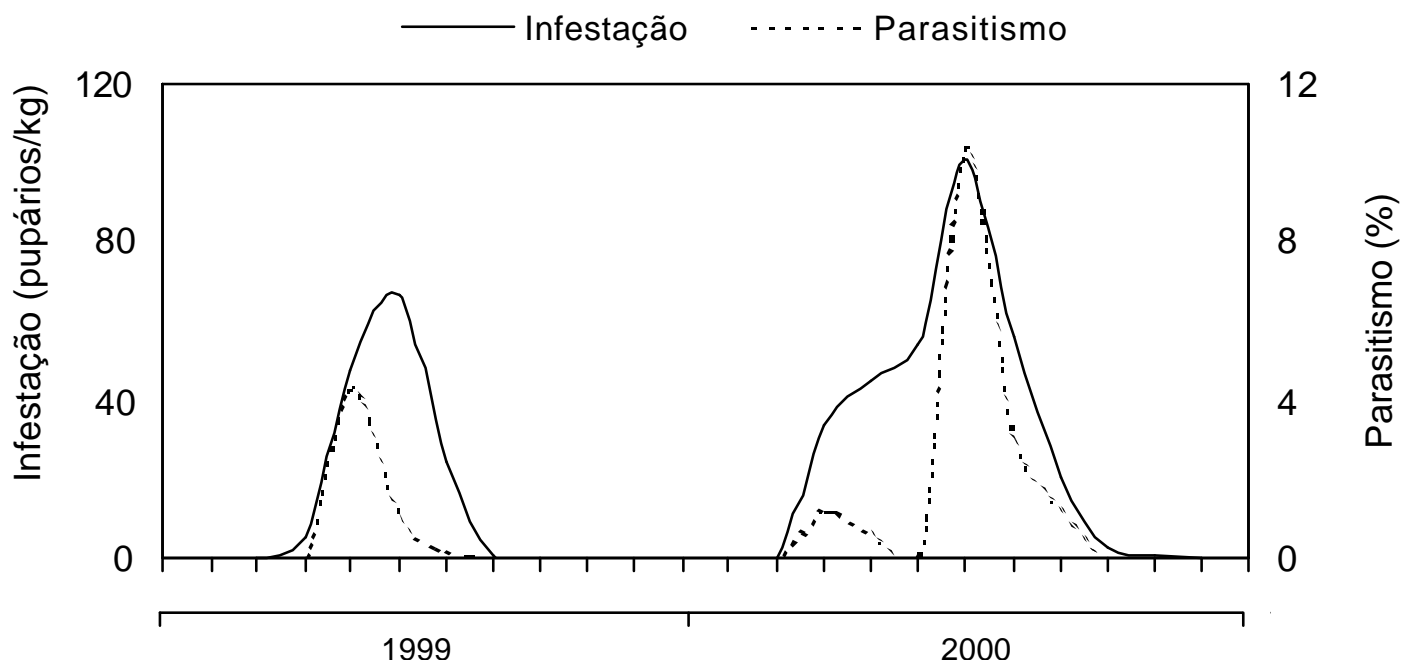

Figura 4 - Relação entre o parasitismo por braconídeos e o índice de infestação de espécies de Anastrepha em pomar de goiaba $P$. guajava, em Mossoró (RN), de janeiro/1999 a dezembro/2000.

\subsubsection{Fatores Abióticos}

Os parâmetros climáticos (temperatura, umidade e precipitação pluvial) são uns dos fatores abióticos que mais interferem sobre as populações das moscas-das-frutas e, portanto sobre seus níveis de infestação (Aluja, 1994 e Salles, 1995).

\subsubsection{Temperatura}

Constatou-se que no pomar de goiaba houve uma correlação negativa $(r=-0,71 ; P \leq 0,01)$ entre o nível de infestação das moscas-das-frutas e a temperatura, ou seja, nos meses de maiores infestações ocorreram as menores temperaturas (Figura 5). Nos meses que ocorreram temperaturas superiores à $28^{\circ} \mathrm{C}$, praticamente não foram observados frutos infestados e os índices de 
captura nas armadilhas foram insignificantes. Provavelmente, as elevadas temperaturas aqueceram o solo e ocasionaram a inviabilidade de muitos pupários, conseqüentemente, houve diminuição na população das moscas-dasfrutas e nos níveis de infestação. A faixa ótima de desenvolvimento pupal e emergência do adulto de $A$. fraterculus está entre 20 e $25^{\circ} \mathrm{C}$. Em temperaturas superiores a $30^{\circ} \mathrm{C}$ há a formação do adulto, mas não ocorre a emergência (Salles, 2000). De acordo com Baker (1944), as altas temperatura são um fator importante de mortalidade em pupas de A. ludens (Loew.), sendo as pupas recém-formadas as mais afetadas.

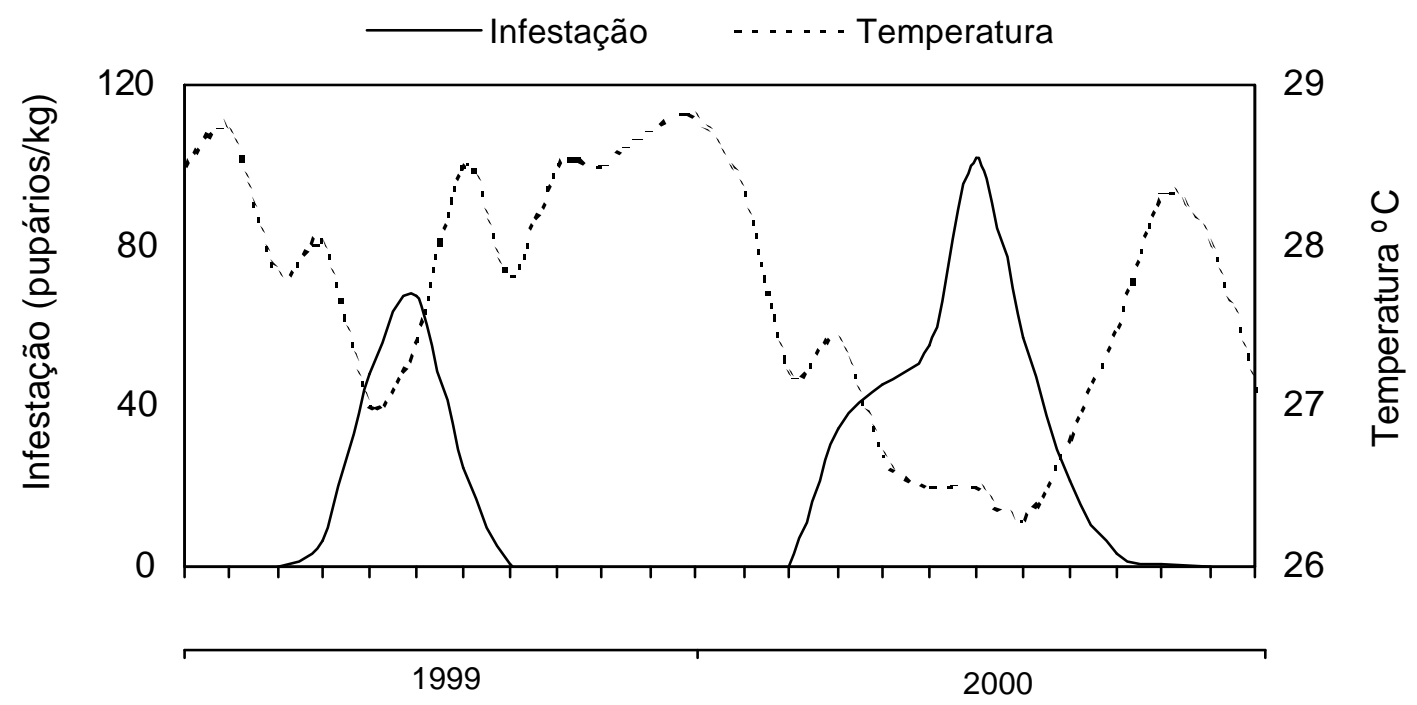

Figura 5 - Relação entre a temperatura e o índice de infestação de espécies de Anastrepha spp. em pomar de goiaba $P$. guajava, em Mossoró (RN), de janeiro/1999 a dezembro/2000.

\subsubsection{Umidade relativa do ar}

Não foi observada correlação entre a umidade relativa do ar e os níveis de infestação. Os maiores índices de infestação ocorreram depois das altas 
umidades e antes das umidades mais baixas, ou seja, no período de elevado índice de infestação não ocorreram umidades médias extremas (Figura 6). De acordo com Salles (1995), as informações a respeito da influência da umidade do ar sobre as fases do desenvolvimento das espécies de Anastrepha são escassas.

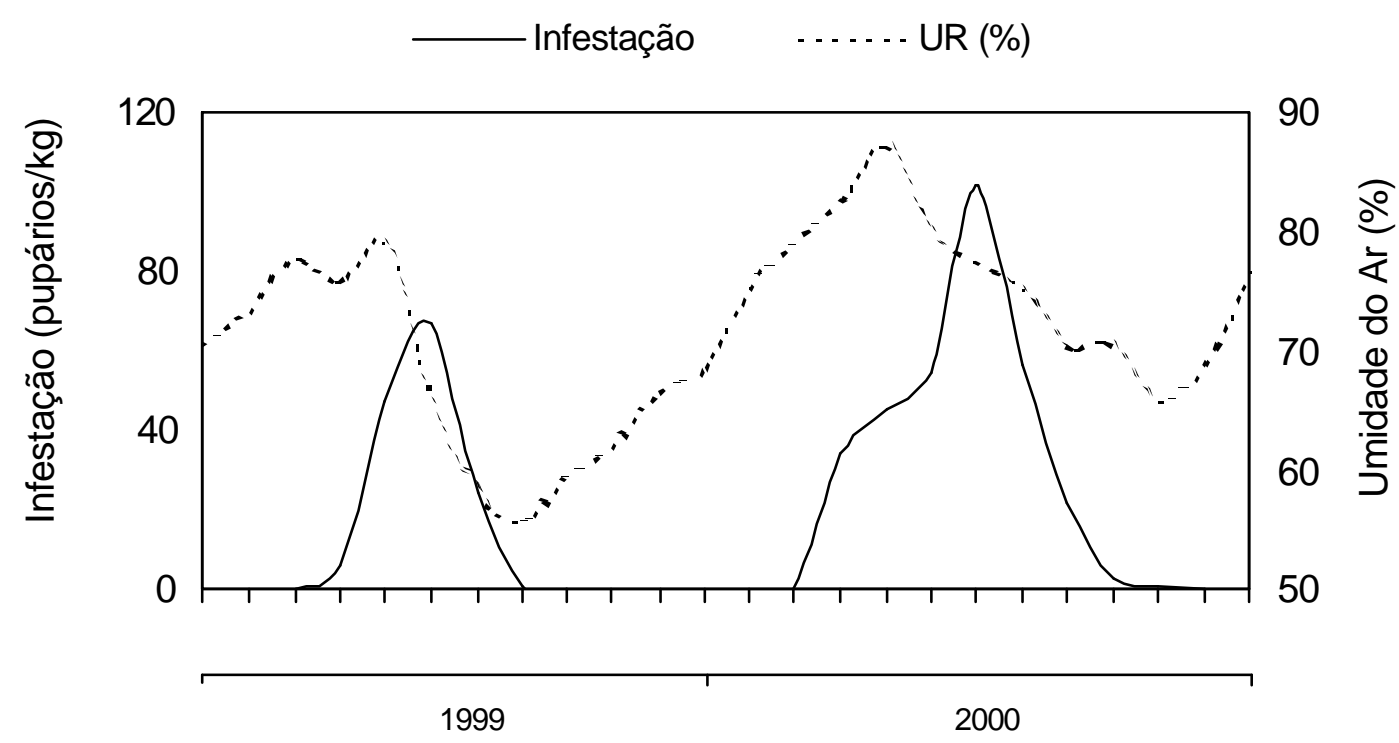

Figura 6 - Relação entre a umidade e o índice de infestação de espécies de Anastrepha em pomar de goiaba $P$. guajava, em Mossoró (RN), de janeiro/1999 a dezembro/2000.

\subsubsection{Precipitação pluvial}

A precipitação pluvial foi o parâmetro climático que mais interferiu na flutuação populacional das moscas-das-frutas e portanto nos seus níveis de infestação. Constatou-se que infestações mais altas ocorreram após o período de maior precipitação pluvial (Figura 7). Contudo, a correlação entre a precipitação pluvial e a população das moscas-das-frutas não foi significativa, 
como observado em outras regiões (Puzzi \& Orlando, 1965; Suplicy Filho et al., 1978; Parra et al., 1982 e Nascimento et al., 1982). Na verdade, nas regiões semi-áridas, a influência da precipitação pluvial sobre as populações de moscas-das-frutas ocorre principalmente de forma indireta, ou seja, a precipitação pluvial proporciona condições favoráveis para a frutificação das plantas hospedeiras dos tefritídeos e, com isso, ocorre o aumento da população das moscas-das-frutas. Como o pomar de goiaba era irrigado, constatou-se a presença de frutos o ano inteiro, mesmo assim, o período de maior frutificação, pico populacional e infestação, ocorreu após as primeiras chuvas. Por outro lado, a falta de água no solo durante os meses secos pode ter provocado a mortalidade de uma grande quantidade de pupas e de adultos recémemergidos, que sofreram dessecação ou tiveram dificuldades para atravessar o solo seco, como relatado por vários autores (Baker, 1944; Bateman, 1972 e Bressan-Nascimento, 2001). Além disso, durante os períodos secos, as populações de moscas-das-frutas são afetadas, pois há redução da fecundidade das fêmeas e da imigração de adultos de outras áreas (Bateman, 1972). Segundo Aluja (1994), a precipitação pluvial é um dos principais fatores relacionados com a flutuação populacional das moscas-das-frutas.

De forma geral, os parâmetros climáticos estão intercalados, ou seja, um é o reflexo do outro e atuam conjuntamente sobre as populações das moscasdas-frutas. Nas regiões semi-áridas, como é o caso de Mossoró (RN), parece que a relação entre os fatores climáticos e as populações de moscas-das-frutas são mais estreitas ainda. 


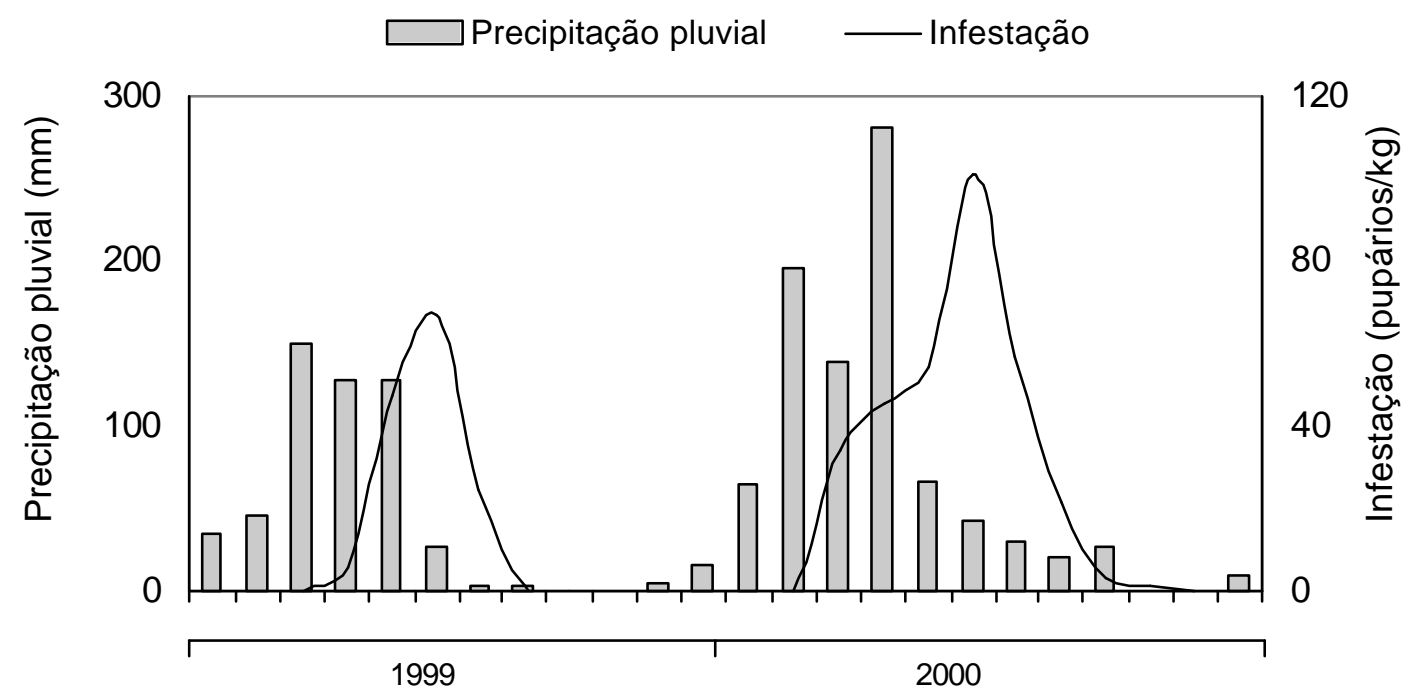

Figura 7 - Relação entre a precipitação pluvial e o índice de infestação de espécies de Anastrepha spp. em pomar de goiaba $P$. guajava, em Mossoró (RN), de janeiro/1999 a dezembro/2000.

De acordo com o que foi observado, constatou-se que a disponibilidade de goiabas no pomar e os parâmetros climáticos (temperatura e precipitação pluvial) foram os fatores que mais influenciaram os níveis de infestação das moscas-das-frutas. Contudo, verificou-se que em alguns meses do ano havia disponibilidade de frutos no pomar e ausência de outros hospedeiros nas proximidades e, mesmo assim, não se observou frutos infestados, nem captura de moscas-das-frutas ras armadilhas. Isto evidencia que os fatores climáticos exerceram uma forte influência sobre as populações nativas de moscas-dasfrutas. Assim, constatou-se que as populações de espécies de Anastrepha desenvolveram algum mecanismo para se proteger durante as épocas críticas, na região semi-árida. Talvez estejam migrando para pomares domésticos das áreas urbanas, conseguindo sobreviver em baixas populações (não sendo detectadas nas armadilhas) ou entram em diapausa no solo (fase de pupa). A 
primeira hipótese é plenamente aceitável, pois as moscas-das-frutas possuem uma boa capacidade de vôo e um elevado potencial biótico (Christenson \& Foot, 1960; Bateman, 1972; Aluja, 1994 e Salles, 2000), sendo assim, poucos indivíduos sobreviventes de uma população podem rapidamente infestar um pomar, quando as condições são favoráveis. Por outro lado, a hipótese de diapausa é mais difícil de ser explicada, pois as espécies de moscas-das-frutas tropicais são multivoltinas e não possuem diapausa (Bateman, 1972 e Malavasi \& Morgante, 1980). Contudo, vale lembrar que nas regiões semi-áridas, a maioria dos seres vivos possui uma série de adaptações para sobreviver no período em que as condições climáticas são críticas. Por exemplo, a vegetação nativa (caatinga) perde todas as folhas e entram em estado de latência para economizar água e sobreviver durante a seca (período crítico). Além disso, em algumas regiões tropicais, tem sido observado a ocorrência de diapausa em espécies de tefritídeos e braconídeos. Smyth (1960) relatou que no Peru, Ragholetis lycopersella Smyth apresenta uma estivação pupal durante os meses quentes e secos do ano. Segundo aquele autor, as pupas são resistentes à dessecação e a chuva induz uma explosão na emergência dos adultos. Recentemente, Bressan-Nascimento (2001) realizou estudos com $A$. obliqua, em Sertãozinho (SP), Brasil, e constatou a existência de dormência na fase de pupa, em condições de campo. Aluja et al. (1998) observaram a existência de diapausa em cinco espécies de parasitóides de larvas/pupas de moscas-das-frutas em condições tropicais, na região central do México. No Brasil, Carvalho et al. (2001) relataram a ocorrência de diapausa em parasitóides de larva/pupa de moscas-das-frutas na região do Recôncavo Baiano. Portanto, não se descarta a possibilidade das populações nativas de moscas-das-frutas utilizarem algum mecanismo de diapausa, para sobreviverem durante o período de estiagem, na região semi-árida do Estado do Rio Grande do Norte. 


\subsection{Conclusões}

A disponibilidade do hospedeiro e a elevada população de adultos são os fatores bióticos que mais favorecem o aumento do nível de infestação de espécies de Anastrepha em goiaba, em Mossoró (RN).

Precipitações pluviais altas e temperaturas baixas são os fatores abióticos que mais contribuem para o aumento do nível de infestação de espécies de Anastrepha em goiaba, em Mossoró (RN). 


\section{HOSPEDEIROS E NÍVEIS DE INFESTAÇÃO DE Neosilba pendula (Bezzi) (DIPTERA: LONCHAEIDAE) NA REGIÃO DE MOSSORÓ/ASSU (RN)}

\section{Resumo}

Os estudos sobre dípteros frugívoros na região de Mossoró/Assu (RN), têm sido limitado às espécies de Anastrepha e à mosca-do-mediterrâneo, Ceratitis capitata (Wied.). Entretanto, levantamentos realizados em pomares de acerola Malpighia emarginata nessa região têm revelado que, em algumas condições, o lonqueídeo Neosilba pendula (Bezzi) pode ser importante invasor primário de acerola.

HOST PLANTS AND INFESTATION OF Neosilba pendula (Bezzi) (DIPTERA: LONCHAEIDAE) IN THE REGION OF MOSSORÓ/ASSU (RN)

\section{Summary}

Study on frugivorous dipterans in the Mossoró/Assu, State of Rio Grande do Norte, have been limited to Anastrepha species and to Mediterranean fruit fly Ceratitis capitata (Wied.). However, surveys on "acerola", Malpighia emarginata (Malpighiaceae), orchards in this region have revealed that, under certain conditions, the lonchaeid Neosilba pendula (Bezzi) can be an important primary invader of "acerola". 


\subsection{Introdução}

Os dípteros da família Lonchaeidae medem de 3 a $6 \mathrm{~mm}$ de comprimento, geralmente tem coloração preto-azulada brilhante e asas transparentes (McAlpine, 1987).

As larvas da maioria dos lonqueídeos estão associadas às flores, frutos danificados e outros tipos de material orgânico em decomposição. No entanto, em algumas espécies, as larvas são invasoras primárias de frutos (McAlpine, 1961 e McAlpine, 1987).

No Brasil, apesar de haver relatos antigos de lonqueídeos infestando frutíferas de importância econômica, são escassos os trabalhos de levantamentos de hospedeiros e níveis de infestação (Uchôa F., 1999). No final

dos anos 70, foi observado a presença de larvas de Neosilba spp. (como Silba spp.) infestando 35 espécies de frutos, em vários Estados Brasileiros (Malavasi et al. 1980 e Malavasi \& Morgante 1980). No Estado do Amazonas, espécies de Neosilba foram associadas a 19 frutíferas (Silva, 1993). Em levantamentos realizados em 94 municípios do Estado de São Paulo, os lonqueídeos infestaram 40 espécies de frutos, sendo tangerina Citrus reticulata e acerola Malphigia glabra uns dos hospedeiros mais infestados (Souza Filho, 1999). Em áreas de cerrado do Estado do Mato Grosso do Sul, Uchôa F. (1999) obteve lonqueídeos de 22 espécies de frutíferas, sendo a uvaia Eugenia sp. uma das mais infestadas (65 larvas $/ \mathrm{kg}$ ).

Na região de Mossoró/Assu (RN), um dos principais polos frutícolas do Nordeste, existe um conhecimento considerável a respeito das moscas-dasfrutas (Tephritidae) (Araujo et al., 2000). Entretanto, as pesquisas sobre os demais dípteros frugívoros, como os lonqueídeos, têm sido negligenciadas.

Portanto, este trabalho teve como objetivos, conhecer os hospedeiros de Neosilba pendula e seus respectivos índices de infestação e verificar o status de $N$. pendula como invasor primário de frutos de acerola Malphigia emarginata. 


\subsection{Material e Métodos}

\subsubsection{Locais das coletas}

As coletas dos lonqueídeos foram realizadas na mesma região mencionada no capítulo 3 (item 3.2.1).

Para verificar o status de $N$. pendula como invasor primário de acerola, foram coletados amostras de frutos da árvore e do solo em dois pomares no município de Mossoró, um localizado na fazenda experimental da ESAM (Alagoinhas) e o outro na Agroindústria Maisa. O pomar situado na ESAM (aproximadamente 1 ha) não era irrigado e o pomar da Maisa (aproximadamente 20 ha) era irrigado pelo sistema de gotejamento.

\subsubsection{Coleta dos lonqueídeos e índice de infestação}

A obtenção dos lonqueídeos e o cálculo do índice de infestação seguiram a mesma metodologia descrita para as moscas-das-frutas no capítulo 3 (itens 3.2.3 e 3.2.4).

\subsubsection{Identificação dos lonqueídeos}

Os lonqueídeos foram identificados pelo Biólogo Pedro Carlos Strikis e depositados na UNICAMP.

\subsubsection{Identificação das frutíferas}

Foram realizadas com base na literatura e no material contido no herbário do laboratório de Botânica do Departamento de Fitossanidade da ESAM. 


\subsection{Resultados e Discussão}

\subsection{1 Índice de infestação}

Nas amostras coletadas, além dos tefritídeos (capítulo 3), apenas uma espécie de lonqueídeo - Neosilba pendula (Bezzi) foi obtida. Das 42 frutíferas nativas e exóticas amostradas, oito estavam infestadas com larvas de $N$. pendula (Tabela 1). Do total de 5.757 pupários de N. pendula, emergiram 4.210 adultos.

Tabela 1. Hospedeiros e níveis de infestação de Neosilba pendula em frutos nativos e exóticos na egião de Mossoró/Assu (RN), coletados de janeiro/1999 a dezembro/2000.

\begin{tabular}{lccc}
\hline Famílias & & \multicolumn{2}{c}{ Índice de Infestação } \\
\cline { 4 - 4 } Hospedeiros & Pupários (n) & Pupários/fruto & Pupários/kg \\
\hline Anacardiaceae & 18 & 0,002 & 0,1 \\
$\begin{array}{l}\text { Cajarana Spondias sp. (N) } \\
\text { Serigüela Spondias purpurea (E) }\end{array}$ & 130 & 0,10 & 6,1 \\
$\begin{array}{l}\text { Malpighiaceae } \\
\text { Acerola Malpighia emarginata (E) }\end{array}$ & 3.495 & 0,08 & 14,9 \\
$\begin{array}{l}\text { Myrtaceae } \\
\text { Goiaba Psidium guajava (N) }\end{array}$ & 442 & 0,08 & 0,9 \\
$\begin{array}{l}\text { Oxalidaceae } \\
\text { Carambola Averrhoa carambola (E) }\end{array}$ & 58 & 0,05 & 1,1 \\
$\begin{array}{l}\text { Rhamnaceae } \\
\text { Juá Ziziphus joazeiro (N) }\end{array}$ & 1.377 & 0,07 & 21,1 \\
$\begin{array}{l}\text { Rutaceae } \\
\text { Tangerina Citrus reticulata (E) }\end{array}$ & 10 & 0,03 & 0,5 \\
$\quad$ Kunquat Fortunella sp. (E) & 227 & 0,07 & 5,0
\end{tabular}

(N) Nativo (E) Exótico 
O número de hospedeiros detectados na região de Mossoró/Assu foi reduzido, quando comparado com os 40 hospedeiros registrados por Souza Filho (1999), no Estado de São Paulo. Entretanto, no trabalho realizado por Souza Filho foram coletadas 113 espécies de frutos em 94 municípios, num período de cinco anos. Além disso, a região de Mossoró/Assu localiza-se no semi-árido, onde a diversidade de frutos potencialmente hospedeiros é menor do que no Estado de São Paulo.

Neosilba pendula infestou indiscriminadamente frutos nativos e exóticos. Considerando-se o índice de infestação pupários $/ \mathrm{kg}$ de fruto, o juá Ziziphus joazeiro e a acerola Malpighia emarginata foram os mais infestados, sendo os índices de infestação de 21,1 e 14,9, respectivamente. Por outro lado, a menor infestação $(0,1$ pupário/kg) foi verificada em cajarana Spondias sp. (Tabela 1). Além da menor infestação, os pupários obtidos de cajarana apresentaram a menor viabilidade pupal (33\%) (Figura 1).

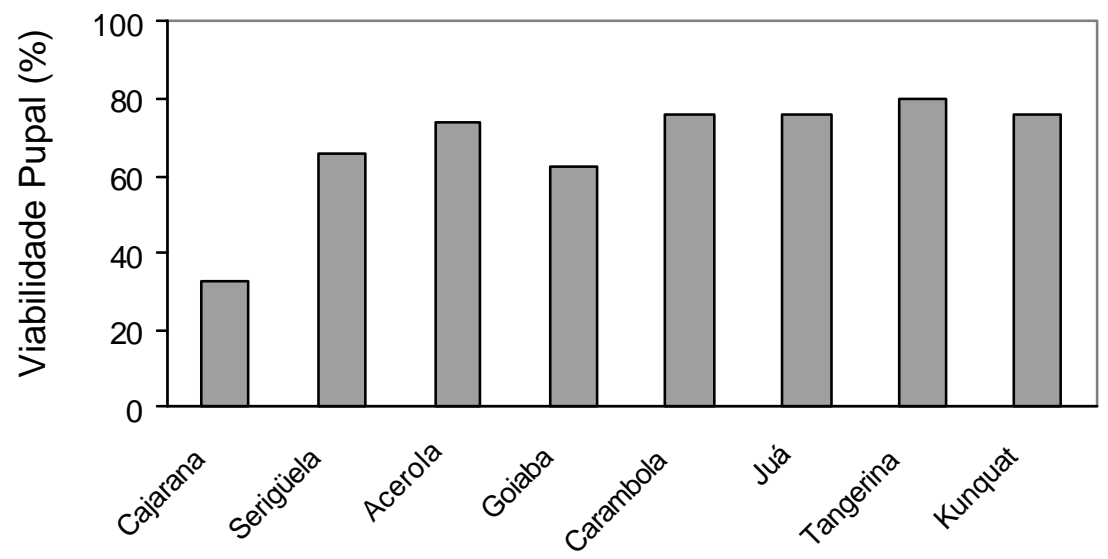

Figura 1 - Viabilidade pupal de Neosilba pendula em frutíferas nativas e exóticas na região de Mossoró/Assu (RN), de janeiro/1999 a dezembro/2000. 
A comparação dos índices de infestação obtidos neste trabalho com os resultados da literatura não foi possível. Nos poucos trabalhos realizados (Malavasi \& Morgante, 1980; Raga et al., 1996; Raga et al., 1997; Uchôa F., 1999 e Souza Filho, 1999), não foram calculados os índices de infestação separadamente para os lonqueídeos, ou seja, os índices de infestação levaram em consideração os pupários de todos os dípteros frugívoros obtidos.

\subsubsection{Neosilba pendula como invasor primário de acerola M. emarginata}

As considerações sobre o status de $N$. pendula como invasor primário de acerola foram baseadas nos resultados de amostras de dois pomares localizados em Mossoró (RN).

Um dos pomares, o da fazenda experimental da ESAM, não era irrigado e por isso, só houve frutificação no período seguinte às primeiras chuvas (março a junho/1999 e março a maio/2000). Neste pomar foram coletados 6.400 frutos $(28,9 \mathrm{~kg})$, dos quais foram obtidos 1.378 pupários e 1.036 adultos de $N$. pendula (Tabela 2).

A maioria dos pomares de acerola da região é infestado por Ceratitis capitata (Wied.) (Tephritidae), mas neste pomar apenas 11 pupários de $C$. capitata foram obtidos durante o período de coletas.

Tabela 2. Dados de coletas de frutos e de Neosilba pendula no pomar nãoirrigado de acerola da fazenda experimental da ESAM, 1999 e 2000.

\begin{tabular}{lcccc}
\hline Coletas & Frutos $(\mathrm{n})$ & Peso $(\mathrm{kg})$ & Pupários $(\mathrm{n})$ & Adultos $(\mathrm{n})$ \\
\hline Árvore & 3.609 & 16,5 & 703 & 584 \\
Solo & 2.791 & 12,4 & 675 & 452 \\
Total & 6.400 & 28,9 & 1.378 & 1.036 \\
\hline
\end{tabular}


Em 1999, as infestações de frutos provenientes do solo variaram entre 11,7 e 83,2 pupários $/ \mathrm{kg}$. As infestações em frutos provenientes da árvore ficaram entre 19,8 e 56,6 pupários/kg de acerola. Em 2000, as infestações em frutos no solo variaram entre 53,1 e 76 pupários $/ \mathrm{kg}$ e nos frutos da árvore entre 35,5 e 80 pupários/kg (Figura 2). Estes índices de infestação foram considerados elevados, quando comparados com os valores detectados no Estado do Mato Grosso do Sul (Uchôa F., 1999), onde foi verificado um índice de 3,5 pupários/kg de acerola. No Mato Grosso do Sul, os lonqueídeos apresentaram preferência por citros.

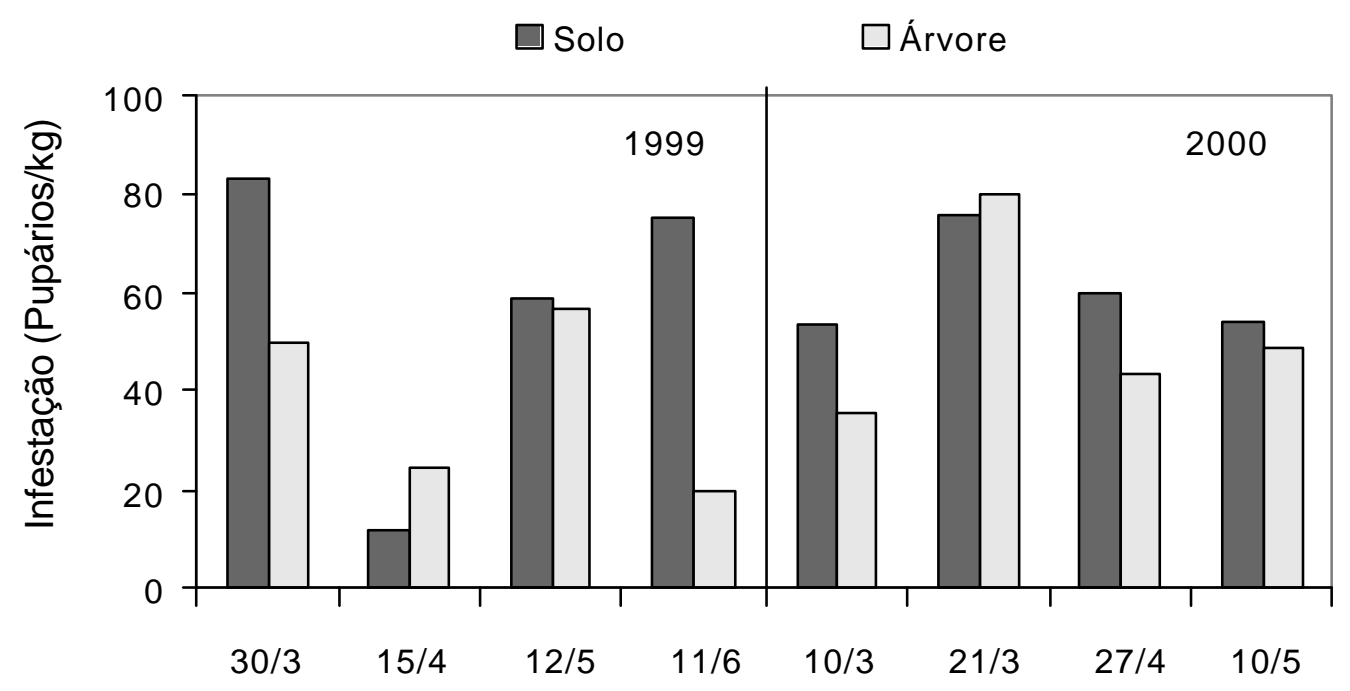

Figura 2 - Índice de infestação de Neosilba pendula no pomar não irrigado de acerola, da fazenda experimental da ESAM.

O outro pomar estudado estava localizado na Agroindústria Maisa. Como esse pomar era irrigado, houve produção de frutos em vários meses do ano. No entanto, foram coletadas amostras apenas no período de abril a junho de 2000 . Um total de 9.029 frutos $(52,7 \mathrm{~kg})$ foram coletados, de onde obtiveram-se 352 
pupários e 206 adultos de N. pendula (Tabela 3). Dos frutos coletados também foram obtidos 205 pupários de $C$. capitata.

Tabela 3. Dados de coletas de frutos e de Neosilba pendula no pomar irrigado de acerola da Maisa, no período de abril a junho de 2000.

\begin{tabular}{lcccc}
\hline Coletas & Frutos $(\mathrm{n})$ & Peso $(\mathrm{kg})$ & Pupários $(\mathrm{n})$ & Adultos $(\mathrm{n})$ \\
\hline Árvore & 5.029 & 26,7 & 153 & 94 \\
Solo & 4.000 & 26,0 & 199 & 112 \\
Total & 9.029 & 52,7 & 352 & 206 \\
\hline
\end{tabular}

Os níveis de infestação nas amostras provenientes do solo variaram de 2,6 a 22,9 pupários/kg de acerola. Nas amostras coletadas nas árvores, houve uma variação no nível de infestação de 3 a 12,4 pupários/kg (Figura 3).

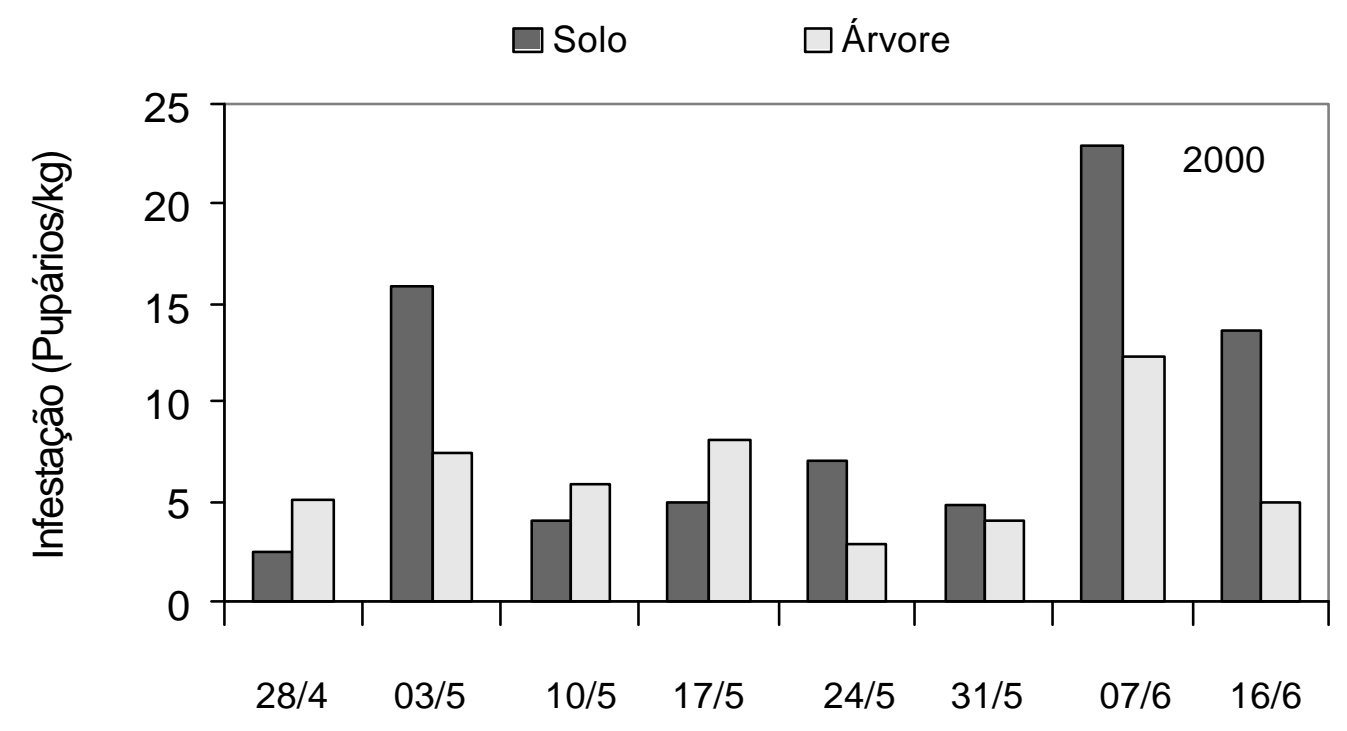

Figura 3 - Índice de infestação de Neosilba pendula no pomar irrigado de acerola, da Maisa. 
Os valores dos níveis de infestação das amostras coletadas no solo e na árvore foram próximos, em várias datas de coleta (Figuras 2 e 3), contudo, as médias gerais das infestações dos frutos provenientes do solo e da árvore, no pomar da ESAM, diferiram significativamente $(P \leq 0,05)$ pelo teste de Wilcoxon (Tabela 4).

Tabela 4. Médias gerais de índice de infestação (pupários/kg) de Neosilba pendula em acerola no município de Mossoró (RN), em 1999 e 2000.

\begin{tabular}{lcc}
\hline Locais de coleta & Árvore & Solo \\
\hline Pomar da ESAM & $44,9 \mathrm{a}$ & $58,9 \mathrm{~b}$ \\
Pomar da Maisa & $6,4 \mathrm{a}$ & $9,5 \mathrm{a}$ \\
\hline
\end{tabular}

Médias, na horizontal, seguidas pelas mesmas letras não diferem entre si pelo teste $Z$ de Wilcoxon $(P \leq 0,05)$.

O pomar localizado na fazenda experimental da ESAM apresentou níveis de infestação de $N$. pendula superiores aos do pomar da Maisa, apesar do maior volume de coleta na Maisa. Além disso, teoricamente as condições do pomar situado na Maisa eram mais propícias às infestações, pois como era irrigado, a disponibilidade de frutos era maior. Por outro lado, havia uma maior população de $C$. capitata no pomar da Maisa, o que pode ter colaborado para uma menor infestação dos lonqueídeos, nesse pomar. Contudo, não foi possível estabelecer por que pomares tão próximos (menos de $10 \mathrm{~km}$ um do outro) apresentaram infestações tão distintas.

De forma geral, os níveis de infestações de $N$. pendula em várias frutíferas da região de Mossoró/Assu fram baixos. No entanto, as infestações de N. pendula em acerola, coletados na árvore e no solo, no pomar da ESAM, foram elevadas e muito próximas. Portanto, em alguns pomares de acerola da região de Mossoró/Assu, os lonqueídeos podem ser importantes invasores 
primários de frutos, como observado por Uchôa F. (1999), que constatou Neosilba spp. como importantes invasores primários de citros no Estado do Mato Grosso do Sul.

\subsection{Conclusões}

Oito espécies de frutíferas são hospedeiras de Neosilba pendula na região de Mossoró/Assu (RN).

O juá e a acerola são os hospedeiros mais infestados por Neosilba pendula na região de Mossoró/Assu (RN).

Neosilba pendula é um importante invasor primário de acerola, em alguns pomares de Mossoró (RN). 


\section{CONCLUSÕES}

Anastrepha obliqua (Macquart), Anastrepha zenildae Zucchi e Ceratitis capitata (Wied.) são as espécies mais comuns na região de Mossoró/Assu $(\mathrm{RN})$.

O juá Ziziphus joazeiro, a cajarana Spondias sp. e a goiaba Psidium guajava são os principais hospedeiros de Anastrepha spp. em Mossoró/Assu.

As maiores infestações de $C$. capitata estão restritas a pequenos pomares de frutiferas exóticas, como kunquat Fortunella sp. e carambola Averrhoa carambola.

As perdas provocadas por Anastrepha spp. em goiaba são consideráveis, sendo a disponibilidade de frutos e a precipitação pluvial os fatores que mais interferem no nível de infestação.

Doryctobracon areolatus (Szépligeti) é o braconídeo mais comum em Mossoró/Assu, sendo de $11,3 \%$ os maiores níveis de parasitismo natural.

Neosilba pendula é um importante invasor primário de acerola, em alguns pomares. 


\section{REFERÊNCIAS BIBLIOGRÁFICAS}

AGUIAR-MENEZES, E.L. Aspectos ecológicos de populações de parasitóides Braconidae (Hymenoptera) de Anastrepha spp. Schiner, 1868 (Diptera: Tephritidae) no município de Seropédica, RJ. Rio de Janeiro, 2000. 133p. Tese (Doutorado) - Universidade Federal Rural do Rio de Janeiro.

AGUIAR-MENEZES, E.L.; MENEZES, E.B. Natural ocorrence of parasitoid of Anastrepha spp. Schiner, 1868 (Diptera: Tephritidae) in different host plants, in Itaguai (RJ), Brazil. Biological Control, v.8, p.1-16, 1997.

ALUJA, M. Bionomics and management of Anastrapha. Annual Review of Entomology, v.39, p.155-178, 1994.

ALUJA, M. A pesquisa com moscas-das-frutas (Diptera: Tephritidae) na América Latina: mitos, realidades e perspectivas. Anais da Sociedade Entomológica do Brasil, v.28, n.4, p.565-594, 1999.

ALUJA, M.; GUILLEN, J.; LIEDO, P.; CABRERA, M.; RIOS, E.; ROSA, G.; CELEDONIO, H.; MOTA, D. Fruit infesting tephritids (Dip.: Tephritidae) and associated parasitoids in Chiapas, Mexico. Entomophaga, v.35, n.1, p.3948, 1990. 
ALUJA, M.; LÓPEZ, M.; SIVINSKI, J. Ecological evidence for diapause in four native and one exotic species of larval-pupal fruit fly (Diptera: Tephritidae) parasitoids in tropical environments. Annals of the Entomological Society of America, v.91, n.6, p.821-833, 1998.

ALVARENGA, C.D.; CANAL D., N.A.; ZUCCHI, R.A. Minas Gerais. In: MALAVASI, A.; ZUCCHI, R.A. (Ed.). Moscas-das-frutas de importância econômica no Brasil: conhecimento básico e aplicado. Ribeirão Preto: Holos Editora, 2000. cap.39, p.265-270.

ARAUJO, E.L.; LIMA, F.A.M.; ZUCCHI, R.A. Rio Grande do Norte. In: MALAVASI, A.; ZUCCHI, R.A. (Ed.). Moscas-das-frutas de importância econômica no Brasil: conhecimento básico e aplicado. Ribeirão Preto: Holos Editora, 2000. cap.31, p.223-226.

ARAUJO, E.L.; ZUCCHI, R.A.; CANAL D., N.A. Caracterização e ocorrência de Anastrepha zenildae Zucchi (Diptera: Tephritidae) e seus parasitóides (Hymenoptera: Braconidae) numa nova planta hospedeira, no Rio Grande do Norte. Anais da Sociedade Entomológica do Brasil, v.25, n.1, p.147150, 1996a.

ARAUJO, E.L.; ZUCCHI, R.A.; MALAVASI, A.; NEGREIROS, J. Levantamento de moscas-das-frutas do gênero Anastrepha Schiner, 1868 (Dip., Tephritidae) nos municípios de Mossoró e Assu - RN. Revista de Agricultura, v.71, n.2, p.225-232, 1996b.

AZEVEDO, E.M.V.W.; PARRA, J.R.P. Influência da umidade em dois tipos de solo, na emergência de Ceratitis capitata. Pesquisa Agropecuária Brasileira, v.24, n.3, p.321-327, 1989. 
BAKER, A.C.; STONE, W.E.; PLUMMER, C.C.; McPHAIL, M. A review of studies on the mexican fruit fly an related mexican species. Washington: USDA, 1944. 155p. (Miscellaneous Publication, 531).

BATEMAN, M.A. The ecology of fruit flies. Annual Review of Entomology, v.17, p.493-518, 1972.

BRESSAN-NASCIMENTO, S. Emergence and pupal mortality factors of Anastrepha obliqua (Macq.) (Diptera: Tephritidae) along the fruiting season of the host Spondias dulcis L. Anais da Sociedade Entomológica do Brasil, v.30, p.207-215, 2001.

BRESSAN, S.; TELES, M.C. Lista de hospedeiros e índices de infestação de algumas espécies do gênero Anastrepha Schiner, 1868 (Diptera: Tephritidae) na região de Ribeirão Preto - SP. Anais da Sociedade Entomológica do Brasil, v.20, n.1, p.5-15, 1991.

CANAL D., N.A. Levantamento, flutuação populacional e análise faunística das espécies de moscas-das-frutas (Dip., Tephritidae) em quatro municípios do Norte de Minas Gerais. Piracicaba, 1997. 113p. Tese (Doutorado) - Escola Superior de Agricultura "Luiz de Queiroz", Universidade de São Paulo.

CANAL D., N.A.; ZUCCHI, R.A. Parasitóides - Braconidae. In: MALAVASI, A.; ZUCCHI, R.A. (Ed.). Moscas-das-frutas de importância econômica no Brasil: conhecimento básico e aplicado. Ribeirão Preto: Holos Editora, 2000. cap.15, p.119-126. 
CANAL D., N.A.; ALVARENGA, C.D.; ZUCCHI, R.A. Níveis de infestação de goiaba por Anastrepha zenildae Zucchi, 1979 (Dip., Tephritidae), em pomares comerciais do Norte de Minas Gerais. Anais da Sociedade de Entomológica do Brasil, v.27, n.4, p.657-661, 1998.

CANAL D., N.A.; ZUCCHI, R.A.; SILVA, N.M.; LEONEL Jr., F.L. Reconociemento de las especies de parsitóides (Hym.: Braconidae) de moscas de las frutas (Dip.: Tephritidae) en dos municipios del Estado del Amazonas, Brasil. Boletin del Museo de Entomologia da la Universidad del Valle, v.2, n.1/2, p.1-17, 1994.

CAREY, J.R.; DOWELL, R.V. Exotic fruit fly pests and California griculture. California Agriculture, v.43, n.3, p.38-40, 1989.

CARVALHO, R.S.; NASCIMENTO, A.S.; MATRANGOLO, W.J.R. Controle biológico. In: MALAVASI, A.; ZUCCHI, R.A. (Ed.). Moscas-das-frutas de importância econômica no Brasil: conhecimento básico e aplicado. Ribeirão Preto: Holos Editora, 2000. cap.14, p.113-117.

CARVALHO, R.S.; MALAVASI, A.; NASCIMENTO, A.S.; SIMÕES, W.L. Primeira evidência no Brasil de diapausa em quatro espécies nativas e uma introduzida de parasitóides larva-pupa de moscas-das-frutas (Diptera: Tephritidae) em ambiente tropical. In: SIMPÓSIO DE CONTROLE BIOLÓGICO, 7., Poços de Caldas, 2001. Resumos. Lavras: UFLA, 2001. p.380.

CHRISTENSON, L.D.; FOOT, R.H. Biology of fruit flies. Annual Review of Entomology, v.5, p.171-192, 1960. 
CLAUSEN, C.P. Biological control of fruit flies. Journal of Economic Entomology, v.49, n.2, p.176-178, 1956.

ESKAFI, F.; KOLBE, M. Predation on larval and pupal Ceratitis capitata (Diptera: Tephritidae) by the ant Solenopsis geminata (Hymenoptera: Formicidae) and other predators in Guatemala. Environmental Entomology, v.19, p.148-153, 1990.

FEHN, L.M. Coleta e reconhecimento de moscas das frutas em região metropolitana de Curitiba e Irati, Paraná, Brasil. Anais da Sociedade Entomológica do Brasil, v.10, n.2, p.209-238, 1981.

FNP CONSULTORIA \& COMÉRCIO. Agrianual 99: anuário da agricultura brasileira. São Paulo, 1999. 521p.

HAJI, F.N.P.; MIRANDA, I.G. Pernambuco. In: MALAVASI, A.; ZUCCHI, R.A. (Ed.). Moscas-das-frutas de importância econômica no Brasil: conhecimento básico e aplicado. Ribeirão Preto: Holos Editora, 2000. cap.33, p.229-233.

HERNÁNDEZ-ORTIZ, V; PÉREZ-ALONSO, R.; WHARTON, R.A. Native parasitoids associated with the genus Anastrepha (Dip.: Tephritidae) in los Tuxtlas, Veracruz, Mexico. Entomophaga, v.39, n.2, p.171-178, 1994.

KOVALESKI, A.; URAMOTO, K.; SUGAYAMA, R.L.; CANAL D., N.A.; MALAVASI, A. A survey of Anastrepha Schiner (Diptera: Tephritidae) species in the apple growing area of state of Rio Grande do Sul, Brazil. Revista Brasileira de Entomologia, v.43, n.3, p.229-234, 1999. 
KOVALESKI, A. Processos adaptativos na colonização da maçã (Malus domestica L.) por Anastrepha fraterculus (Wied.) (Diptera: Tephritidae) na região de Vacaria, RS. São Paulo, 1977. 122p. Tese (Doutorado) - Instituto de Biociências, Universidade de São Paulo.

LEONEL Jr., F.L. Espécies de Braconidae (Hymenoptera) parasitóides de moscas-das-frutas (Diptera, Tephritidae) no Brasil. Piracicaba, 1991. 83p. Dissertação (Mestrado) - Escola Superior de Agricultura Luiz de Queiroz, Universidade de São Paulo.

LEONEL Jr., F.L.; ZUCCHI, R.A.; CANAL D., N.A. Parasitismo de moscas-dasfrutas (Diptera: Tephritidae) por Braconidae (Hymenoptera) em duas localidades do Estado de São Paulo. Anais da Sociedade Entomológica do Brasil, v.25, p.199-206, 1996.

LEONEL Jr., F.L.; ZUCCHI, R.A.; WHARTON, R.A. Distribution and tephritid hosts (Diptera) of braconid parasitoids (Hymenoptera) in Brazil. International Journal of Pest Management, v.41, n.4, p.208-213, 1995.

LEYVA, J.L.; BROWNING, H.W.; GILSTRAP, F.E. Effect of host fruit species, size, and color on parasitization of Anastrepha ludens (Diptera: Tephritidae) by Diachasmimorpha longicaudata (Hymenoptera: Braconidae). Environmental Entomology, v.20, n.5, p.1469-1474, 1991.

LIMA, A.C. Moscas das frutas do gênero Anastrepha Schiner, 1868 (Diptera: Trypetidae). Memórias do Instituto Oswaldo Cruz, v.28, n.4, p.487-575, 1934.

LIMA, A.C. Novas moscas de frutas do gênero Anastrepha (Diptera: Trypetidae). O Campo, v.8, n.90, p.34-38, 1937a. 
LIMA, A.C. Novas moscas de frutas do gênero Anastrepha (Diptera: Trypetidae). O Campo, v.8, n.94, p.60-64, 1937b.

LIMA, A.C. Novas moscas de frutas do gênero Anastrepha (Diptera: Trypetidae). O Campo, v.9, n.97, p.61-64, 1938.

LIQUIDO, N.J.; BARR, P.G.; CUNNINGHAM, R.T. An encyclopedic bibliography of the host plants of the mediterranean fruit fly, Ceratitis capitata (Wiedemann). In: THOMPSON, F.C. (Ed.) Fruit fly expert system and systematic information database: Diptera data dissemination; disk Version 1.0, MEDHOST, 1998.

LOPÉZ, M.; ALUJA, M.; SIVINSKI, J. Hymenopterous larval-pupal and pupal parasitoids of Anastrepha flies (Diptera: Tephritidae) in Mexico. Biological Control, v.15, p.119-129, 1999.

MALAVASI, A.; MORGANTE, J.S. Biologia de "moscas-das-frutas" (Diptera, Tephritidae). II: índices de infestação em diferentes hospedeiros e localidades. Revista Brasileira de Biologia, v.40, n.1, p.17-24, 1980.

MALAVASI, A.; MORGANTE, J.S. Adult and larval population fluctuation of Anastrepha fraterculus and its relationship to host availability. Annals of the Entomological Society of America, v.10, n.3, p.275-278, 1981.

MALAVASI, A.; MORGANTE, J.S.; ZUCCHI, R.A. Biologia de "moscas-dasfrutas" (Diptera, Tephritidae). I: lista de hospedeiros e ocorrência. Revista Brasileira de Biologia, v.40, n.1, p.9-16, 1980. 
MALAVASI, A.; SAUERS-MULLER, A. V.; MIDGARDEN, D.; KELLMAN, V.; DIDELOT, D.; CAPLONG, P.; RIBEIRO, O. Regional programme for the erradication of the carambola fruit fly in South America. In: TAN, KENGHONG (Ed.). Area-wide control of fruit flies and others insect pests. Penang: Sinaran Bros, 2000. p.395-399.

MANICA, I; ICUMA, I.M.; JUNQUEIRA, N.T.V.; SALVADOR, J.O.; MOREIRA, A.; MALAVOLTA, E. Fruticultura tropical 6. Goiaba. Porto Alegre: Cinco Continentes, 2000. 374p.

MATRANGOLO, W.J.R.; NASCIMENTO, A.S.; CARVALHO, R.S.; MELO, E.D.; JESUS, M. Parasitóides de moscas-das-frutas (Diptera: Tephritidae) associados a frutíferas tropicais. Anais da Sociedade Entomológica do Brasil, v.27, n.4, p.593-603, 1998.

McALPINE, J.F. A new species of Dasiops (Diptera: Tephritidae) injurious to apricots. Canadian Entomologist, v.93, n.7, p.539-544, 1961.

McALPINE, J.F. Lonchaeidae. In: McALPINE, J.F. (Ed.). Manual of Nearctic Diptera. Ottawa: Research Branch Agriculture Canada, 1987. v.2, p.791796. (Monograph, 28).

MESSING, R.H.; JANG, E.B. Response of the fruit fly parasitoid Diachasmimorpha longicaudata (Hymenoptera: Braconidae) to host-fruit stimuli. Environmental Entomology, v.21, n.5, p.1189-1195, 1992.

MORGANTE, J.S. Moscas-das-frutas (Tephritidae): características biológicas, detecção e controle. Brasília: Ministério da Agricultura e Reforma Agrária; SENIR, 1991. 19p. (Boletim Técnico de Recomendação para os Perímetros Irrigados do Vale do São Francisco, 2). 
NASCIMENTO, A.S. Aspectos ecológicos e tratamento pós-colheita de moscasdas-frutas (Tephritidae) em manga, Mangifera indica. São Paulo, 1990. 97p. Tese (Doutorado) - Instituto de Biociências, Universidade de São Paulo.

NASCIMENTO, A.S.; ZUCCHI, R.A.; MORGANTE, J.S.; MALAVASI, A. Dinâmica populacional das moscas-das-frutas do gênero Anastrepha (Dip., Tephritidae) no recôncavo baiano. II - flutuação populacional. Pesquisa Agropecuária Brasileira, v.17, n.7, p.969-980, 1982.

NORRBOM, A.L. The diptera site: Systematic Entomology Laboratory. http://www.sel.barc.usda.gov/diptera/tephriti/tephclas.htm. (15 out. 2001).

NORRBOM, A.L.; ZUCCHI, R.A.; HERNÁNDEZ-ORTIZ, V. Phylogeny of the genera Anastrepha and Toxotrypana (Trypetinae: Toxotrypanini) based on morphology. In: ALUJA, M.; NORRBOM, A.L. (Ed.). Fruit flies (Tephritidae): phylogeny and evolution of behavior. Washington: CRC Press, 2000. cap.12, p. 299-342.

NORRBOM, A.L.; KIM, K.C. A list of the reported host plants of the species of Anastrepha (Diptera: Tephritidae). Washington: USDA, Animal and Plant Health Inspection Service, Plant Protection and Quarentine, 1988. $114 p$.

OHASHI, O.S.; DOHARA, R.; ZUCCHI, R.A.; CANAL D., N.A. Ocorrência de Anastrepha obliqua (Macquart, 1835) (Dip., Tephritidae) em acerola Malpighia punicifolia L., no Estado do Pará. Anais da Sociedade Entomológica do Brasil, v.26, p.389-390, 1997. 
ORTH, A.; RIBEIRO, L.G.; REIS FILHO, W. Manejo de pragas. In: EMPRESA CATARINENSE DE PESQUISA AGROPECUÁRIA. Manual da cultura da macieira. Florianópolis, 1996. p. 341-379.

OVRUSKI, S.; ALUJA, M.; SIVINSKI, J.; WHARTON, R.A. Hymenopteran parasitoids on fruit-infesting Tephritidae (Diptera) in Latin America and the southern United State: Diversity, distribution, taxonomic status and their use in fruit fly biological control. Integrated Pest Management Reviews, v.5, p.81-107, 2000.

PARRA, J.R.P.; ZUCCHI, R.A.; SILVEIRA NETO, S. Flutuação populacional e atividade diária de vôo da mosca-do-mediterrâneo em cafeeiro "Mundo Novo". Pesquisa Agropecuária Brasileira, v.17, n.7, p.985-992, 1982.

PEREIRA, F.M.; MARTINEZ Jr., M. Goiaba para industrialização. Jaboticabal: Legis Summa, 1986. 142p.

PURCELL, M.F.; JACKSON, C.G.; LONG, J.P.; BATCHELOR, M.A. Influence of guava ripening on parasitism of the Oriental fruit fly, Bactrocera dorsalis (Hendel) (Diptera: Tephritidae), by Diachasmimorpha longicaudata (Ashmead) (Hymenoptera: Braconidae) and other parasitoids. Biological Control, v.4, p.396-403, 1994.

PUZZI, D.; ORLANDO, A. Estudos sobre a ecologia das "moscas-das-frutas" (Trypetidae) no Estado de São Paulo, visando o controle racional da praga. Arquivos do Instituto Biológico, v.32, n.1, p.7-20, 1965.

RAGA, A.; SOUZA FILHO, M.F.; ARTHUR, V.; MARTINS, A.L.M. Avaliação da infestação de moscas-das-frutas em variedades de café (Coffea spp.). Arquivos do Instituto Biológico, v.63, n.2, p.59-63, 1996. 
RAGA, A.; SOUZA FILHO, M.F.; ARTHUR, V.; SATO, M.E.; MACHADO, L.A.; BATISTA FILHO, A. Observação sobre a incidência de moscas-das-frutas (Diptera: Tephritidae) em frutos de laranja (Citrus sinensis). Arquivos do Instituto Biológico, v.64, n.2, p.125-129, 1997.

RONCHI-TELES, B. Ocorrência e flutuação populacional de Espécies de moscas-das-frutas e parasitóides com ênfase para o gênero Anastrepha (Diptera: Tephritidae) na Amazônia Brasileira. Manaus, 2000. 156p. Tese (Doutorado) - Fundação Universidade do Amazonas.

SALLES, L.A.B. Bioecologia e controle da mosca-das-frutas Sul-americana. Pelotas: EMBRAPA/CNPCT, 1995. $58 \mathrm{p}$.

SALLES, L.A.B. Parasitismo de Anastrepha fraterculus (Wied.) (Diptera: Tephritidae) por Hymenoptera, na região de Pelotas, RS. Pesquisa Agropecuária Brasileira, v.31, n.11, p.769-774, 1996.

SALLES, L.A.B. Biologia e ciclo de vida de Anastrepha fraterculus. In: MALAVASI, A.; ZUCCHI, R.A. (Ed.). Moscas-das-frutas de importância econômica no Brasil: conhecimento básico e aplicado. Ribeirão Preto: Holos Editora, 2000. cap.8, p. 81-86.

SALLES, L.A.B.; CARVALHO, F.L.C.; JUNIOR, C.R. Efeito da temperatura e umidade do solo sobre pupas e emergências de Anastrepha fraterculus (Wied.). Anais da Sociedade Entomológica do Brasil, v.24, n.1, p.147152, 1995. 
SELIVON, D. Relações com as plantas hospedeiras. In: MALAVASI, A.; ZUCCHI, R.A. (Ed.). Moscas-das-frutas de importância econômica no Brasil: conhecimento básico e aplicado. Ribeirão Preto: Holos Editora, 2000. cap.9, p. 87-91.

SILVA, N.M. Levantamento e análise faunística de moscas-das-frutas (Diptera: Tephritidae) em quatro locais do Estado do Amazonas. Piracicaba, 1993. 152p. Tese (Doutorado) - Escola Superior de Agricultura "Luiz de Queiroz", Universidade de São Paulo.

SILVA, N.M.; SILVEIRA NETO, S.; ZUCCHI, R.A. The natural host plants of Anastrepha in the state of Amazonas, Brazil. In: STECK, G.J.; McPHERON, B.A. (Ed.). Fruit fly pest: a world assessment of their biology and management. Delray Beach: St. Luice Press, 1996. p.353-357.

SIVINSKI, J.; ALUJA, M.; LOPÉZ, M. Spatial and temporal distribution of parasitoids of mexican Anastrepha species (Diptera: Tephritidae) within the canopies of fruit trees. Annals of the Entomological Society of America, v.90, n.5, p.604-618, 1997.

SIVINSKI, J.; ALUJA, M.; HOLLER, T.; EITAM, A. Phenological comparison of two braconid parasitoids of the Caribbean fruit fly (Diptera: Tephritidae). Environmental Entomology, v.27, n.2, p.360-365, 1998.

SMYTH, E.G. A new tephritid fly injurious to tomatoes in Peru. California Agricultural Experiment Station Bulletin, v.49, p.16-22, 1960. 
SOUZA FILHO, M.F. Biodiversidade de moscas-das-frutas (Diptera: Tephritidae) e seus parasitóides (Hymenoptera) em plantas hospedeiras no Estado de São Paulo. Piracicaba, 1999. 173p. Dissertação (Mestrado) Escola Superior de Agricultura "Luiz de Queiroz", Universidade de São Paulo.

SOUZA FILHO, M.F.; RAGA, A.; ZUCCHI, R.A. Incidencia de Anastrepha obliqua (Macquart) y Ceratitis capitata (Wiedemann) (Diptera: Tephritidae) en carambola (Averrhoa carambola L.) en ocho localidades del Estado de São Paulo, Brasil. Anais da Sociedade Entomológica do Brasil, v.29, n.2, p.367-371, 2000.

STEYSKAL, G.C. Pictorial key to species of the genus Anastrepha (Dip., Tephritidae). Washington: The Entomological Society of Washington, 1977. $35 p$.

STONE, A. The fruit flies of the genus Anastrepha. Washington: USDA, 1942. 112p. (Miscellaneous Publication, 439).

SUGAYAMA, R.L. Anastrepha fraterculus (Wiedemann) (Diptera: Tephritidae) na região produtora de maçãs do Rio Grande do Sul: relação com seus inimigos naturais e potencial para controle biológico. São Paulo, 2000. 117p. Tese (Doutorado) - Instituto de Biociências, Universidade de São Paulo.

SUPLICY FILHO, N.; SAMPAIO, A.S.; MYAZAKI, I. Flutuação populacional das "moscas-das-frutas" (Anastrepha spp. e Ceratitis capitata (Wied., 1824)) em citros na fazenda Guanabara, Barretos, SP. O Biológico, v.44, p.279-284, 1978. 
UCHÔA F., M.A. Biodiversidade de moscas frugívoras (Diptera: Tephritidae), seus frutos hospedeiros e parasitóides (Hymenoptera) em áreas de cerrado do Estado do Mato Grosso do Sul. Piracicaba, 1999. 104p. Tese (Doutorado) - Escola Superior de Agricultura "Luiz de Queiroz", Universidade de São Paulo.

VELOSO, V.R.S. Dinâmica populacional de Anastrepha spp. e Ceratitis capitata (Wied., 1824) (Diptera, Tephritidae) nos cerrados de Goiás. Goiânia, 1997. 115p. Tese (Doutorado) - Universidade Federal de Goiás.

WHARTON, R.A. Classical biological control of fruit-infesting Tephritidae. In: ROBINSON, A.S.; HOOPER, G. (Ed.). Fruit flies: their biology, natural enemies and control. Amsterdam: Elsevier, 1989. p. 303-313. (World Crop Pest, 3B).

WHARTON, R.A.; GILSTRAP, F.E. Key and status of Opiinae Braconid (Hymenoptera) parasitoids used in biological control of Ceratitis and Dacus (Diptera: Tephritidae). Annals of the Entomological Society of America. v.76, p.721-146, 1983.

WHITE, I.A.; ELSON-HARRIS, M.M. Fruit flies of economic significance: their identification and bionomics. Wallingford: CAB International, 1994. $601 \mathrm{p}$.

ZUCCHI, R.A. Taxonomia das espécies de Anastrepha Schiner, 1868 (Diptera: Tephritidae) assinaladas no Brasil. Piracicaba, 1978. 105p. Tese (Doutorado) - Escola Superior de Agricultura "Luiz de Queiroz", Universidade de São Paulo. 
ZUCCHI, R.A. Novas espécies de Anastrepha Schiner, 1868 (Diptera, Tephritidae). Revista Brasileira de Entomologia, v.23, n.1, p.35-41, 1979.

ZUCCHI, R.A. Taxonomia. In: MALAVASI, A.; ZUCCHI, R.A. (Ed.). Moscasdas-frutas de importância econômica no Brasil: conhecimento básico e aplicado. Ribeirão Preto: Holos Editora, 2000a. cap.1, p.13-24.

ZUCCHI, R.A. Lista das espécies de Anastrepha, sinonímias, plantas hospedeiras e parasitóides. In: MALAVASI, A.; ZUCCHI, R.A. (Ed.). Moscas-das-frutas de importância econômica no Brasil: conhecimento básico e aplicado. Ribeirão Preto: Holos Editora, 2000b. cap.4, p.41-48.

ZUCCHI, R.A. Mosca-do-mediterrâneo, Ceratitis capitata (Diptera: Tephritidae). In: VILELA, E.F.; ZUCCHI, R.A.; CANTOR, F. (Ed.). Histórico e impacto das pragas introduzidas no Brasil. Ribeirão Preto: Holos Editora, 2001. cap.1, p. 15-22. 


\section{APÊNDICES}


Apêndice 1. Espécies de frutíferas amostradas na região de Mossoró/Assu (RN), de janeiro/1999 a dezembro/2000.

\begin{tabular}{|c|c|c|c|c|}
\hline \multirow{2}{*}{$\begin{array}{l}\text { Famílias } \\
\text { Espécies }\end{array}$} & \multirow[b]{2}{*}{ Origem } & \multirow[b]{2}{*}{ Amostras (n) } & \multicolumn{2}{|c|}{ Frutos } \\
\hline & & & $\mathrm{n}$ & Peso $(\mathrm{kg})$ \\
\hline \multicolumn{5}{|l|}{ Anacardiaceae } \\
\hline Anacardium occidentale Caju & $\mathrm{N}$ & 9 & 255 & 15,08 \\
\hline Mangifera indica Manga & $\mathrm{E}$ & 50 & 2.781 & $1.266,73$ \\
\hline Spondias sp.1 Cajarana & $\mathrm{N}$ & 37 & 9.544 & 129,69 \\
\hline Spondias sp. 2 Cajá & $\mathrm{N}$ & 11 & 988 & 7,47 \\
\hline Sondias cytherea Caja-manga & $\mathrm{E}$ & 2 & 18 & 1,82 \\
\hline Spondias purpurea Serigüela & $\mathrm{E}$ & 18 & 1.289 & 21,40 \\
\hline Spondias tuberosa Umbu & $\mathrm{N}$ & 8 & 1.387 & 26,28 \\
\hline \multicolumn{5}{|l|}{ Anonnaceae } \\
\hline Annona sp. Atemoia & $\mathrm{N}$ & 1 & 4 & 1,00 \\
\hline Annona muricata Graviola & $\mathrm{E}$ & 1 & 6 & 4,20 \\
\hline \multicolumn{5}{|l|}{ Arecaceae } \\
\hline Copernica prunifera Carnaúba & $\mathrm{N}$ & 2 & 407 & 2,23 \\
\hline
\end{tabular}

Apêndice 1. Espécies de frutíferas amostradas na região de Mossoró/Assu (RN), de janeiro/1999 a dezembro/2000. 


\begin{tabular}{|c|c|c|c|c|}
\hline \multirow{2}{*}{$\begin{array}{l}\text { Famílias } \\
\text { Espécies }\end{array}$} & \multirow[b]{2}{*}{ Origem } & \multirow[b]{2}{*}{ Amostras (n) } & \multicolumn{2}{|c|}{ Frutos } \\
\hline & & & $\mathrm{n}$ & Peso $(\mathrm{kg})$ \\
\hline \multicolumn{5}{|l|}{ Cactaceae } \\
\hline Cereus jamacaru Mandacaru & $\mathrm{N}$ & 2 & 15 & 1,31 \\
\hline Opuntia ficus-indica Palma & $\mathrm{N}$ & 1 & 64 & 0,60 \\
\hline \multicolumn{5}{|l|}{ Capparidaceae } \\
\hline Crateva tapia Trapia & $\mathrm{N}$ & 6 & 864 & 16,36 \\
\hline Capparis flexuosa Feijão-bravo & N & 1 & 99 & 0,80 \\
\hline \multicolumn{5}{|l|}{ Caricaceae } \\
\hline Carica papaya Mamão & E & 1 & 25 & 11,43 \\
\hline \multicolumn{5}{|l|}{ Combretaceae } \\
\hline Terminalia catappa Castanhola & $\mathrm{E}$ & 18 & 1.491 & 38,72 \\
\hline \multicolumn{5}{|l|}{ Chrysobalanaceae } \\
\hline Licania rigida Oiticica & $\mathrm{N}$ & 1 & 220 & 1,55 \\
\hline
\end{tabular}

Apêndice 1. Espécies de frutíferas amostradas na região de Mossoró/Assu (RN), de janeiro/1999 a dezembro/2000. 


\begin{tabular}{|c|c|c|c|c|}
\hline \multirow{2}{*}{$\begin{array}{l}\text { Famílias } \\
\text { Espécies }\end{array}$} & \multirow[b]{2}{*}{ Origem } & \multirow[b]{2}{*}{ Amostras (n) } & \multicolumn{2}{|c|}{ Frutos } \\
\hline & & & $\mathrm{n}$ & Peso $(\mathrm{kg})$ \\
\hline \multicolumn{5}{|l|}{ Cucurbitaceae } \\
\hline Cucumis anguria Maxixe & $\mathrm{N}$ & 6 & 218 & 5,40 \\
\hline Cucumis melo Melão & $E$ & 9 & 2.676 & $3.529,34$ \\
\hline Citrullus lanatus Melância & $E$ & 1 & 4 & 8,81 \\
\hline Momordica charantia Melão-de-são-caetano & $\mathrm{N}$ & 1 & 19 & 0,20 \\
\hline \multicolumn{5}{|l|}{ Euphorbiacae } \\
\hline Jatropha sp. Pinhão-roxo & E & 1 & 124 & 0,67 \\
\hline Jatropha mollissima Pinhão-bravo & N & 7 & 914 & 5,71 \\
\hline Manihot esculenta Mandioca & N & 1 & 10 & 0,05 \\
\hline Manihot glaziovii Maniçoba & $\mathrm{N}$ & 6 & 1.573 & 9,15 \\
\hline Phyllanthus acidus Groselha & E & 1 & 14 & 0,03 \\
\hline \multicolumn{5}{|l|}{ Fabaceae } \\
\hline Geoffroca spinosa Mari & $\mathrm{N}$ & 3 & 1.184 & 11,10 \\
\hline \multicolumn{5}{|l|}{ Malpighiaceae } \\
\hline Malpighia emarginata Acerola & $E$ & 78 & 42.475 & 234,90 \\
\hline
\end{tabular}

Apêndice 1. Espécies de frutíferas amostradas na região de Mossoró/Assu (RN), de janeiro/1999 a dezembro/2000. 


\begin{tabular}{|c|c|c|c|c|}
\hline \multirow{2}{*}{$\begin{array}{l}\text { Famílias } \\
\text { Espécies }\end{array}$} & \multirow[b]{2}{*}{ Origem } & \multirow[b]{2}{*}{ Amostras (n) } & \multicolumn{2}{|c|}{ Frutos } \\
\hline & & & $\mathrm{n}$ & Peso $(\mathrm{kg})$ \\
\hline \multicolumn{5}{|l|}{ Meliaceae } \\
\hline Melia azedarach Lírio & $\mathrm{E}$ & 1 & 746 & 1,06 \\
\hline \multicolumn{5}{|l|}{ Mimosaceae } \\
\hline Mimosa caesalpiniifolia Sabiá & $\mathrm{N}$ & 1 & 68 & 1,45 \\
\hline \multicolumn{5}{|l|}{ Myrtaceae } \\
\hline Psidium guajava Goiaba & $\mathrm{N}$ & 80 & 5.660 & 470,48 \\
\hline Syzygium jambos Jambo & $\mathrm{E}$ & 1 & 112 & 4,55 \\
\hline \multicolumn{5}{|l|}{ Olacaceae } \\
\hline Ximenia americana Ameixa-do-mato & $\mathrm{N}$ & 1 & 50 & 0,25 \\
\hline \multicolumn{5}{|l|}{ Oxalidaceae } \\
\hline Averrhoa carambola Carambola & $\mathrm{E}$ & 20 & 1.171 & 54,07 \\
\hline \multicolumn{5}{|l|}{ Rhamnaceae } \\
\hline Ziziphus joazeiro Juá & $\mathrm{N}$ & 25 & 19.246 & 65,35 \\
\hline
\end{tabular}

Apêndice 1. Espécies de frutíferas amostradas na região de Mossoró/Assu (RN), de janeiro/1999 a dezembro/2000. 


\begin{tabular}{|c|c|c|c|c|}
\hline \multirow{2}{*}{$\begin{array}{l}\text { Famílias } \\
\text { Espécies }\end{array}$} & \multirow[b]{2}{*}{ Origem } & \multirow[b]{2}{*}{ Amostras (n) } & \multicolumn{2}{|c|}{ Frutos } \\
\hline & & & $\mathrm{n}$ & Peso $(\mathrm{kg})$ \\
\hline \multicolumn{5}{|l|}{ Rutaceae } \\
\hline Citrus limon Limão & $\mathrm{E}$ & 3 & 40 & 1,29 \\
\hline Citrus reticulata Tangerina & $\mathrm{E}$ & 8 & 385 & 19,08 \\
\hline Citrus sinensis Laranja & $\mathrm{E}$ & 1 & 63 & 13,10 \\
\hline Fortunella sp. Kunquat & E & 16 & 3.326 & 45,07 \\
\hline \multicolumn{5}{|l|}{ Sapotaceae } \\
\hline Achras sapota Sapoti & $\mathrm{E}$ & 1 & 19 & 2,70 \\
\hline \multicolumn{5}{|l|}{ Solanaceae } \\
\hline Solanum agrarium Melância-da-praia & $\mathrm{N}$ & 1 & 107 & 1,31 \\
\hline Physalis angulata Canapum & $\mathrm{N}$ & 1 & 425 & 0,39 \\
\hline
\end{tabular}

N - Nativa; E - Exótica 
Apêndice 2. Peso e quantidade de goiabas coletadas no pomar da Fazenda experimental da ESAM, em Mossoró, de janeiro/1999 a dezembro/2000.

\begin{tabular}{lrrrr}
\hline & \multicolumn{3}{c}{ Peso $(\mathrm{kg})$} & \multicolumn{3}{c}{ Frutos $(\mathrm{n})$} \\
Mês & 1999 & 2000 & 1999 & 2000 \\
\cline { 2 - 5 } Jan. & $*$ & 4,8 & $*$ & 47 \\
Fev. & $*$ & 1,0 & $*$ & 12 \\
Mar. & $*$ & 4,8 & $*$ & 38 \\
Abr. & 4,6 & 7,8 & 40 & 50 \\
Mai. & 29,9 & 15,1 & 217 & 82 \\
Jun. & 4,7 & 13,5 & 27 & 71 \\
Jul. & 18,9 & 19,2 & 96 & 103 \\
Ago. & 15,5 & 8,1 & 74 & 52 \\
Set. & 42,7 & 11,8 & 263 & 72 \\
Out. & 4,7 & 22,3 & 39 & 106 \\
Nov. & 15,0 & 4,6 & 129 & 31 \\
Dez. & 1,2 & 13,4 & 12 & 99 \\
\hline
\end{tabular}

\footnotetext{
* O pomar sem frutos (havia sido podado).
} 
Apêndice 3. Dados climáticos da região de Mossoró (RN), obtidos na estação climatológica da ESAM.

\begin{tabular}{|l|cc|cc|rr|}
\hline & \multicolumn{2}{|l|}{ Temperatura $\left(^{\circ}\right.$ C) } & \multicolumn{2}{|l|}{$\begin{array}{l}\text { Umidade Relativa (\%) } \\
\text { (Média) }\end{array}$} & & \multicolumn{2}{|c|}{$\begin{array}{l}\text { Precipitação pluvial } \\
\text { (Acumulada) }\end{array}$} \\
\hline Mês & 1999 & 2000 & 1999 & 2000 & 1999 & 2000 \\
\hline Jan. & 28,5 & 28,3 & 70,4 & 75,2 & 34,2 & 63,8 \\
Fev. & 28,7 & 27,2 & 73,2 & 79,0 & 44,7 & 194,7 \\
Mar. & 27,8 & 27,4 & 77,8 & 82,7 & 149,5 & 137,5 \\
Abr. & 28,0 & 26,7 & 76,0 & 87,2 & 127,3 & 280,4 \\
Mai. & 27,0 & 26,5 & 79,1 & 80,2 & 127,4 & 66,2 \\
Jun. & 27,4 & 26,5 & 65,7 & 77,7 & 25,4 & 42,5 \\
Jul. & 28,5 & 26,3 & 58,3 & 75,2 & 1,3 & 30,0 \\
Ago. & 27,8 & 26,8 & 55,8 & 70,6 & 1,8 & 19,7 \\
Set. & 28,5 & 27,5 & 59,4 & 70,4 & 0,0 & 26,5 \\
Out. & 28,5 & 28,3 & 61,9 & 65,9 & 0,2 & 0,0 \\
Nov. & 28,7 & 28,0 & 66,5 & 68,7 & 4,0 & 0,0 \\
Dez. & 28,8 & 27,1 & 68,4 & 76,3 & 15,3 & 9,3 \\
\hline
\end{tabular}

